
of Engineers ${ }_{\circledast}$ Engineer Research and Development Center

\title{
In Situ Geophysical Surveys for Estimation of Foundation Rock Properties, Concrete Gravity Section, Folsom Dam
}

José L. Llopis, Michael K. Sharp, and Enrique E. Matheu

August 2005

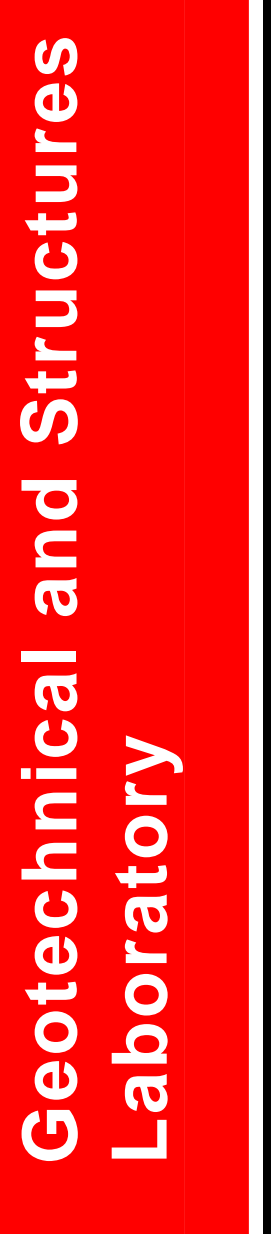




\section{In Situ Geophysical Surveys for Estimation of Foundation Rock Properties, Concrete Gravity Section, Folsom Dam}

José L. Llopis, Michael K. Sharp, Enrique E. Matheu

Geotechnical and Structures Laboratory

U.S. Army Engineer Research and Development Center

3909 Halls Ferry Road

Vicksburg, MS 39180-6199

Final report

Approved for public release; distribution is unlimited 


\begin{abstract}
This report presents a series of geophysical studies performed to determine the material characteristics of the foundation rock beneath the concrete gravity sections of Folsom Dam, California. The geophysical investigations were conducted to measure the values of compression- and shear-wave (P- and S-wave) propagation velocities as well as density of the foundation materials. The U.S. Army Engineer District, Sacramento, and the U.S. Army Engineer Research and Development Center agreed upon a finalized test program consisting of seismic crosshole testing and sonic and gamma-gamma logging. These measurements are used to compute rock property information for a dynamic analysis of the dam and its foundation. The field investigations and corresponding findings are described in this report.
\end{abstract}

DISCLAIMER: The contents of this report are not to be used for advertising, publication, or promotional purposes. Citation of trade names does not constitute an official endorsement or approval of the use of such commercial products. All product names and trademarks cited are the property of their respective owners. The findings of this report are not to be construed as an official Department of the Army position unless so designated by other authorized documents. 


\section{Contents}

Conversion Factors, Non-SI to SI Units of Measurement................................ viii

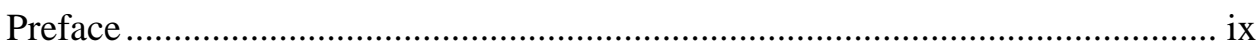

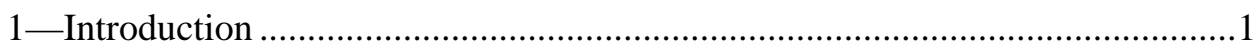

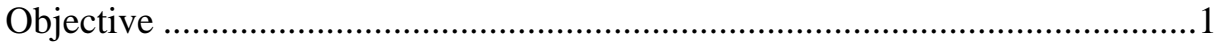

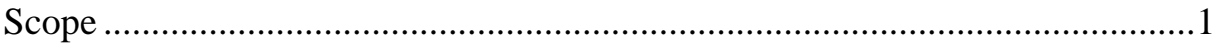

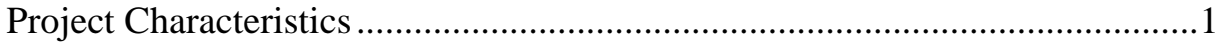

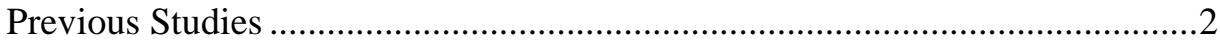

Need for Additional Investigations ................................................................4

2-Geophysical Test Principles and Field Procedures........................................6

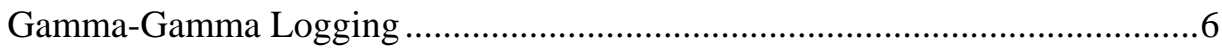

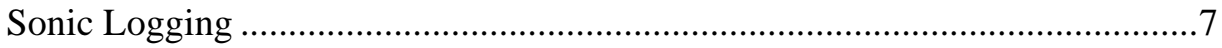

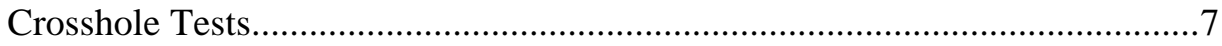

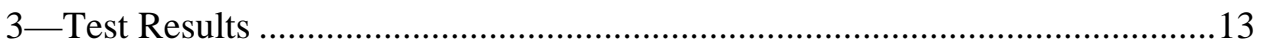

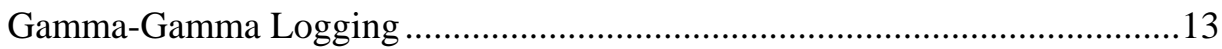

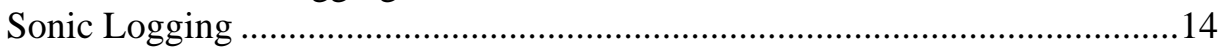

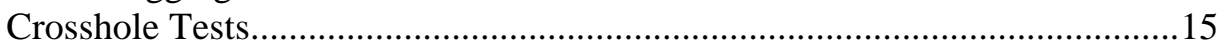

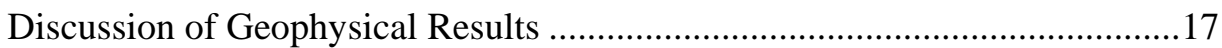

Computed Elastic Parameters ..................................................................17

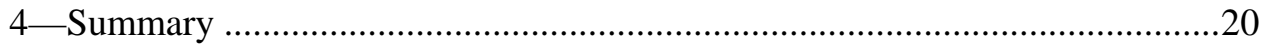

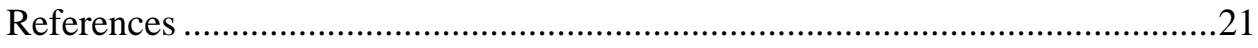

Appendix A: Sample Sonic Log....................................................................

Appendix B: Sonic and Gamma-Gamma Logging Results ................................ B1

Appendix C: Monolith Average P- and S-Wave Crosshole Velocities...............C1

Appendix D: Computed Elastic Moduli Based on Sonic Logging.....................D1

Appendix E: Computed Young's Modulus Based on Average Crosshole

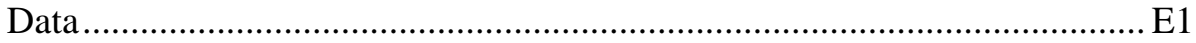

SF 298 


\section{List of Figures}

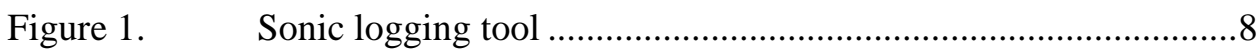

Figure 2. Sonic tool being lowered into a relief well..................................8

Figure 3. Triaxial geophone used for crosshole testing ..............................9

Figure 4. Crosshole testing being conducted in Monolith 14 ....................10

Figure 5. An example of a crosshole P-wave record ................................11

Figure 6. An example of a crosshole S-wave record where the downhole hammer was hit with an upward motion.....................11

Figure 7. An example of a crosshole S-wave record where the downhole hammer was hit with a downward motion...................12

Figure A1. Monolith 14 - Relief Well No. 1 .............................................A2

Figure A2. Monolith 21 - Relief Well No. 1 ............................................A7

Figure B1. Monolith 2 - Relief Well No. 1 …........................................... B2

Figure B2. Monolith 2 - Relief Well No. 2 …...........................................B3

Figure B3. Monolith 2 - Relief Well No. 3 ..............................................B4

Figure B4. Monolith 2 - Relief Well No. 4 ..............................................B5

Figure B5. Monolith 2 - Relief Well No. 5 …...........................................B6

Figure B6. Monolith 11 - Relief Well No. 1 …...........................................B7

Figure B7. Monolith 11 - Relief Well No. 2 …..........................................B8

Figure B8. Monolith 11 - Relief Well No. 3 ..............................................B9

Figure B9. Monolith 11 - Relief Well No. 4 ........................................... B10

Figure B10. Monolith 11 - Relief Well No. 5 ........................................... B11

Figure B11. Monolith 14 - Relief Well No. 1 ........................................... B12

Figure B12. Monolith 14 - Relief Well No. 2 …....................................... B13

Figure B13. Monolith 14 - Relief Well No. 3 ........................................... B14

Figure B14. Monolith 14 - Relief Well No. 4 …........................................ B15

Figure B15. Monolith 15 - Relief Well No. 1 …........................................ B16

Figure B16. Monolith 15 - Relief Well No. 2 …....................................... B17

Figure B17. Monolith 15 - Relief Well No. 3 .......................................... B18

Figure B18. Monolith 15 - Relief Well No. 4 ............................................ B19

Figure B19. Monolith 21 - Relief Well No. 1 …....................................... B20

Figure B20. Monolith 21 - Relief Well No. 2 ........................................... B21 
Figure B21. Monolith 21 - Relief Well No. 3 ..........................................B22

Figure B22. Monolith 21 - Relief Well No. 4 ............................................B23

Figure B23. Monolith 22 - Relief Well No. 2 ..........................................B24

Figure B24. Monolith 22 - Relief Well No. 3 ............................................B25

Figure B25. Monolith 22 - Relief Well No. 4 ...........................................B26

Figure B26. Monolith 27 - Relief Well No. 1 …........................................B27

Figure B27. Monolith 27 - Relief Well No. 2 …......................................B28

Figure B28. Monolith 27 - Relief Well No. 3 ..........................................B29

Figure B29. Monolith 27 - Relief Well No. 4 ...........................................B30

Figure B30. Monolith 27 - Relief Well No. 5 ...........................................B31

Figure C1. Average P- and S-wave crosshole velocities, Monolith 2......... C2

Figure C2. Average P- and S-wave crosshole velocities, Monolith 11....... C3

Figure C3. Average P- and S-wave crosshole velocities, Monolith 14....... C4

Figure C4. Average P- and S-wave crosshole velocities, Monolith 15....... C5

Figure C5. Average P- and S-wave crosshole velocities, Monolith 21....... C6

Figure C6. Average P- and S-wave crosshole velocities, Monolith 27....... C7

Figure D1. Monolith 2 - Relief Well No. 1 …...........................................D2

Figure D2. Monolith 2 - Relief Well No. 2 ..............................................D3

Figure D3. Monolith 2 - Relief Well No. 3 ..............................................D4

Figure D4. Monolith 2 - Relief Well No. 4 ..............................................D5

Figure D5. Monolith 2 - Relief Well No. 5 ...............................................D6

Figure D6. Monolith 11 - Relief Well No. 1 …..........................................D7

Figure D7. Monolith 11 - Relief Well No. 2 ….........................................D8

Figure D8. Monolith 11 - Relief Well No. 3 .............................................D9

Figure D9. Monolith 11 - Relief Well No. 4 ...........................................D10

Figure D10. Monolith 11 - Relief Well No. 5 ……....................................D11

Figure D11. Monolith 14 - Relief Well No. 1 …….....................................D12

Figure D12. Monolith 14 - Relief Well No. 2 ….......................................D13

Figure D13. Monolith 14 - Relief Well No. 3 ...........................................D14

Figure D14. Monolith 14 - Relief Well No. 4 …........................................D15

Figure D15. Monolith 15 - Relief Well No. 1 ……....................................D16

Figure D16. Monolith 15 - Relief Well No. 2 …......................................D17

Figure D17. Monolith 15 - Relief Well No. 3 ...........................................D18

Figure D18. Monolith 15 - Relief Well No. 4 ...........................................D19 
Figure D19. Monolith 21 - Relief Well No. 1 ............................................D20

Figure D20. Monolith 21 - Relief Well No. 2 ..........................................D21

Figure D21. Monolith 21 - Relief Well No. 3 ...........................................D22

Figure D22. Monolith 21 - Relief Well No. 4 ............................................D23

Figure D23. Monolith 22 - Relief Well No. 2 ............................................D24

Figure D24. Monolith 22 - Relief Well No. 3 ............................................D25

Figure D25. Monolith 22 - Relief Well No. 4 ...........................................D26

Figure D26. Monolith 27 - Relief Well No. 1 ..........................................D27

Figure D27. Monolith 27 - Relief Well No. 2 …......................................D28

Figure D28. Monolith 27 - Relief Well No. 3 ...........................................D29

Figure D29. Monolith 27 - Relief Well No. 4 ............................................D30

Figure D30. Monolith 27 - Relief Well No. 5 ...........................................D31

Figure E1. Average Young's modulus, Monolith 2 .................................. E2

Figure E2. Average Young's modulus, Monolith 11 ................................. E3

Figure E3. Average Young's modulus, Monolith 14 ................................. E4

Figure E4. Average Young's modulus, Monolith 15 …............................. E5

Figure E5. Average Young's modulus, Monolith 21 ................................. E6

Figure E6. Average Young's modulus, Monolith 27 ............................... E7

\section{List of Tables}

Table 1. Monoliths and Borings Used for Gamma-Gamma and Sonic Logging .............................................................................13

Table 2. Average Boring and Monolith Densities....................................14

Table 3. Average Sonic Logging-Derived P-Wave Velocities..................15

Table 4. Average Sonic Logging-Derived S-Wave Velocities..................15

Table 5. Location of Source and Receiver Borings Used for Crosshole Testing ......................................................................16

Table 6. Average Crosshole-Derived P-Wave Velocities ..........................16

Table 7. Average Crosshole-Derived S-Wave Velocities ..........................16

Table 8. $\quad$ Average Sonic Logging Data and Computed Elastic

Parameters .........................................................................18 
Table 9. Average Crosshole Logging Data and Computed Elastic

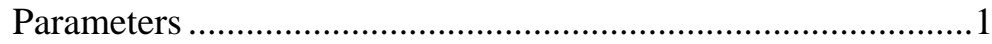

Table 10. Average Velocity and Elastic Parameter Values for Foundation Materials Beneath Concrete Section of Folsom Dam ..........19 


\section{Conversion Factors, Non-SI to SI Units of Measurement}

Non-SI units of measurement used in this report can be converted to SI units as follows:

\begin{tabular}{||l|l|l||}
\hline \hline Multiply & By & To Obtain \\
\hline \hline cubic feet & 0.028317685 & cubic meters \\
\hline feet & 0.3048 & meters \\
\hline inches & 25.4 & millimeters \\
\hline miles & 1.609347 & kilometers \\
\hline pounds (force) per square inch & 6.894757 & kilopascals \\
\hline pounds (mass) per cubic foot & 16.01846 & kilograms per cubic meter \\
\hline square inches & 6.4516 & square centimeters \\
\hline
\end{tabular}




\section{Preface}

This report describes a research study commissioned by the U.S. Army Engineer District, Sacramento, and conducted by the U.S. Army Engineer Research and Development Center (ERDC) to determine the material characteristics of the foundation rock beneath the concrete gravity sections of Folsom Dam, California.

The research described herein was conducted by Mr. José L. Llopis, Mr. Eric W. Smith, and Dr. Michael K. Sharp, ERDC, Geotechnical and Structures Laboratory (GSL), Vicksburg, MS. This report was written by Mr. Llopis and Dr. Sharp, in collaboration with Dr. Enrique E. Matheu, GSL. Text editing was performed by Mrs. Julia C. Baker, CAP, GSL.

The work was conducted under the general supervision of Dr. Lillian D. Wakeley, Chief, Engineering Geology and Geophysics Branch; Dr. Joseph P. Koester, Chief, Geotechnical and Earthquake Engineering Branch; Dr. Robert L. Hall, Chief, Geosciences and Structures Division; and Dr. David W. Pittman, Director, GSL.

At the time of publication of this report, COL James R. Rowan, EN, was Commander and Executive Director of ERDC, and Dr. James R. Houston was Director. 


\section{Introduction}

\section{Objective}

The objective of the research documented in this report was to determine the relevant material characteristics of the foundation materials beneath the concrete gravity sections of Folsom Dam, California. The results and findings from this investigation are used to identify representative values of foundation rock properties that can be used for dynamic analyses of the dam-foundation system.

\section{Scope}

A geophysical investigation was conducted at Folsom Dam to measure the values of compression- and shear-wave (P- and S-wave) propagation velocities as well as density of the foundation materials. The geophysical studies included seismic crosshole testing and sonic and gamma-gamma logging conducted below a series of concrete gravity monoliths. Average values of elastic parameters for the foundation rock materials beneath the concrete gravity dam section are estimated based on the velocity and density data.

\section{Project Characteristics}

Folsom Dam is located on the American River, about 20 miles $^{1}$ northeast of the city of Sacramento, CA. The reservoir is used for flood control, irrigation, and power-generation purposes. The maximum height of the gravity dam section is $340 \mathrm{ft}$ with a crest length of about 1,400 ft. It consists of 28 monoliths, $50 \mathrm{ft}$ wide each, and its construction was completed in 1956.

The gravity dam section is underlain by igneous rock, which ranges from granodiorite to quartz diorite. The rock is medium gray in color and medium to coarse grained. The constituent mineral grains are highly micro-fractured. This granite, of quartz diorite composition, is considered to be part of the Sierra Nevada batholith emplaced during the Jurassic period, 208 to 146 million years ago (U.S. Army Engineer District (USAED), Sacramento 2004).

1 A table of factors for converting non-SI units of measurement to SI units is presented on page viii. 
Four significant faults were identified beneath the concrete gravity section during construction. Two parallel faults, termed the Penstock and Wingwall Faults, were exposed beneath Monoliths 4, 5, and 6. These faults were found to strike in an upstream-downstream direction and dip 30 to 45 deg NW. They contained a brecciated zone about 3 to $4 \mathrm{ft}$ in thickness. The Channel Fault was exposed on the left abutment, and it dips towards the center of the valley. The fault continues at a low angle under the dam and ranges from surface exposures on the left abutment to depths greater than $150 \mathrm{ft}$ to the right of Monolith 12 (facing downstream). It strikes northeastward (N 30 to 45 deg E). In the vicinity of Monoliths 12 and 13, the Channel Fault has an apparent upstream dip of about 10 deg, whereas near Monoliths 22 and 23, it is at a relatively flat angle. The Channel Fault zone ranges up to $4 \mathrm{ft}$ in thickness and consists of a major fracture zone, numerous short fractures and fault gouge of soft chlorite, fault breccia, and thin lenses of broken quartz. At Monoliths 22 through 24, the Channel Fault is underlain by a secondary fault termed the Subsidiary Fault.

While minor variations existed from monolith to monolith, joints could generally be grouped into three major sets. The first and most prominent set strikes N 38 deg to 55 deg E and dips 37 deg to 55 deg NW; the second set strikes $\mathrm{N} 71$ deg to $90 \mathrm{deg} \mathrm{E}$ and dips 64 deg to $87 \mathrm{deg}$ SE; the final set strikes N 30 deg to $80 \mathrm{deg} \mathrm{W}$ and dips $60 \mathrm{deg}$ to $80 \mathrm{deg}$ NE. Of the three sets observed, set one is the most continuous, with joint length often exceeding $100 \mathrm{ft}$ (USAED, Sacramento 2004).

\section{Previous Studies}

In 1983, an evaluation of foundation rock mass properties was performed by Woodward Clyde Consultants (1983). A series of six NX-size core holes were drilled from locations within the foundation grouting gallery in Monoliths 5, 8, $13,18,21$, and 25 . The purpose of the rock coring was not only to obtain samples for laboratory testing, but also to facilitate borehole jacking tests for in situ modulus determinations. Borehole jack tests were performed at approximate depths of 2,10 , and $20 \mathrm{ft}$ below the concrete/rock contact. The measurements were used to estimate static deformation modulus and static Young's modulus of the rock mass. The modulus of deformation is defined as the ratio of stress to corresponding strain during loading of a rock mass including elastic and inelastic behavior. Young's modulus (or modulus of elasticity) is defined as the ratio of stress to corresponding strain below the proportionality of the material. The corresponding average values identified in this study were $1.6 \times 10^{6}$ and $2.1 \times 10^{6} \mathrm{psi}$, respectively.

In 1989, the U.S. Army Engineer Waterways Experiment Station (WES) performed a series of geophysical investigations to estimate material properties for the dam embankments and foundation (Llopis 1989). These investigations were performed to support seismic evaluation studies and consisted of surface seismic refraction, surface vibratory, downhole, and crosshole seismic tests. One P-wave surface seismic refraction line, termed R1, was conducted at the downstream toe of the left wing embankment dam. The ground surface along line R1 was between elevation 360 and $370 \mathrm{ft}$. The competent rock line, determined from 
boring data analyzed by U.S. Army Engineer District, Sacramento District, was determined to be fairly horizontal at this location at an elevation of $295 \mathrm{ft}$.

Refraction line R1 was $400 \mathrm{ft}$ long, which corresponds to a depth of investigation of about 100 to $130 \mathrm{ft}$ below the ground surface. A value of 13,450 fps was determined for the compression wave velocity, $V_{p}$. This value was assumed representative of the material extending to elevations between 235 and $265 \mathrm{ft}$, lying below the competent rock profile line. Therefore, it was believed that this velocity of 13,450 fps was indicative of very slightly weathered/fractured rock. Two boring sets, each one consisting of three borings located about $10 \mathrm{ft}$ apart, were used for the performance of crosshole seismic tests in the same downstream toe area. The measured P-wave velocities ranged from 9,000 to 10,000 fps. The slower velocities obtained from the crosshole test are indicative of the more weathered rock at this elevation. This procedure only tested the material located at a particular elevation between the three holes, one containing a seismic source and the others containing receivers.

A second $\mathrm{P}$-wave refraction line, $\mathrm{R} 2$, was run at the toe of the right wing embankment dam. Data from this line penetrated to a depth of about 85 to $110 \mathrm{ft}$ and showed a velocity of 13,655 fps for the deepest layers. This layer begins at elevation $365 \mathrm{ft}$ and extends to about elevation 280 to $255 \mathrm{ft}$. This velocity, which is comparable to the first line (R1), was also interpreted as being indicative of slightly weathered/fractured granite. A third crosshole set was conducted in this area, for which a penetration of about $15 \mathrm{ft}$ into competent rock was estimated. The test results showed a P-wave velocity of 11,700 fps at the bottom of the hole, which was assumed to represent a moderately weathered/fractured granodiorite/granite. Based on the above information, a value of 14,000 fps was estimated as a lower bound for the competent rock beneath the concrete gravity dam, 16,000 fps for an average velocity, and 18,000 fps as an upper bound.

Considering these geophysical tests and the results from the borings drilled in 1983, relevant material properties for the bedrock were developed by WES. It was determined that the rock materials beneath the concrete gravity dam and the wing dams were very similar if not the same. Correlation of the available information allowed selections of lower, average, and upper bound values for the bulk unit weight, $w_{f}$, given by 167,171 , and 174 pcf, respectively.

Since values for the velocity and total unit weight were estimated as outlined above, only the value of the Poisson's ratio, $v_{f}$, was left to be obtained. Usually, Poisson's ratio is determined with seismic data based on the shear and compression wave velocities of the in situ material. Since only the P- and S-wave velocities were available, this usual procedure could not be employed. Although shear wave velocities were obtained from the crosshole seismic tests, the holes did not penetrate deeply enough into competent rock to generate shear waves in the zone of interest. Lower bound, average, and upper bound values of 0.20 , 0.25 , and 0.30 were estimated for the Poisson's ratio based on engineering judgment.

The lower, average, and upper bound values of compression-wave velocity, bulk modulus, and Poisson's ratio, $v_{f}$, described in the preceding paragraphs, 
were used to compute the corresponding values for the dynamic Young's modulus, $E_{f}^{d}$, based on the following expression:

$$
E_{f}^{d}=\rho_{f} V_{p}^{2} \frac{\left(1-2 v_{f}\right)\left(1+v_{f}\right)}{\left(1-v_{f}\right)}
$$

where $\rho_{f}$ denotes the mass density, i.e., $\rho_{f}=w_{f} / g$. Lower, average, and upper bound values of 5.8, 7.9, and $11.0 \times 10^{6}$ psi were determined, respectively.

An estimation of specific foundation rock mass properties was later performed by URS Corporation (2001). The study focused on shear strength properties of the jointed rock mass below the concrete/rock interface and modulus of elasticity of the rock. The work involved a review of available information, visual observations of the rock mass at the project site, and observation of a limited number of rock cores. In particular, this study reviewed the results from the 1983 borehole jacking tests, and it concluded that the value of modulus of elasticity determined under quasi-static conditions (such as Goodman Jack tests) constitutes a lower bound for the value that should be used in a seismic analysis. Static modulus values of $1.2,1.9$, and $2.5 \times 10^{6}$ psi were recommended for the right, channel, and left abutment sections, respectively.

\section{Need for Additional Investigations}

An essential part of the input required to develop a numerical model of a dam-foundation system is the elastic properties of the materials involved. In particular, the model should adequately capture the effects associated with the flexibility of the foundation region, and therefore its elastic characteristics should be appropriately quantified. Ideally, the analysis should use the actual properties of the in situ foundation rock mass, measured at the in situ moisture content and confining pressure and at the stress level that will exist in practice. However, there are many practical difficulties in accurately determining actual in situ elastic properties for a rock mass. It is current practice to use modulus estimates obtained under different test conditions, and Engineer Manual (EM) 1110-1-2908 (Department of the Army 1994) indicates several commonly used methods of estimating foundation rock modulus, such as static laboratory compression testing of intact core specimens, downhole geophysical logging, borehole jacking tests, and others. EM 1110-1-2908 recommends that the selection process for design moduli should not rely on a single method, but rather involve an integrated approach in which a number of methods are incorporated.

The elastic modulus values recommended by URS based on borehole jacking tests would appear to be very lower bound values. The geophysical investigation undertaken by WES estimated significantly higher values of elastic modulus. However, no data were measured from the foundation material beneath the monoliths. All of the recorded data were for the foundation material beneath the left and right wing dams. Based on this information, extrapolations of the rock properties beneath the monoliths were inferred. The value of $7.9 \times 10^{6} \mathrm{psi}$ recommended for the dynamic elastic modulus was considered a reasonable 
value for the foundation rock beneath the concrete gravity sections, and this value has been used in a series of seismic evaluation studies conducted for the Folsom Dam Outlet Modifications Project.

However, since the values reported by WES were based on geophysical investigations that did not penetrate deep enough to engage the foundation rock in all locations tested, and no direct data were obtained beneath the sections of interest, new geophysical investigations were recently proposed and conducted by the Geotechnical and Structures Laboratory of the U.S. Army Engineer

Research and Development Center. This report summarizes the results of these investigations. 


\section{Geophysical Test Principles and Field Procedures}

The geophysical survey procedures, including a brief description of each survey as it pertains to this investigation, are given below. Additional information can be found in EM 1110-1-1802 (Department of the Army 1995).

\section{Gamma-Gamma Logging}

Gamma-gamma logging is used to determine the density of the material inside a boring. Gamma-gamma logs record the backscattered radiation by surrounding rock from a gamma source that is in a downhole probe. The logs are calibrated in terms of bulk density. Gamma-gamma logging is based on the principle that the attenuation of gamma radiation, as it passes through the borehole and surrounding rocks, is related to the electron density of those rocks. If a probe detects only radiation resulting from Compton scattering, the count rate will be inversely proportional to the electron density of the material through which the radiation passes; that is, the measured count rate will be lower in more dense rocks (Keys 1997).

The volume of investigation of the gamma-gamma probe is about 5 to 6 in. The accuracy of bulk-density determinations with these logs is reported by various authors to be between 0.03 and $0.05 \mathrm{~g} / \mathrm{cm}^{3}$. A significant source of error for density logs is large changes in borehole diameter (Keys 1997). Details of the gamma-gamma probe, operation procedures, and theory of operation are given in Mount Sopris Instrument Company, Inc. (2003).

The gamma-gamma logging was conducted by the COLOG Division of Layne Christensen Company during the periods 22-24 June and 24-27 August 2004. The gamma source was attached to the downhole probe, and the gammagamma tool was lowered to the bottom of the boring being tested by means of a braided steel cable attached to an electric-powered winch. After the tool was properly positioned at the bottom of the hole, the tool was then raised at a slow, steady rate to the surface while recording the backscatter radiation the entire time. The information was transmitted by wires embedded in the braided steel cable to a laptop computer at the surface, where the information was continuously monitored by the operator. 


\section{Sonic Logging}

Sonic logging is used to measure the P- and S-wave velocity of the materials surrounding a borehole. The velocities are computed by measuring the time a transmitted acoustic pulse takes to travel from transmitter to one or more receivers in a probe. The pulse travels from the probe through the borehole fluid, into the surrounding material, and to the receivers. Knowing the distance between the transmitter and receivers, the P-and S-wave velocities can be computed. The acoustic pulse is transmitted 2 to 10 times apart at frequency ranges of 20 to $35 \mathrm{kHz}$. The probe material between the transmitter and receiver has a low velocity and is acoustically attenuating. The logs are the continuous record of the transit times of the propagated wave. Figure 1 shows the sonic probe along with the locations of the receivers and transmitter. An advantage of sonic logging over crosshole testing is that sonic logging requires only one boring in which to conduct testing rather than multiple borings required by the crosshole method.

The radius of investigation for sonic logging is reported to be approximately three times the wavelength (Keys 1997). The wavelength is equal to the velocity divided by the frequency. At a frequency of $20,000 \mathrm{~Hz}$ and for a velocity of 25,000 fps (the velocity of a hard rock), the radius of investigation is about $3.75 \mathrm{ft}$. Details of the sonic logging probe, operation procedures, and theory of operation are given in Mount Sopris Instrument Company, Inc. (2002).

The sonic logging was also conducted by the COLOG Division of Layne Christensen Company during the periods 22-24 June and 24-27 August 2004. The probe was lowered to the bottom of the boring being tested by means of the same braided steel cable used for the gamma-gamma tool (Figure 2). Once the tool was properly positioned at the bottom of the hole, the tool was then raised at a slow, steady rate to the surface while recording the transmitted acoustic pulse the entire time. The information was transmitted by wires embedded in the braided steel cable to a laptop computer at the surface, where the information was continuously monitored by the operator. An example of a sonic log is presented in Appendix A.

\section{Crosshole Tests}

Crosshole tests were used to determine horizontal P- and S-wave velocities as a function of depth. One advantage of crosshole testing as opposed to surface seismic refraction is its ability to detect lower velocity layers underlying or sandwiched between layers of higher velocity. The crosshole technique is therefore considered to be inherently more definitive and accurate than the surface refraction test, but has the shortcomings of requiring boreholes and not being able to cover as much areal extent. Basically, the testing consists of measuring the arrival time of a P- or S-wave that has traveled from a source in one boring to a detector in another borehole at the same elevation. This procedure is then repeated for test elevations. Knowing the distance between borings and the time the seismic wave takes to travel across this distance, the velocity can be computed (distance divided by time). 


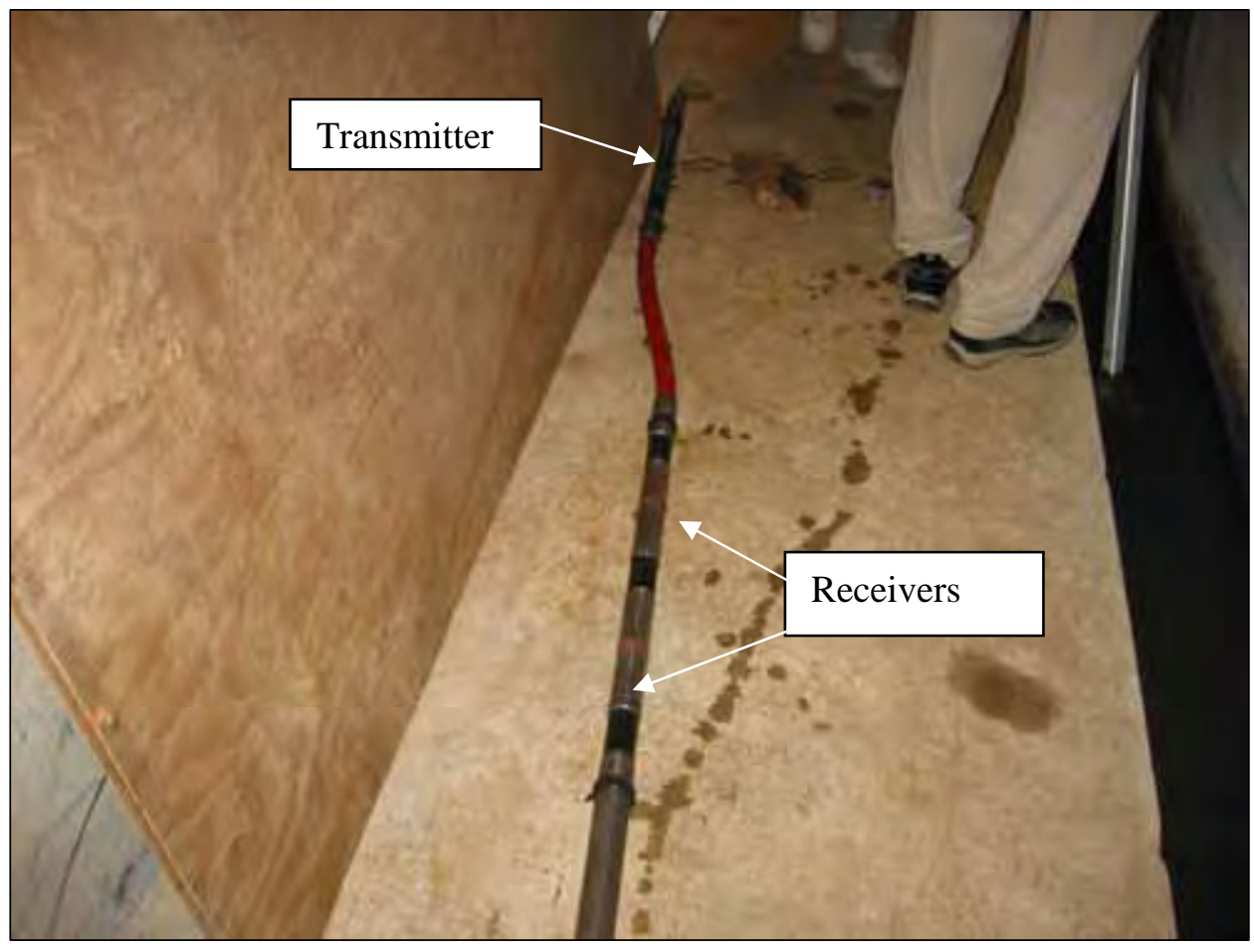

Figure 1. Sonic logging tool

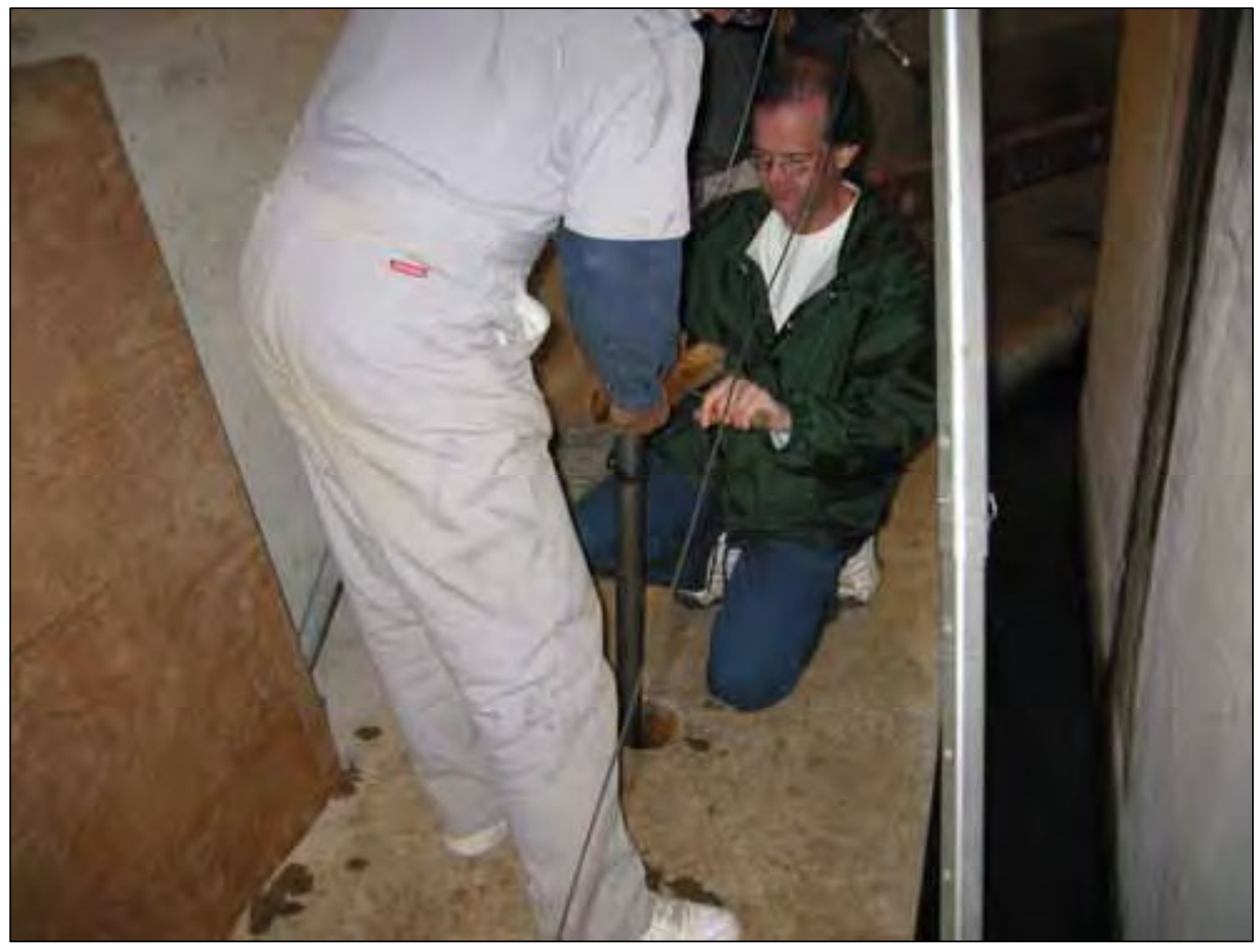

Figure 2. Sonic tool being lowered into a relief well 
Crosshole testing was conducted at selected locations inside the dam's lowest gallery. Existing in-line drain holes (borings) that were located along the base of the dam and penetrated the granite foundation were used for testing. The section of the borings that penetrated the concrete base of the dam was cased with steel pipe approximately $3 \mathrm{in}$. in diameter. On average, the steel casing was approximately $30 \mathrm{ft}$ in length. The borings were uncased in the granitic bedrock.

Gyroscopic borehole directional (drift) surveys were conducted to determine the precise easting and northing ( $\mathrm{x}-\mathrm{y}$ coordinates) of the crosshole test borings as a function of depth. Accurate reduction of data from the crosshole test requires knowledge of the drift of each boring so that a straight-line distance between borings at each test depth can be established. The surveys were conducted during the period 24-26 August 2004 by Wellbore Navigation, Inc., of Tustin, CA. Prior to being able to perform the directional survey, the $x-y$ coordinates as well as the elevation (z) must be known. The $\mathrm{x}, \mathrm{y}, \mathrm{z}$ coordinates used by Wellbore Navigation were provided by the USAED, Sacramento.

The P- and S-wave velocity crosshole measurements were obtained by placing a seismic wave source in a boring (source boring) and a set of detectors, at the same depth, in other borings (receiver borings). The detectors consisted of a triaxial array of geophones, or velocity transducers (two mounted horizontally and aligned 90 deg to each other, and one oriented vertically), in one container (Figure 3). The container housing the geophone array was clamped firmly to the casing wall by means of an expanding steel spring. Hydrophones (pressure transducers) were also used in some cases to measure the P-wave arrival. The hydrophones were lowered to the desired depth and allowed to hang freely in the boring. A downhole hammer was used as a source of vertically polarized

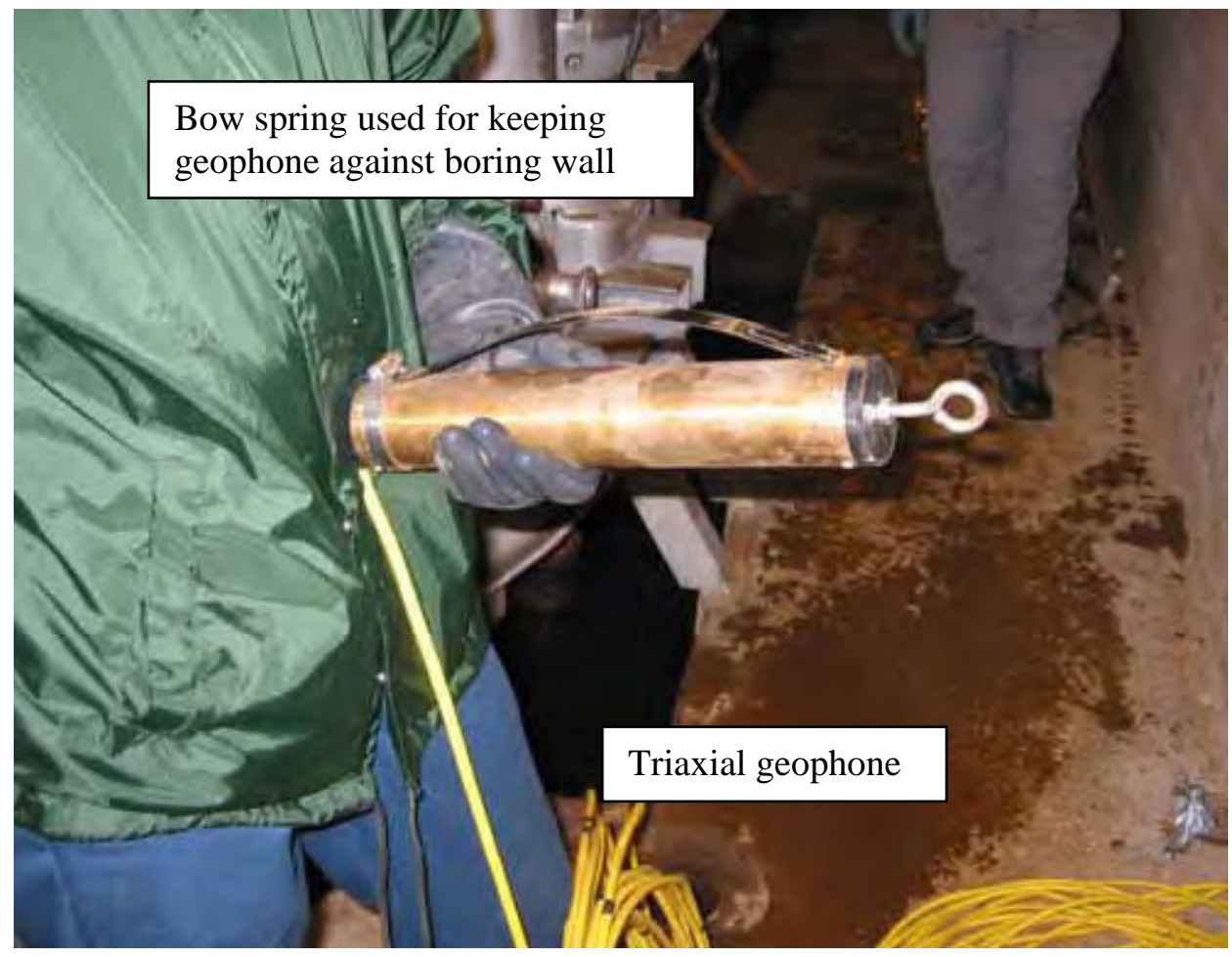

Figure 3. Triaxial geophone used for crosshole testing 
$\mathrm{S}$-waves. The S-wave testing procedure consisted of lowering the hammer in the boring to a selected test depth and clamping the hammer firmly to the sidewalls of the casing by pumping air into an expanding rubber bladder. When the hammer assembly was in position, the operator would tug in a quick upward motion on a cable connected to a vertically sliding hammer inside the hammer assembly. When the upward traveling sliding hammer struck the clamped hammer assembly, a vertically polarized wave was propagated.

The bottom of the sliding hammer is also attached to the bottom of the hammer assembly by means of a spring. Thus, when the cable attached to the sliding hammer is released at the surface by the operator, the sliding hammer is accelerated downward, striking the hammer assembly and creating S-waves of opposite polarity. Each time the sliding hammer struck the top or bottom of the hammer assembly, P-waves were also produced. The time required for the P- and S-wave to travel from source to receiver was recorded with a portable battery-powered, 24-channel seismograph with data-enhancement capability. Crosshole testing at each crosshole set was performed at 5 -ft depth intervals. Figure 4 shows crosshole testing being conducted in Monolith 14.

When the sliding hammer strikes opposite ends of the clamped hammer assembly, the polarity of the $\mathrm{S}$-wave is reversed, whereas the polarity of the $\mathrm{P}$-wave is not. This allows the interpreter to pick the S-wave arrival by comparing signal wave forms in successive tests with reverse polarity. Figure 5 is an example of a crosshole P-wave record. Examples of S-wave records for a given elevation are shown in Figures 6 and 7. Figure 6 is an example where the downhole hammer was struck in an upward motion, whereas Figure 7 shows a record where the hammer was struck in a downward motion.

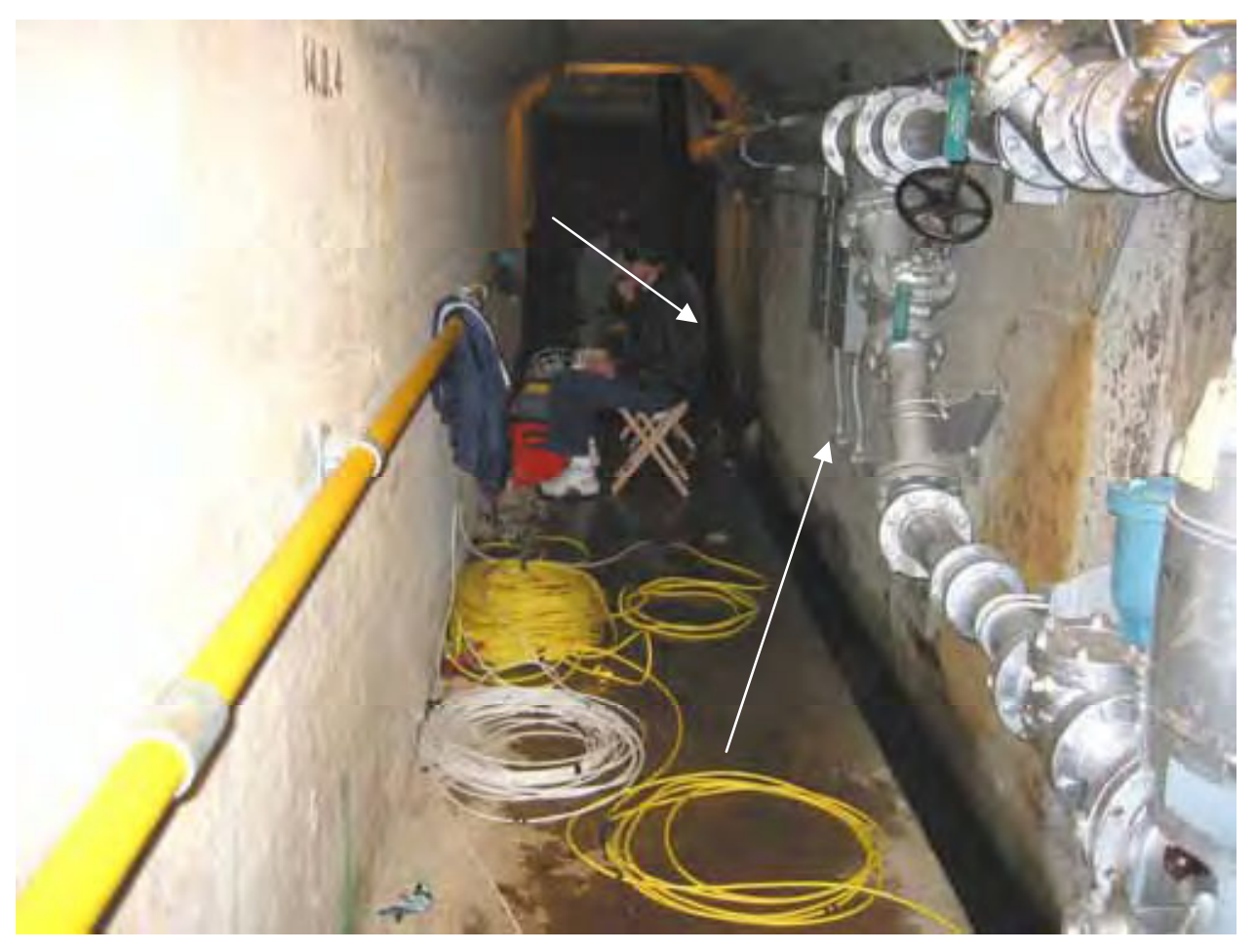

Figure 4. Crosshole testing being conducted in Monolith 14 


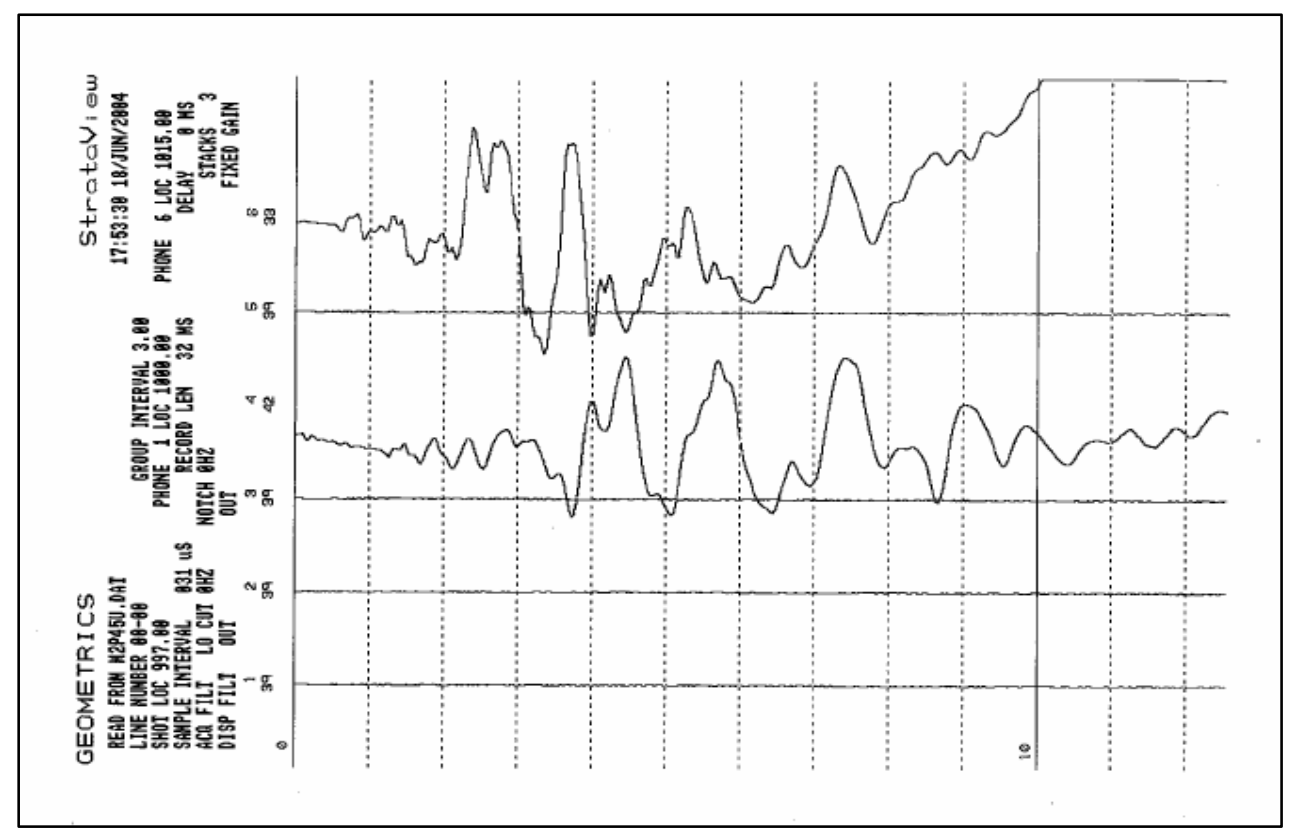

Figure 5. An example of a crosshole P-wave record

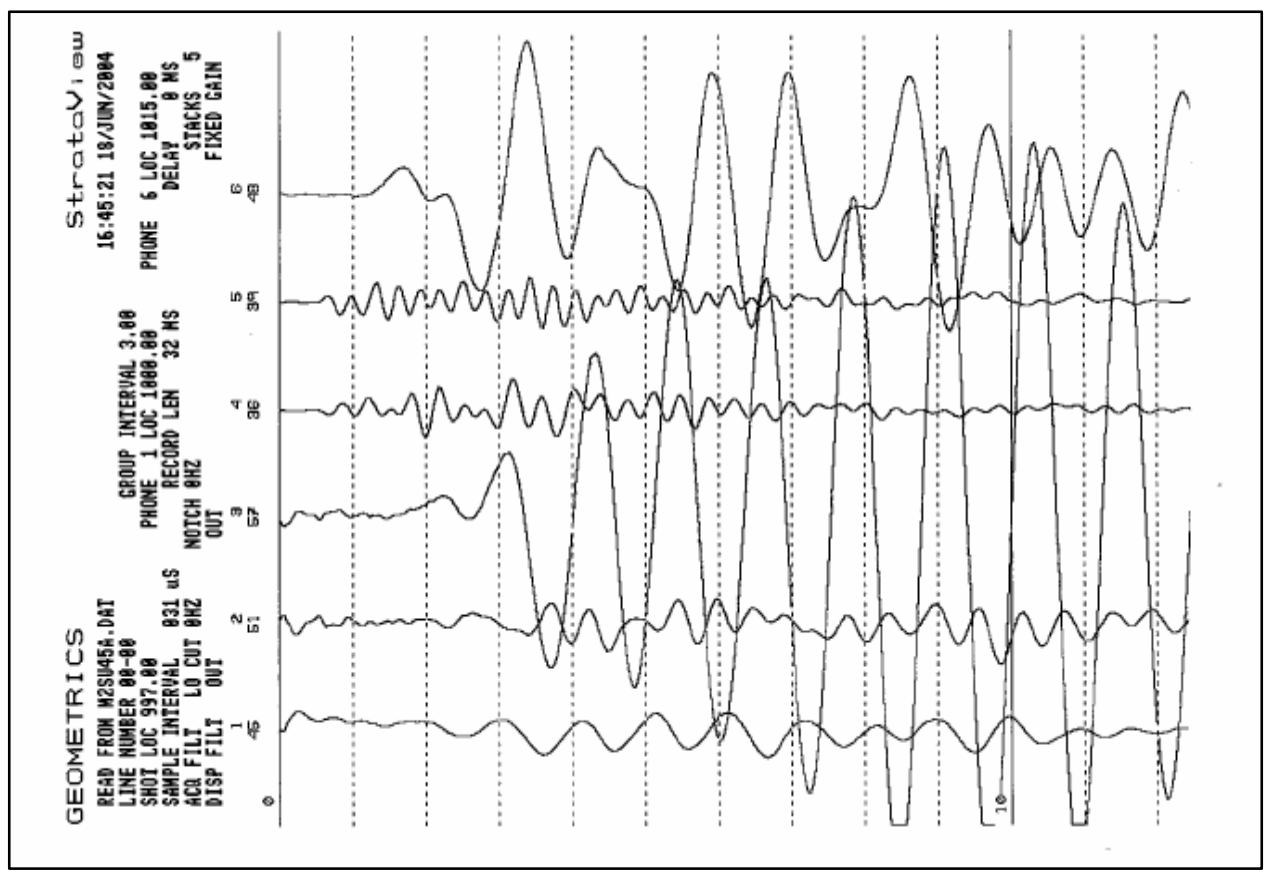

Figure 6. An example of a crosshole S-wave record where the downhole hammer was hit with an upward motion 


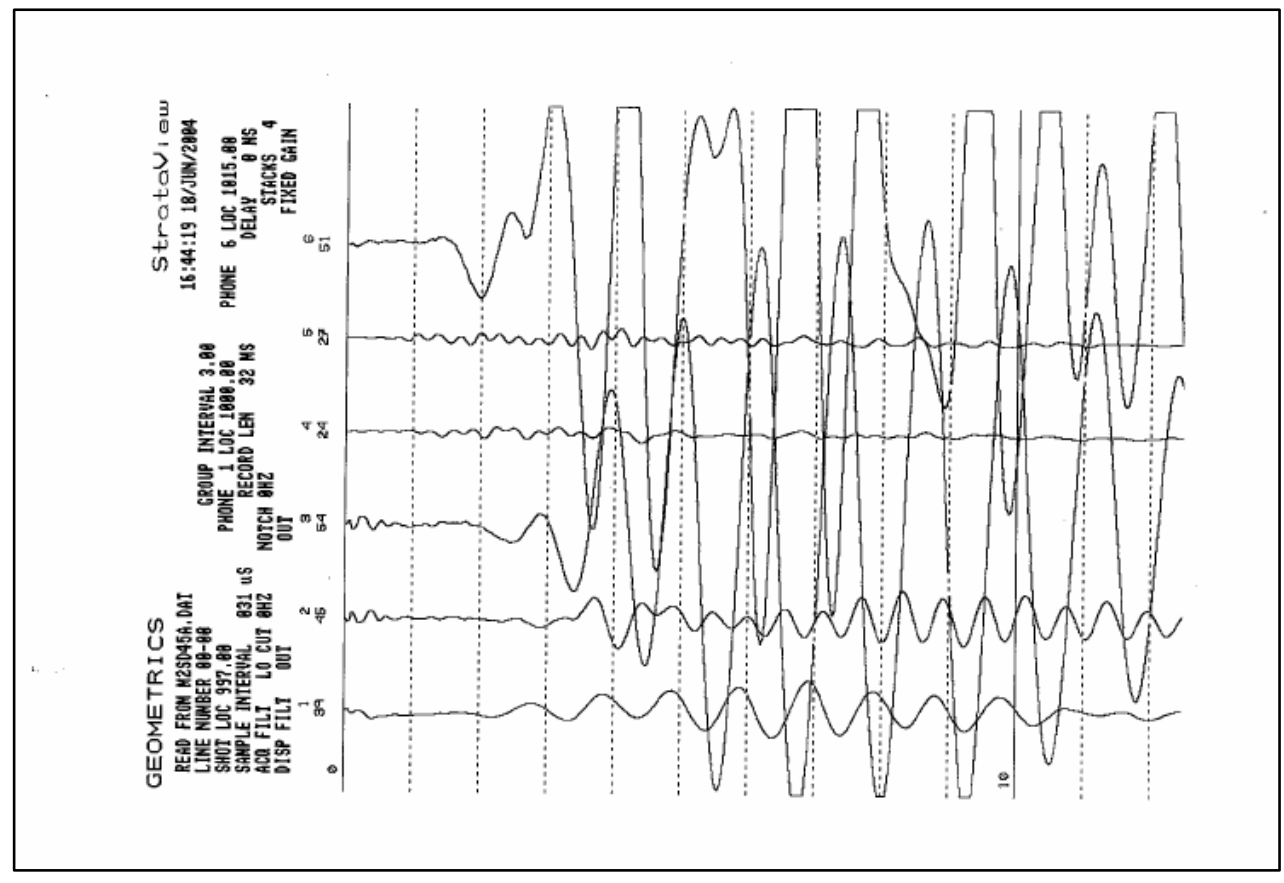

Figure 7. An example of a crosshole S-wave record where the downhole hammer was hit with a downward motion 


\section{Test Results}

The following sections describe the results corresponding to the geophysical tests conducted at Folsom Dam. Crosshole testing was conducted during the period 16-24 June 2004 and deviation surveys, 24-26 August 2004.

\section{Gamma-Gamma Logging}

Gamma-gamma logging was conducted in selected monoliths of the dam. The monoliths and the borings used for gamma-gamma logging are shown in Table 1 . The depth of the borings in which testing was conducted ranged between approximately 75 and $150 \mathrm{ft}$ and averaged about $130 \mathrm{ft}$.

\begin{tabular}{|c|c|c|c|c|c|}
\hline \multicolumn{6}{|c|}{$\begin{array}{l}\text { Table } 1 \\
\text { Monoliths and Borings Used for Gamma-Gamma and Sonic } \\
\text { Logging }\end{array}$} \\
\hline Monolith No. & Boring 1 & Boring 2 & Boring 3 & Boring 4 & Boring 5 \\
\hline 2 & $x$ & $x$ & $x$ & $x$ & $x$ \\
\hline 11 & $x$ & $x$ & $x$ & $x$ & $x$ \\
\hline 14 & $x$ & $x$ & $x$ & $x$ & \\
\hline 15 & $x$ & $x$ & $x$ & $x$ & \\
\hline 21 & $x$ & $x$ & $x$ & $x$ & \\
\hline 22 & & $x$ & $x$ & $x$ & \\
\hline 27 & $x$ & $x$ & $x$ & $x$ & $x$ \\
\hline
\end{tabular}

The results of the gamma-gamma loggings are presented in Appendix B. The results show that the density values vary considerably in approximately the upper $30 \mathrm{ft}$, which corresponds with the steel-cased portion of the boring that penetrates the concrete base. The density values in the granite foundation are fairly consistent in each hole and vary on average by about $0.1 \mathrm{~g} / \mathrm{cc}$. The prominent lowdensity spikes that appear in the density data are caused by fractures in the granite bedrock.

A manual best fit of the density data, excluding the portion of the data collected in approximately the upper $30 \mathrm{ft}$, was performed to determine an average density value for each boring. Table 2 presents the average density value 
for each boring in which density logging was conducted. The average boring densities ranged between 2.68 and $2.94 \mathrm{~g} / \mathrm{cc}$. The highest average densities of 2.82 and $2.86 \mathrm{~g} / \mathrm{cc}$ were measured under Monoliths 14 and 15, respectively. These are the tallest dam monoliths. The lowest average monolith density, $2.72 \mathrm{~g} / \mathrm{cc}$, was measured beneath Monolith 2.

\begin{tabular}{|c|c|c|c|c|c|c|}
\hline \multicolumn{7}{|c|}{$\begin{array}{l}\text { Table } 2 \\
\text { Average Boring and Monolith Densities }\end{array}$} \\
\hline \multirow{2}{*}{$\begin{array}{l}\text { Monolith } \\
\text { No. }\end{array}$} & \multicolumn{6}{|c|}{ Density, g/cc } \\
\hline & Boring 1 & Boring 2 & Boring 3 & Boring 4 & Boring 5 & Average \\
\hline 2 & 2.68 & 2.68 & 2.70 & 2.70 & 2.82 & 2.72 \\
\hline 11 & 2.73 & 2.72 & 2.80 & 2.78 & 2.76 & 2.76 \\
\hline 14 & 2.87 & 2.85 & 2.83 & 2.72 & -- & 2.82 \\
\hline 15 & 2.76 & 2.82 & 2.92 & 2.94 & --- & 2.86 \\
\hline 21 & 2.74 & 2.76 & 2.76 & 2.78 & --- & 2.76 \\
\hline 22 & --- & 2.80 & 2.80 & 2.76 & --- & 2.79 \\
\hline 27 & 2.77 & 2.78 & 2.78 & 2.76 & 2.78 & 2.77 \\
\hline
\end{tabular}

The average density for the foundation materials beneath the concrete gravity sections is $2.78 \mathrm{~g} / \mathrm{cc}$, which corresponds to a bulk unit weight of $174 \mathrm{pcf}$.

\section{Sonic Logging}

Sonic logging, which was conducted to obtain P- and S-wave velocities of the foundation, was conducted in the same monoliths and borings as used for gamma-gamma logging (Table 1). The results of the sonic logging are presented in Appendix B. As was the case for the gamma-gamma logs, the data measured in the concrete (approximately the upper $30 \mathrm{ft}$ of each boring) deviate significantly from the values measured in the granite.

Tables 3 and 4 present the averaged P- and S-wave velocities, respectively, of the granite for each boring and monolith tested. The average monolith P-wave velocities ranged from a low of 17,550 fps beneath Monolith 11 to a high of 19,500 fps beneath Monoliths 21 and 22. The average monolith S-wave velocities ranged from a low of 10,200 fps beneath Monolith 11 to a high of 11,450 fps beneath Monolith 22. The average sonic logging-derived P- and S-wave velocities for the foundation materials beneath the concrete gravity sections are 18,900 and 11,075 fps, respectively. 


\begin{tabular}{|l|l|l|l|l|l|l||}
\hline \hline $\begin{array}{l}\text { Table 3 } \\
\text { Average Sonic Logging-Derived P-Wave Velocities }\end{array}$ \\
\hline \hline \multirow{2}{*}{$\begin{array}{l}\text { Monolith } \\
\text { No. }\end{array}$} & \multicolumn{7}{|c||}{ P-Wave Velocity, fps } \\
\cline { 2 - 7 } & Boring 1 & Boring 2 & Boring 3 & Boring 4 & Boring 5 & Average \\
\hline \hline 2 & 18,400 & 18,000 & 19,600 & 18,400 & 18,800 & 18,650 \\
\hline 11 & 18,000 & 18,800 & 16,000 & 16,500 & 18,400 & 17,550 \\
\hline 14 & 18,000 & 20,400 & 18,400 & 18,500 & --- & 18,800 \\
\hline 15 & 19,000 & 18,000 & 19,200 & 19,200 & -- & 18,850 \\
\hline 21 & 19,800 & 19,800 & 19,400 & 19,000 & --- & 19,500 \\
\hline 22 & --- & 19,700 & 19,600 & 19,400 & -- & 19,500 \\
\hline 27 & 19,400 & 19,300 & 19,600 & 19,600 & 19,400 & 19,450 \\
\hline \hline
\end{tabular}

\begin{tabular}{|c|c|c|c|c|c|c|}
\hline \multirow{2}{*}{$\begin{array}{l}\text { Monolith } \\
\text { No. }\end{array}$} & \multicolumn{6}{|c|}{ S-Wave Velocity, fps } \\
\hline & Boring 1 & Boring 2 & Boring 3 & Boring 4 & Boring 5 & Average \\
\hline 2 & 10,000 & 10,400 & 9,800 & 11,200 & 11,200 & 10,500 \\
\hline 11 & 9,600 & 11,200 & 10,000 & 9,000 & 11,200 & 10,200 \\
\hline 14 & 11,400 & 11,400 & 11,200 & 11,200 & --- & 11,300 \\
\hline 15 & 11,200 & 11,400 & 11,000 & 11,200 & --- & 11,200 \\
\hline 21 & 11,400 & 11,500 & 11,300 & 11,400 & --- & 11,400 \\
\hline 22 & --- & 11,500 & 11,600 & 11,200 & --- & 11,450 \\
\hline 27 & 11,500 & 11,400 & 11,400 & 11,300 & 11,300 & 11,400 \\
\hline
\end{tabular}

\section{Crosshole Tests}

Crosshole testing was conducted in Monoliths 2, 11, 14, 15, 21, and 27. Table 5 presents the location of the source and receiver borings used for crosshole testing. Testing was typically conducted between depths of 75 and $25 \mathrm{ft}$ at 5 -ft testing intervals. The average distance between borings is about $10 \mathrm{ft}$. The results of the crosshole P- and S-wave velocity testing are presented in Tables 6 and 7, respectively. Average boring P-wave velocities ranged between 13,100 and 25,700 fps, whereas average monolith P-wave velocities ranged between 14,850 and 24,350 fps. Average boring S-wave velocities ranged between 6,150 and 25,700 fps, and the average monolith $\mathrm{S}$-wave velocities ranged between 6,500 and 8,525 fps. Appendix C presents plots of the average crosshole P- and $\mathrm{S}$-wave versus elevation for each monolith tested. 


\begin{tabular}{|c|c|c|c|c|}
\hline \multicolumn{5}{|c|}{$\begin{array}{l}\text { Table } 5 \\
\text { Location of Source and Receiver Borings Used for Crosshole } \\
\text { Testing }\end{array}$} \\
\hline Monolith No. & Boring 1 & Boring 2 & Boring 3 & Boring 4 \\
\hline 2 & & Source & Receiver & Receiver \\
\hline $\mid 11$ & Receiver & Receiver & Source & --- \\
\hline $\mid 14$ & --- & Source & Receiver & Receiver \\
\hline 15 & -.- & Receiver & Receiver & Source \\
\hline 21 & --- & Receiver & --.- & Source \\
\hline 27 & Receiver & Receiver & Source & --- \\
\hline
\end{tabular}

\begin{tabular}{|c|c|c|c|c|c|}
\hline \multicolumn{6}{|c|}{\begin{tabular}{|l|l|} 
Table 6 \\
Average Crosshole-Derived P-Wave Velocities \\
\end{tabular}} \\
\hline \multirow{2}{*}{$\begin{array}{l}\text { Monolith } \\
\text { No. }\end{array}$} & \multicolumn{5}{|c|}{ P-Wave Velocity, fps } \\
\hline & Boring 1 & Boring 2 & Boring 3 & Boring 4 & Average \\
\hline 2 & & & 17,575 & 13,450 & 15,525 \\
\hline $\mid 11$ & 15,100 & 16,300 & & & 15,700 \\
\hline 14 & & & 26,000 & 22,700 & 24,350 \\
\hline 15 & & 23,400 & 25,050 & & 24,225 \\
\hline 21 & & 14,825 & & & 14,825 \\
\hline 27 & 21,700 & 25,700 & & & 23,700 \\
\hline
\end{tabular}

\section{Table 7}

Average Crosshole-Derived S-Wave Velocities

\begin{tabular}{||l|l|l|l|l|l||}
\hline \multirow{2}{*}{$\begin{array}{l}\text { Monolith } \\
\text { No. }\end{array}$} & \multicolumn{5}{|c||}{ S-Wave Velocity, fps } \\
\cline { 2 - 6 } & Boring 1 & Boring 2 & Boring 3 & Boring 4 & Average \\
\hline \hline 2 & & & 6,150 & 6,850 & 6,500 \\
\hline 11 & 7,200 & 6,600 & & & 6,900 \\
\hline 14 & & & 7,400 & 9,200 & 8,300 \\
\hline 15 & & 8,750 & 8,275 & & 8,525 \\
\hline 21 & & 7,225 & & & 7,225 \\
\hline 27 & 6,225 & 6,425 & & & 6,325 \\
\hline \hline
\end{tabular}

The averaged P- and S-wave crosshole-derived velocities for the foundation materials beneath the concrete gravity sections are 19,725 and 7,300 fps, respectively. 


\section{Discussion of Geophysical Results}

The average foundation sonic and crosshole P-wave velocities, 18,900 and 19,725 fps, respectively, discussed in the previous section indicate very good agreement. The average P-wave velocity difference between the two methods is 825 fps. However, the average S-wave velocity difference between the two methods is greater than the difference for the P-wave velocities. The sonicderived S-wave average foundation velocity is 11,075 whereas the crossholederived velocity is 7,300 fps, a difference of 3,775 fps. There are several possible sources of error that can explain the discrepancy in this velocity difference. Picking S-wave arrival times from the sonic and crosshole records is more subjective than picking the P-wave arrivals, leading to discrepancies between the two methods. Small picking errors in fast materials such as those encountered at Folsom Dam and small distances between source and receiver can lead to large velocity errors. There may also be errors in the gyroscopic drift surveys that can lead to the computation of erroneous hole-to-hole distances, thus leading to erroneous velocities. The foundation material may be dispersive, meaning that the wave velocities are a function of frequency. The frequencies used for sonic logging are much higher than those used for crosshole testing.

Problems were encountered with the borings during crosshole testing, which consequently caused data degradation. One problem was that the borings were inclined approximately 8 to $10 \mathrm{deg}$. This prevented the vertically oriented geophone, which is used for detecting the S-wave, from moving freely. Another problem with the borings was encountered at the concrete-rock interface. While lowering the downhole geophones and source in the borings, the instruments tended to hang up at depths of about 25 to $30 \mathrm{ft}$. There was concern that these instruments would become permanently lodged in the hole. A downhole camera was borrowed from the dam office and lowered into the holes to determine what was causing the tools to catch. The camera showed, in all cases, a small cavity at the concrete-rock interface. Because of these cavities, the inclination of the borings, and the relatively short dimension of the downhole geophone housing, the geophones kept dropping into the cavities rather than sliding down the boring. Modifications had to be made to the geophone housing so that it could pass the problem area. In some cases, it was necessary to remove the spring that pushes the geophone housing firmly to the borehole wall and let it hang freely in the boring. Since the geophone could not be coupled firmly to the borehole wall, the data were degraded.

\section{Computed Elastic Parameters}

Using the P- and S-wave velocities derived from sonic logging and crosshole testing and the density values derived from gamma-gamma logging, a series of elastic material parameters was computed. The parameters include dynamic shear modulus, Poisson's ratio, Young's modulus, constrained modulus, and bulk modulus. The dynamic shear modulus, $G_{f}$, is determined as follows: 


$$
G_{f}^{d}=\rho_{f} V_{S}^{2}
$$

where Poisson's ratio, $v_{f}$, is obtained in terms of the ratio of the P-and S-wave velocities $\left(V_{P} / V_{S}\right)$,

$$
\frac{V_{P}}{V_{S}}=\sqrt{\frac{2\left(1-\nu_{f}\right)}{\left(1-2 \nu_{f}\right)}} \Rightarrow v_{f}=\frac{1-0.5\left(V_{P} / V_{S}\right)^{2}}{1-\left(V_{P} / V_{S}\right)^{2}}
$$

An alternate expression to Equation 1 for computing the dynamic Young's modulus, $E_{f}^{d}$, is

The corresponding constrained modulus, $D_{f}^{d}$, can be computed as

$$
\begin{aligned}
& E_{f}^{d}=2\left(1+v_{f}\right) G_{f}^{d} \\
& D_{f}^{d}=\left(V_{P} / V_{S}\right)^{2} G_{f}^{d}
\end{aligned}
$$

The bulk modulus, $K$, is computed as

$$
E=K_{f} / 3\left(1-2 v_{f}\right)
$$

Table 8 shows the computed average elastic parameters under each monolith tested using averaged sonic logging-derived $\mathrm{P}$ - and S-wave velocities and densities. Appendix D shows plots of sonic logging-computed elastic parameters as a function of elevation for each relief well tested. Table 9 presents the average elastic parameters under each monolith tested using averaged crosshole testingderived P- and S-wave velocities and densities. Plots of Young's modulus versus elevation based on averaged crosshole results for each monolith tested are shown in Appendix E. Table 10 presents the average velocity and elastic parameter values for the foundation materials beneath the concrete section of Folsom Dam.

\section{Table 8}

Average Sonic Logging Data and Computed Elastic Parameters

\begin{tabular}{||l|l|l|l|l|l|l|l|l||}
\hline \hline $\begin{array}{l}\text { Monolith } \\
\text { No. }\end{array}$ & $\begin{array}{l}\text { Density } \\
\text { g/cc }\end{array}$ & $\begin{array}{l}\text { P-wave } \\
\text { Velocity } \\
\text { fps }\end{array}$ & $\begin{array}{l}\text { S-wave } \\
\text { Velocity } \\
\text { fps }\end{array}$ & $\begin{array}{l}\text { Poisson's } \\
\text { Ratio }\end{array}$ & $\begin{array}{l}\text { Shear } \\
\text { Modulus } \\
\text { psi }\end{array}$ & $\begin{array}{l}\text { Young's } \\
\text { Modulus } \\
\text { psi }\end{array}$ & $\begin{array}{l}\text { Constrained } \\
\text { Modulus } \\
\text { psi }\end{array}$ & $\begin{array}{l}\text { Bulk } \\
\text { Modulus } \\
\text { psi }\end{array}$ \\
\hline \hline 2 & 2.72 & 18,650 & 10,500 & 0.27 & $4.037 \mathrm{E}+06$ & $1.024 \mathrm{E}+07$ & $2.206 \mathrm{E}+07$ & $7.354 \mathrm{E}+06$ \\
\hline 11 & 2.76 & 17,550 & 10,200 & 0.24 & $3.866 \mathrm{E}+06$ & $9.626 \mathrm{E}+06$ & $1.887 \mathrm{E}+07$ & $6.290 \mathrm{E}+06$ \\
\hline 14 & 2.82 & 18,800 & 11,300 & 0.22 & $4.848 \mathrm{E}+06$ & $1.180 \mathrm{E}+07$ & $2.086 \mathrm{E}+07$ & $6.955 \mathrm{E}+06$ \\
\hline 15 & 2.86 & 18,850 & 11,200 & 0.23 & $4.830 \mathrm{E}+06$ & $1.185 \mathrm{E}+07$ & $2.172 \mathrm{E}+07$ & $7.242 \mathrm{E}+06$ \\
\hline 21 & 2.76 & 19,500 & 11,400 & 0.24 & $4.829 \mathrm{E}+06$ & $1.198 \mathrm{E}+07$ & $2.307 \mathrm{E}+07$ & $7.691 \mathrm{E}+06$ \\
\hline 22 & 2.79 & 19,500 & 11,450 & 0.24 & $4.925 \mathrm{E}+06$ & $1.218 \mathrm{E}+07$ & $2.315 \mathrm{E}+07$ & $7.717 \mathrm{E}+06$ \\
\hline 27 & 2.77 & 19,450 & 11,400 & 0.24 & $4.847 \mathrm{E}+06$ & $1.200 \mathrm{E}+07$ & $2.294 \mathrm{E}+07$ & $7.646 \mathrm{E}+06$ \\
\hline Average $=$ & 2.78 & 18,900 & 11,064 & 0.24 & $4.597 \mathrm{E}+06$ & $1.138 \mathrm{E}+07$ & $2.181 \mathrm{E}+07$ & $7.271 \mathrm{E}+06$ \\
\hline
\end{tabular}




\begin{tabular}{|c|c|c|c|c|c|c|c|c|}
\hline \multicolumn{9}{|c|}{$\begin{array}{l}\text { Table } 9 \\
\text { Average Crosshole Logging Data and Computed Elastic Parameters }\end{array}$} \\
\hline $\begin{array}{l}\text { Monolith } \\
\text { No. } \\
\end{array}$ & $\begin{array}{l}\text { Density } \\
\text { g/cc }\end{array}$ & \begin{tabular}{|l|} 
P-wave \\
Velocity \\
fps
\end{tabular} & $\begin{array}{l}\text { S-wave } \\
\text { Velocity } \\
\text { fps }\end{array}$ & \begin{tabular}{|l} 
Poisson's \\
Ratio \\
\end{tabular} & $\begin{array}{l}\text { Shear } \\
\text { Modulus } \\
\text { psi }\end{array}$ & $\begin{array}{l}\text { Young's } \\
\text { Modulus } \\
\text { psi }\end{array}$ & $\begin{array}{l}\text { Constrained } \\
\text { Modulus } \\
\text { psi }\end{array}$ & \begin{tabular}{|l} 
Bulk \\
Modulus \\
psi
\end{tabular} \\
\hline 2 & 2.72 & 15,525 & 6,500 & 0.39 & $1.547 \mathrm{E}+06$ & $4.313 E+06$ & $2.029 \mathrm{E}+07$ & $6.764 \mathrm{E}+06$ \\
\hline 11 & 2.76 & 15,700 & 6,900 & 0.38 & $1.769 \mathrm{E}+06$ & $4.884 \mathrm{E}+06$ & $2.040 \mathrm{E}+07$ & $6.800 \mathrm{E}+06$ \\
\hline 14 & 2.82 & 24,300 & 8,300 & 0.43 & $2.616 \mathrm{E}+06$ & $7.501 \mathrm{E}+06$ & $5.679 \mathrm{E}+07$ & $1.893 E+07$ \\
\hline 15 & 2.86 & 24,225 & 8,525 & 0.43 & $2.798 \mathrm{E}+06$ & $8.000 E+06$ & $5.660 \mathrm{E}+07$ & $1.887 \mathrm{E}+07$ \\
\hline 21 & 2.76 & 14,825 & 7,225 & 0.34 & $1.940 \mathrm{E}+06$ & $5.215 E+06$ & $1.674 \mathrm{E}+07$ & $5.581 \mathrm{E}+06$ \\
\hline 27 & 2.77 & 23,700 & 6,325 & 0.46 & $1.492 \mathrm{E}+06$ & $4.361 \mathrm{E}+06$ & $5.687 \mathrm{E}+07$ & $1.896 \mathrm{E}+07$ \\
\hline Average $=$ & 2.78 & 19,725 & 7,300 & 0.41 & $2.027 \mathrm{E}+06$ & $5.712 \mathrm{E}+06$ & $3.795 \mathrm{E}+07$ & $1.265 \mathrm{E}+07$ \\
\hline
\end{tabular}

\begin{tabular}{|c|c|c|c|c|c|c|c|}
\hline \multicolumn{8}{|c|}{$\begin{array}{l}\text { Table } 10 \\
\text { Average Velocity and Elastic Parameter Values for Foundation Materials Beneath } \\
\text { Concrete Section of Folsom Dam }\end{array}$} \\
\hline $\begin{array}{l}\text { Density } \\
\text { g/cc }\end{array}$ & $\begin{array}{l}\text { P-wave } \\
\text { Velocity } \\
\text { fps }\end{array}$ & $\begin{array}{l}\text { S-wave } \\
\text { Velocity } \\
\text { fps }\end{array}$ & $\begin{array}{l}\text { Poisson's } \\
\text { Ratio }\end{array}$ & $\begin{array}{l}\text { Shear } \\
\text { Modulus } \\
\text { psi }\end{array}$ & $\begin{array}{l}\text { Young's } \\
\text { Modulus } \\
\text { psi }\end{array}$ & $\begin{array}{l}\text { Constrained } \\
\text { Modulus } \\
\text { psi }\end{array}$ & $\begin{array}{l}\text { Bulk } \\
\text { Modulus } \\
\text { psi }\end{array}$ \\
\hline 2.78 & 19,300 & 9,200 & 0.32 & $3.312 \mathrm{E}+06$ & $8.548 \mathrm{E}+06$ & $2.988 \mathrm{E}+07$ & $9.960 \mathrm{E}+06$ \\
\hline
\end{tabular}




\section{Summary}

A geophysical investigation was conducted at Folsom Dam, California, in June and August 2004. The purpose of the investigation was to measure the values of the in situ compression- and shear-wave (P- and S-wave) propagation velocities as well as density of the foundation materials as a function of depth. The geophysical studies included seismic crosshole testing and sonic and gamma-gamma logging. The tests were conducted inside the lowest gallery of a series of concrete gravity monoliths. Existing drain holes at the base of the monoliths that penetrated more than $100 \mathrm{ft}$ into the granitic foundation materials were used for testing.

Seismic velocities for materials under selected monoliths were measured using both testing methods. A set of average P- and S-wave velocities corresponding to sonic and crosshole testing were assigned to each monolith tested. Based on the sonic and crosshole average monolith velocities, several elastic parameters were computed and tabulated for each monolith. The computed parameters included dynamic shear modulus, Poisson's ratio, Young's modulus, constrained modulus, and bulk modulus. The tabulated elastic parameters indicate differences in values based on the testing method used. The computed elastic parameters for each monolith and test method were averaged to provide a global average for the foundation materials beneath the concrete dam. 


\section{References}

Department of the Army. (1994). “Rock foundations,” Engineer Manual 1110-1-2908, Headquarters, U.S. Army Corps of Engineers, Washington, DC.

. (1995). "Geophysical exploration for engineering and environmental investigations,” Engineer Manual 1110-1-1802, Headquarters, U.S. Army Corps of Engineers, Washington, DC.

Keys, W. S. (1997). A practical guide to borehole geophysics in environmental investigations, CRC Press, Inc., New York.

Llopis, J. L. (1989). "In situ investigation of Folsom Dam and reservoir project,” Technical Report GL-89-10, U.S. Army Engineer Waterways Experiment Station, Vicksburg, MS.

Mount Sopris Instrument Company, Inc. (2002). “2SAA-100 Sonic Probe, user’s manual,” Golden, CO.

\section{Golden, CO.}

(2003). "2GDA-1000 DX series density probe, user’s manual,”

U.S. Army Engineer District, Sacramento. (2004). "Design documentation report-Folsom Dam outlet works modifications project; Vol 1, Sacramento, CA.

URS Corporation. (2001). "Memorandum, final report, Folsom Dam modifications, evaluation of rock mass properties,” San Francisco, CA.

Woodward Clyde Consultants. (1983). "Investigation of concrete and foundation conditions at Folsom Dam, Folsom, California,” prepared for U.S. Army Engineer District, Sacramento, Sacramento, CA. 


\section{Appendix A Sample Sonic Log}




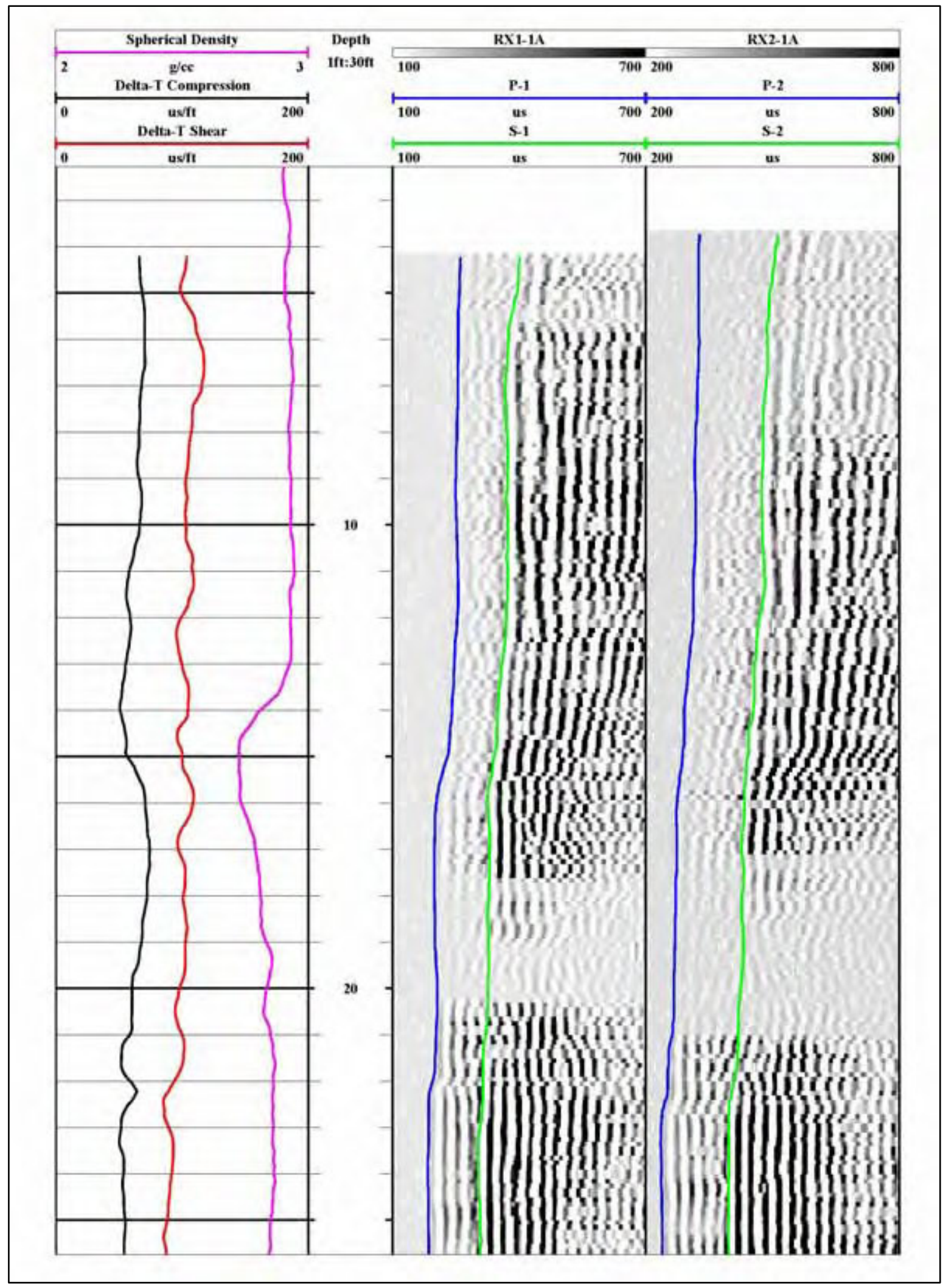

Figure A1. Monolith 14 - Relief Well No. 1 (Sheet 1 of 5) 


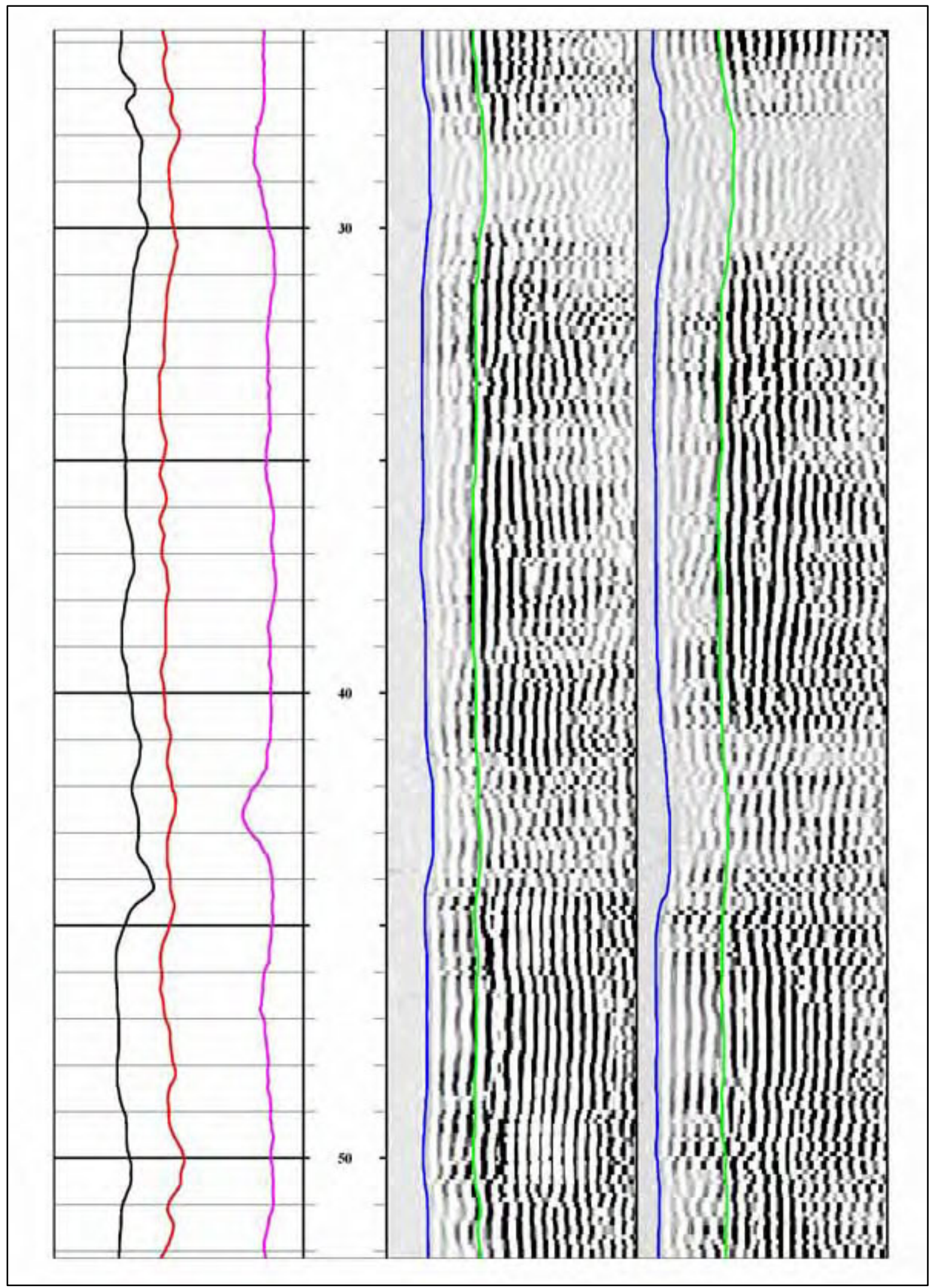

Figure A1. (Sheet 2 of 5) 


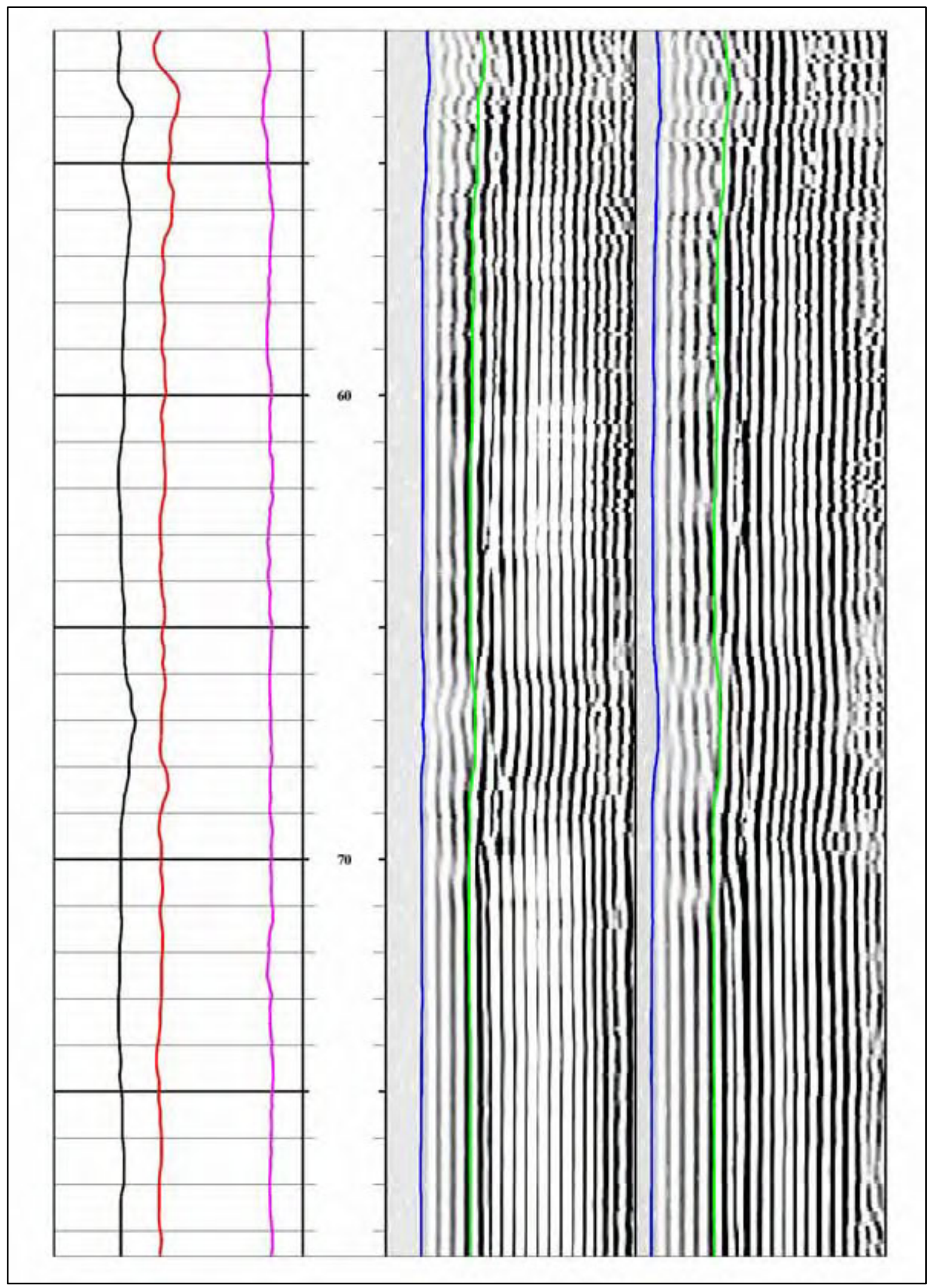

Figure A1. (Sheet 3 of 5) 


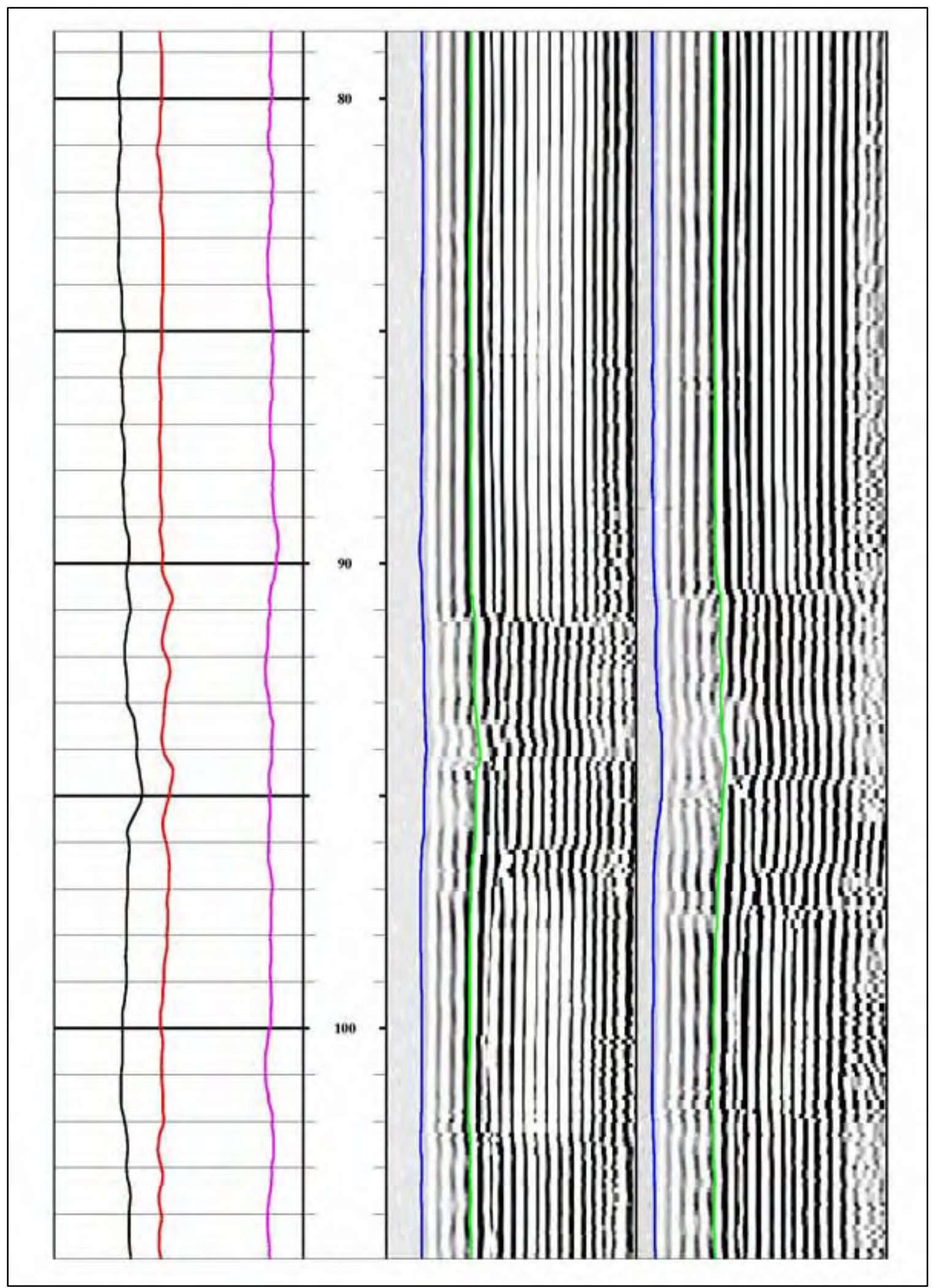

Figure A1. (Sheet 4 of 5) 


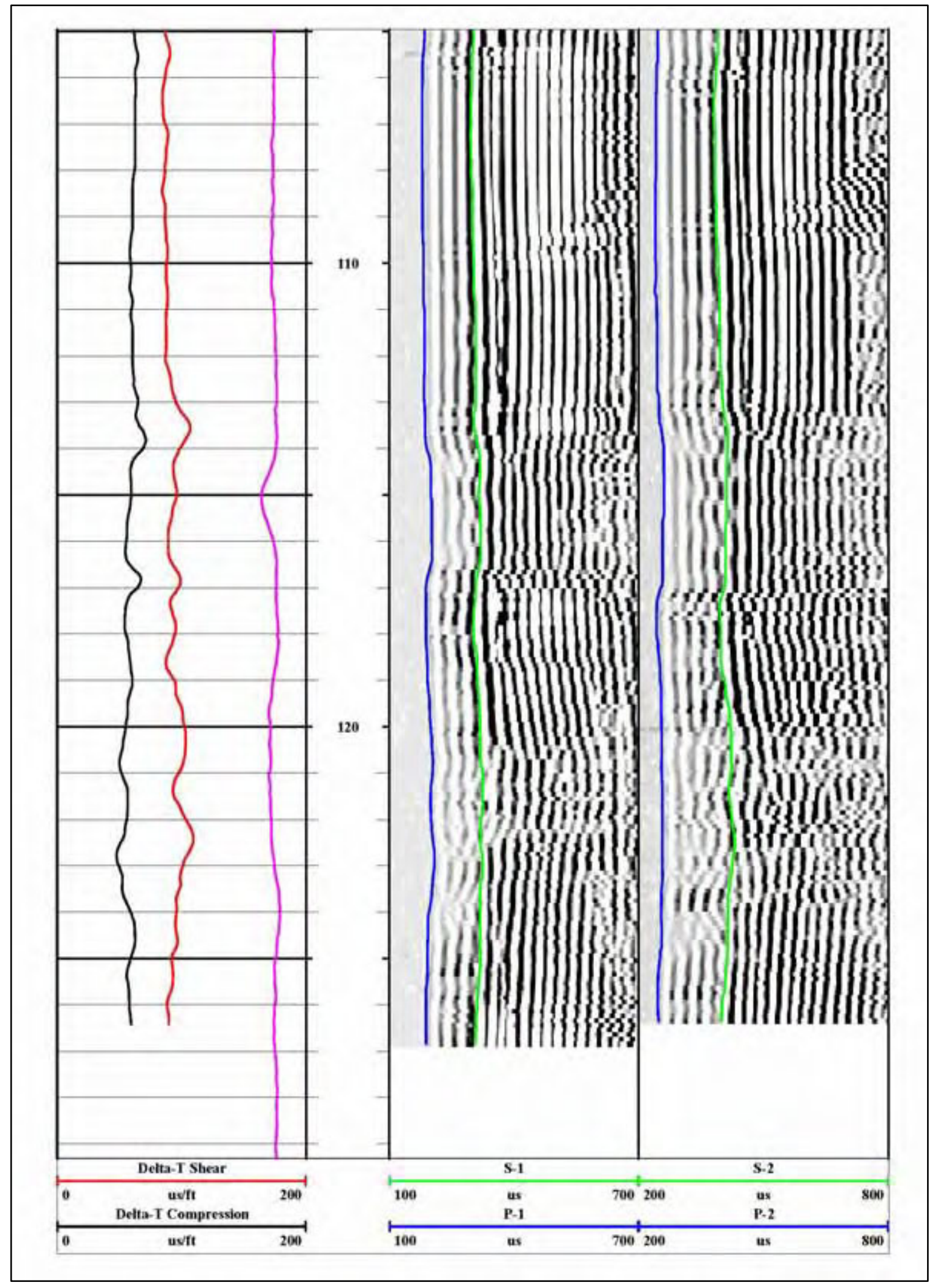

Figure A1. (Sheet 5 of 5 ) 


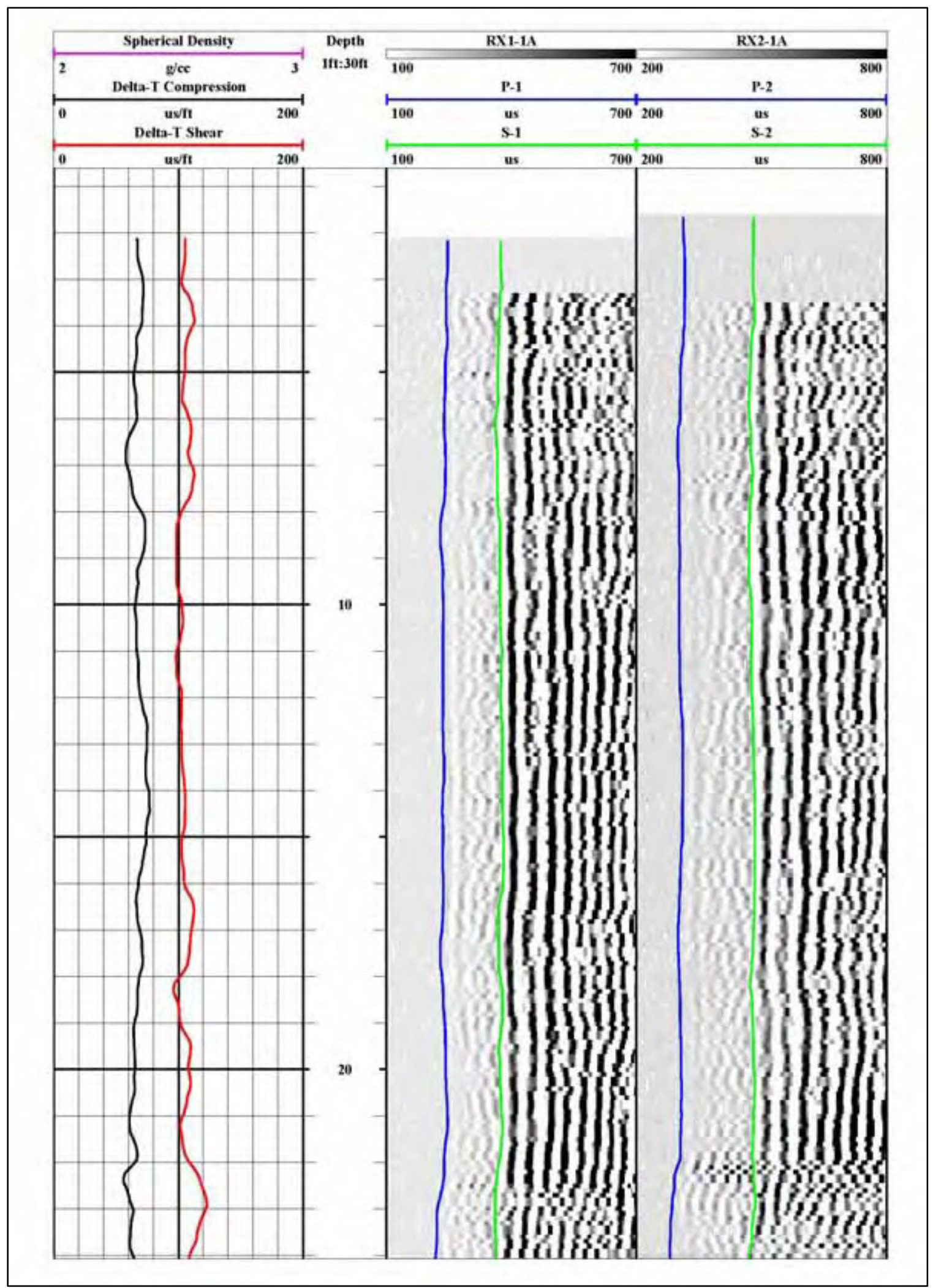

Figure A2. Monolith 21 - Relief Well No. 1 (Sheet 1 of 6) 


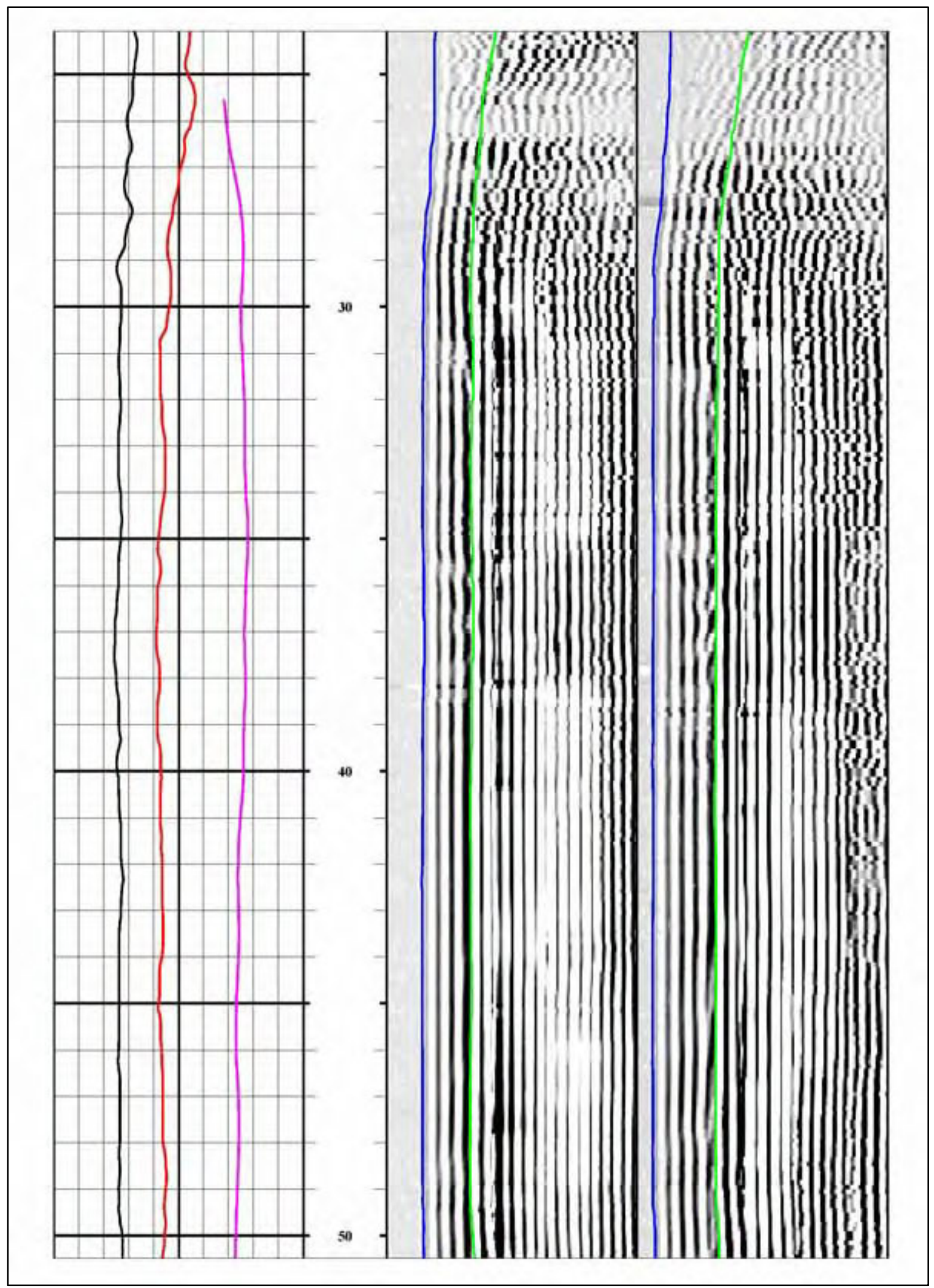

Figure A2. (Sheet 2 of 6 ) 


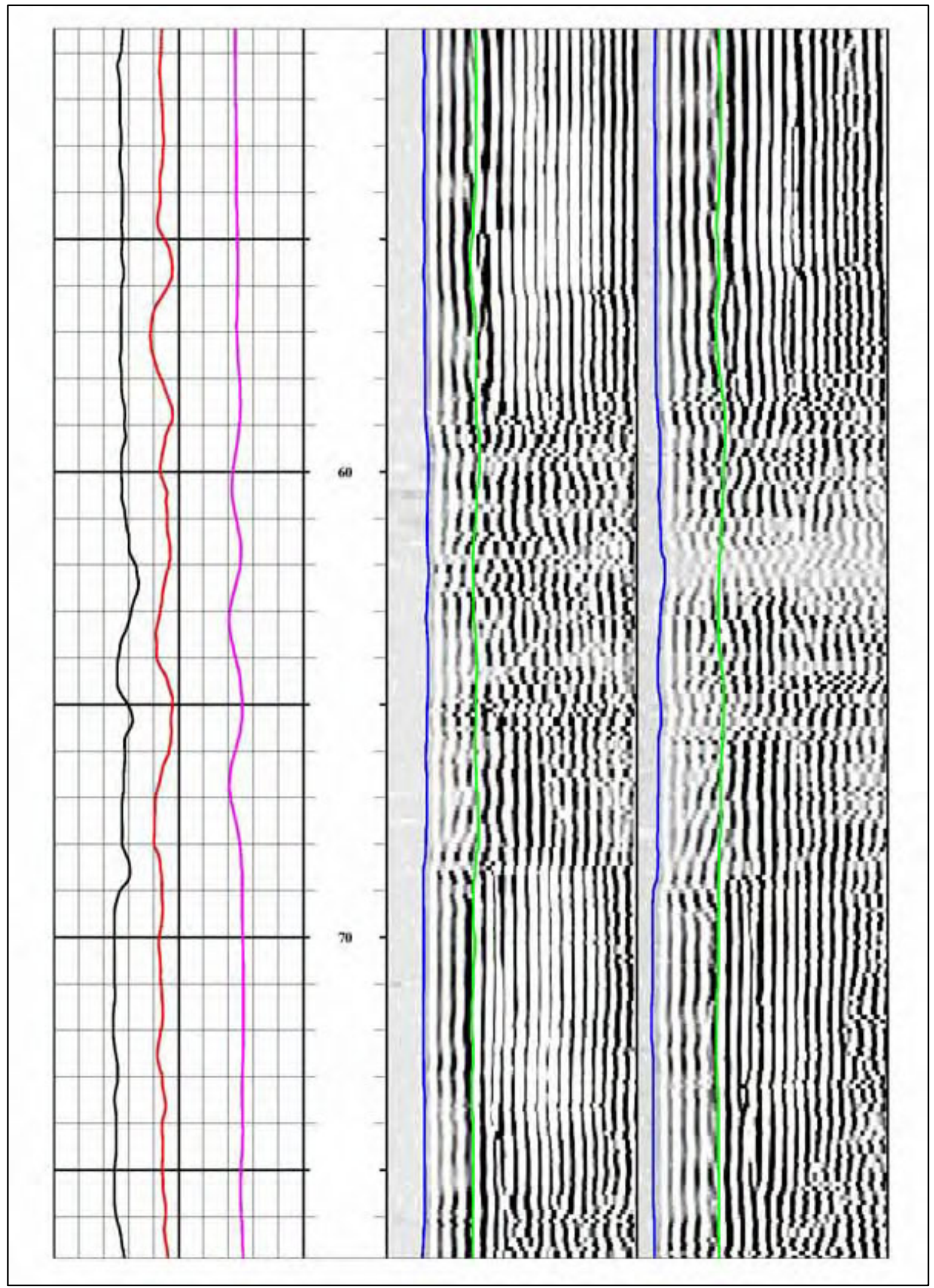

Figure A2. (Sheet 3 of 6 ) 


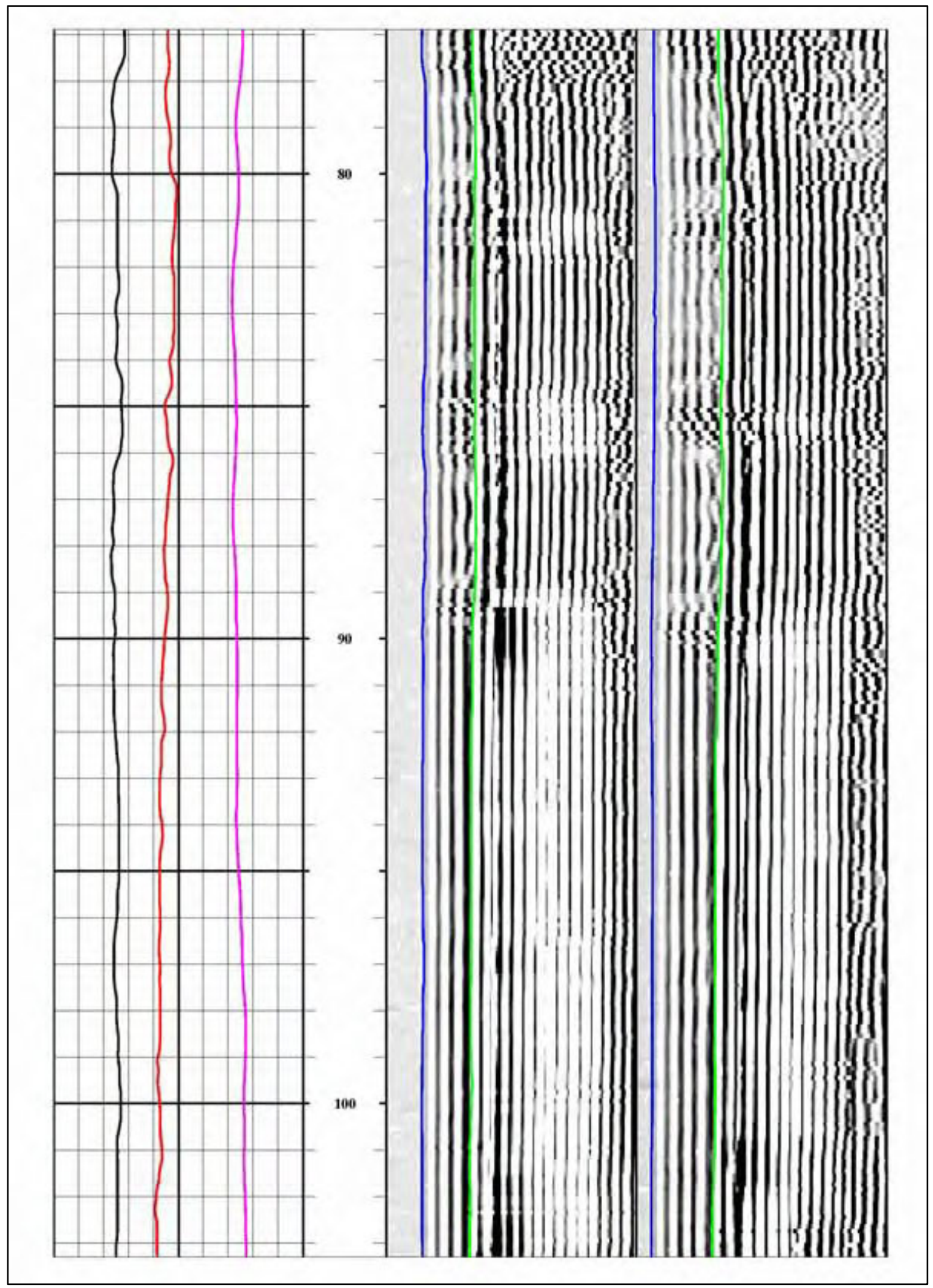

Figure A2. (Sheet 4 of 6) 


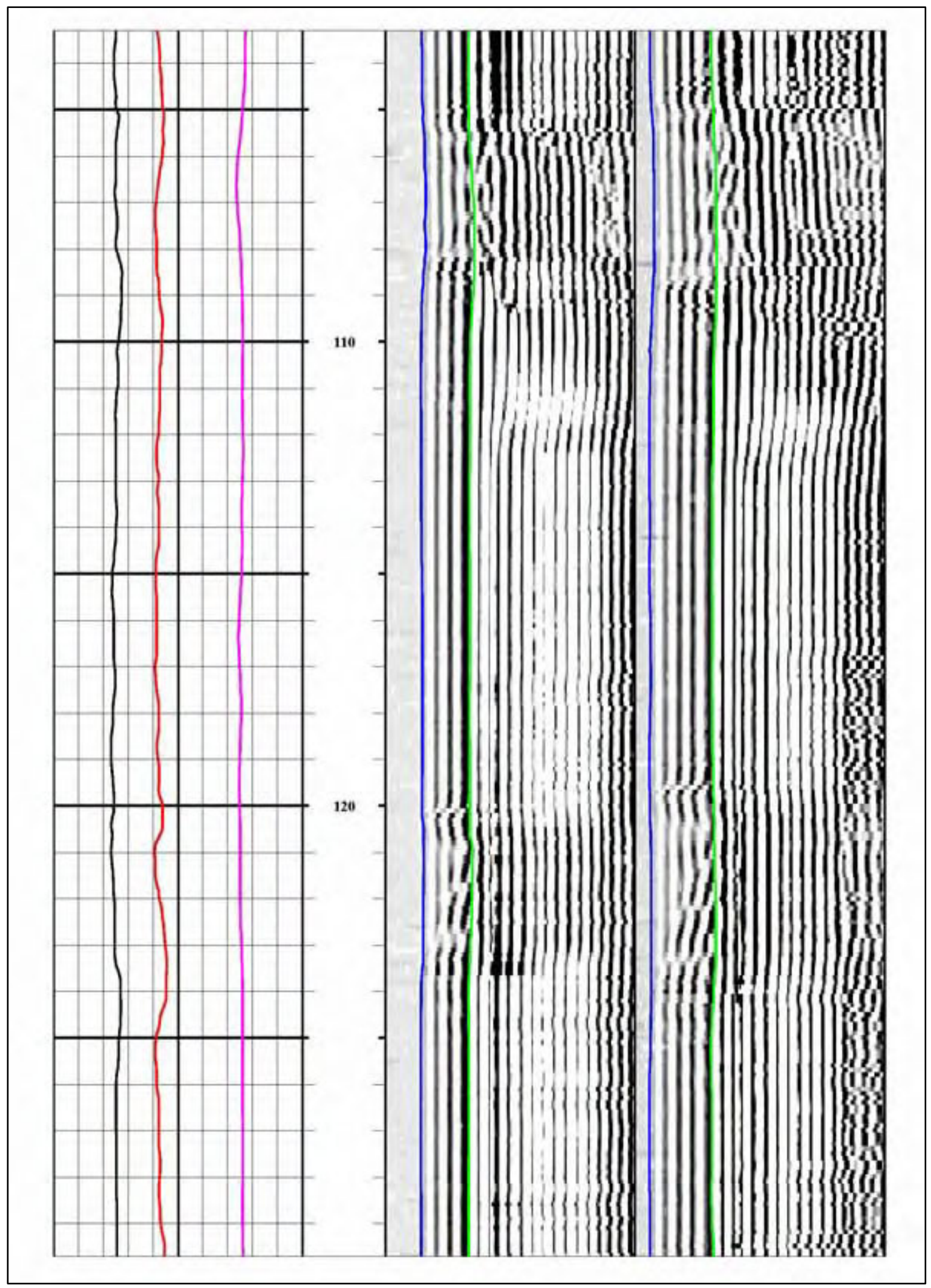

Figure A2. (Sheet 5 of 6 ) 


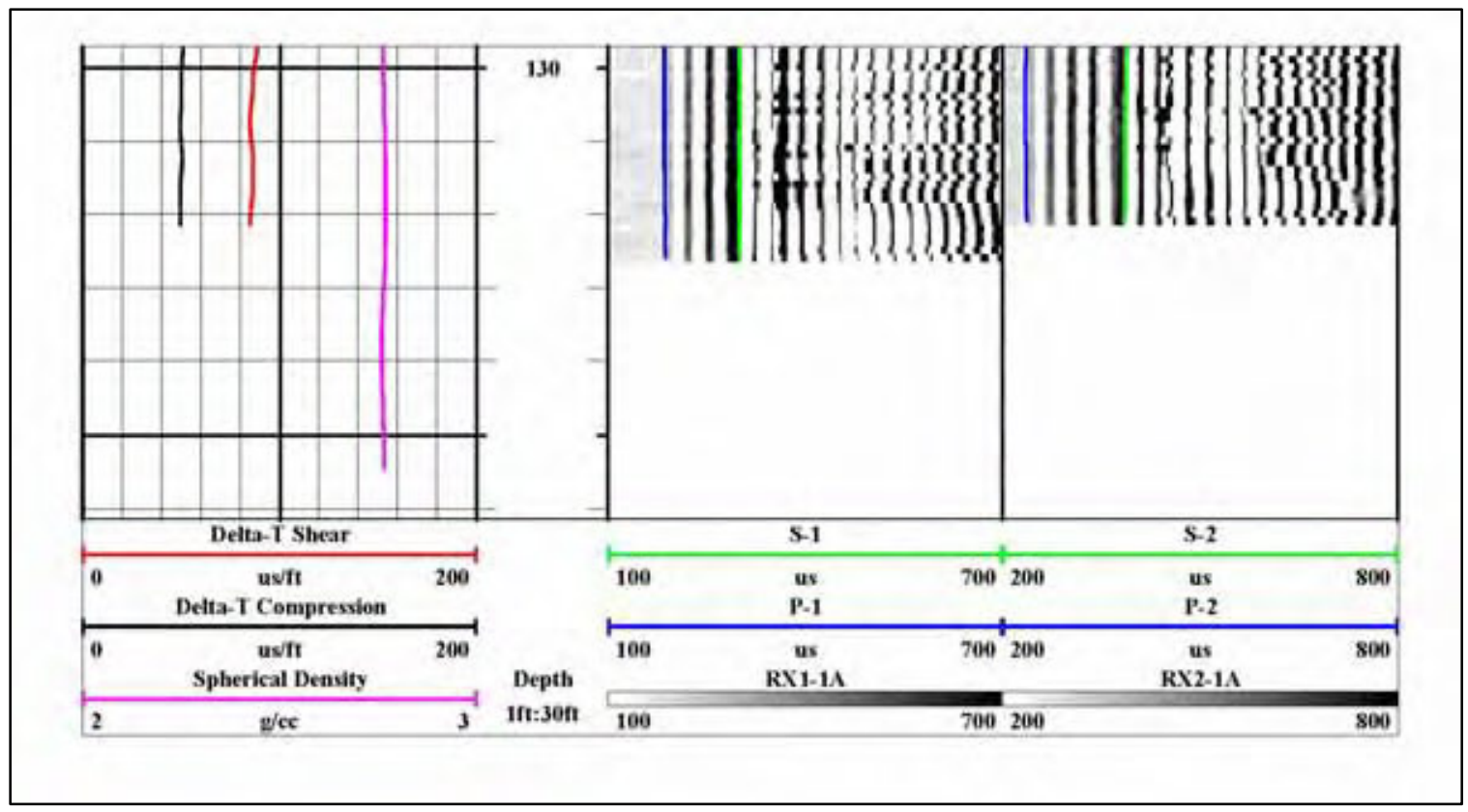

Figure A2. (Sheet 6 of 6 ) 


\section{Appendix B Sonic and Gamma-Gamma Logging Results}




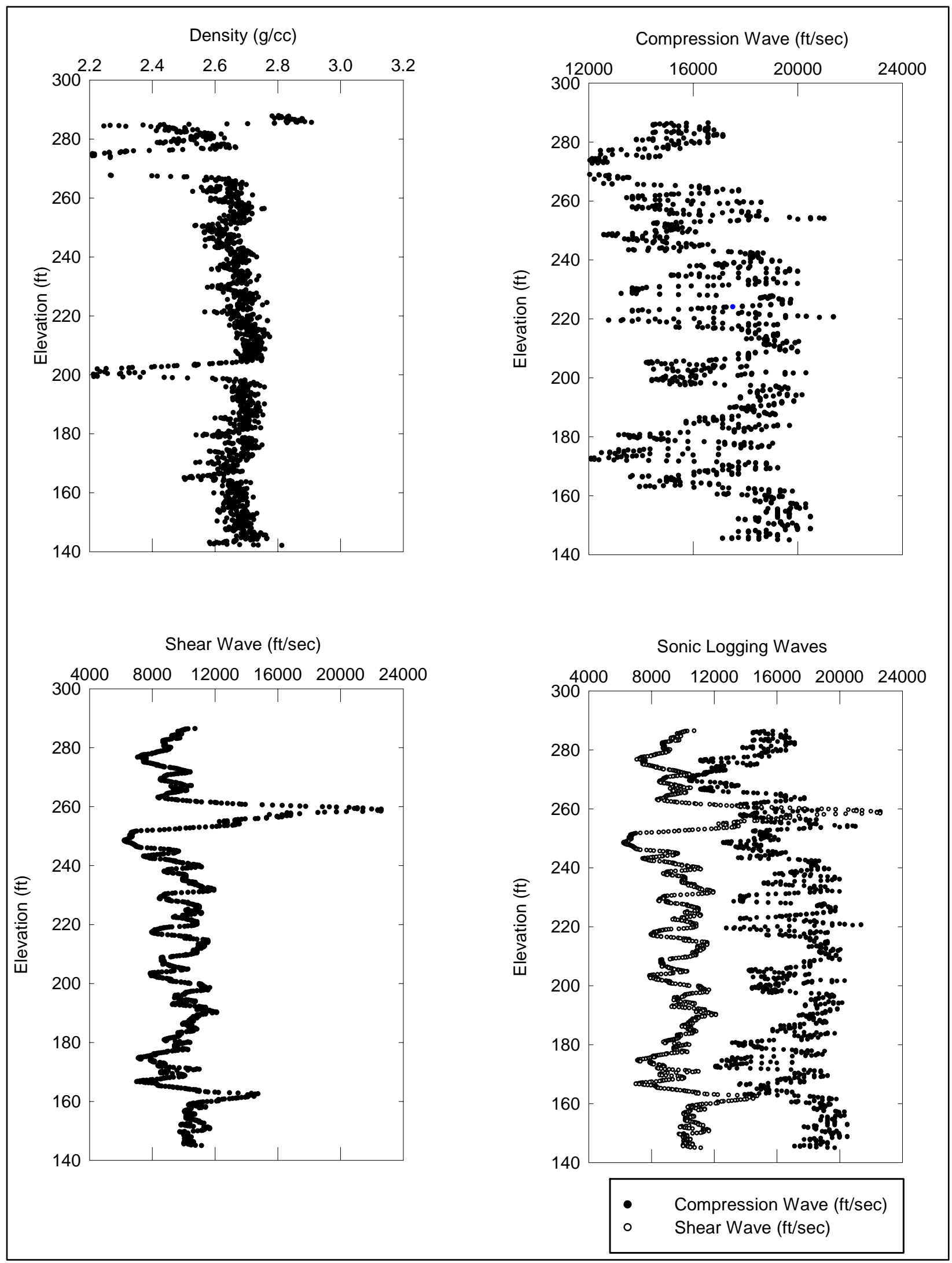

Figure B1. Monolith 2 - Relief Well No. 1 


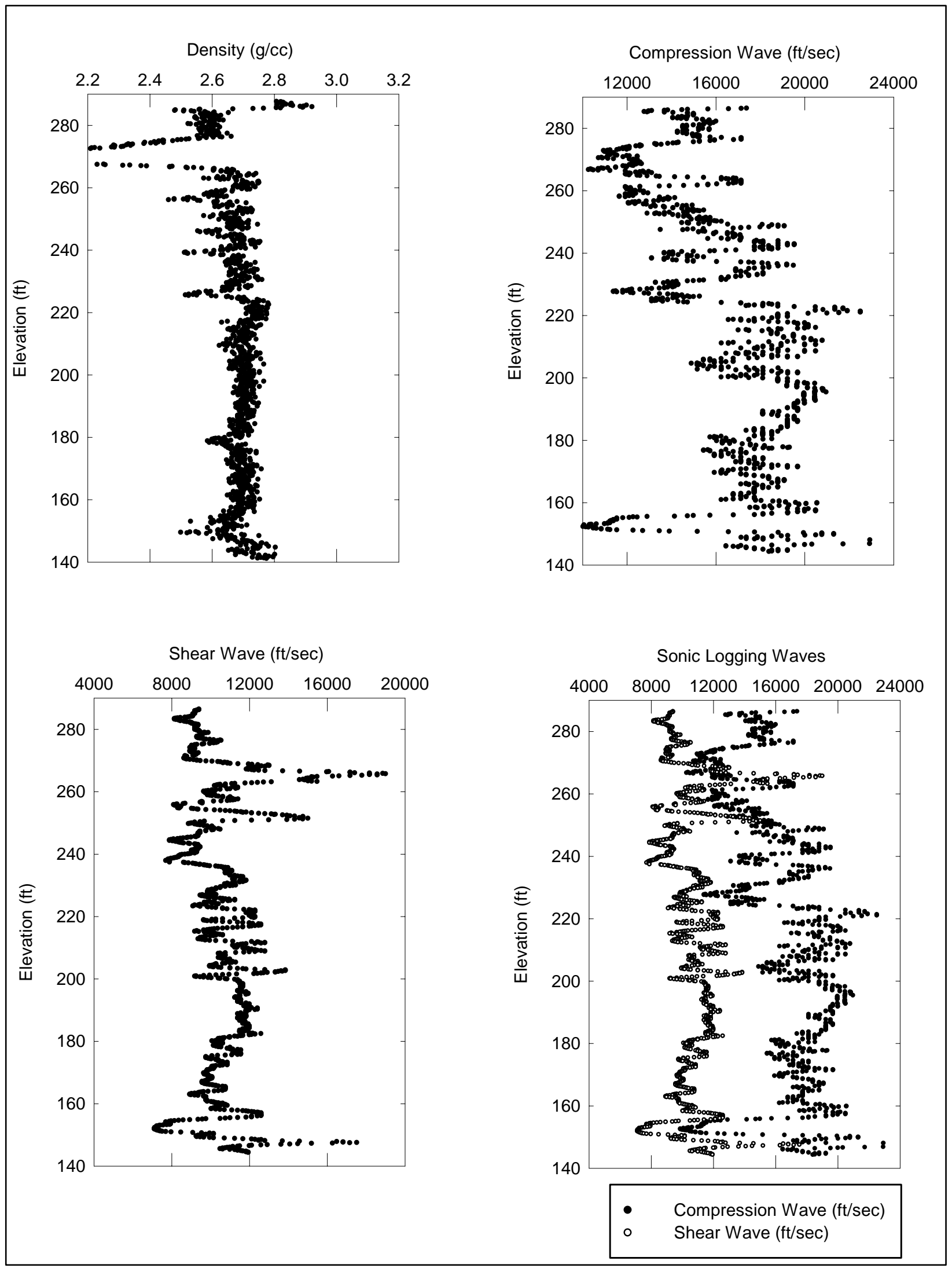

Figure B2. Monolith 2 - Relief Well No. 2 


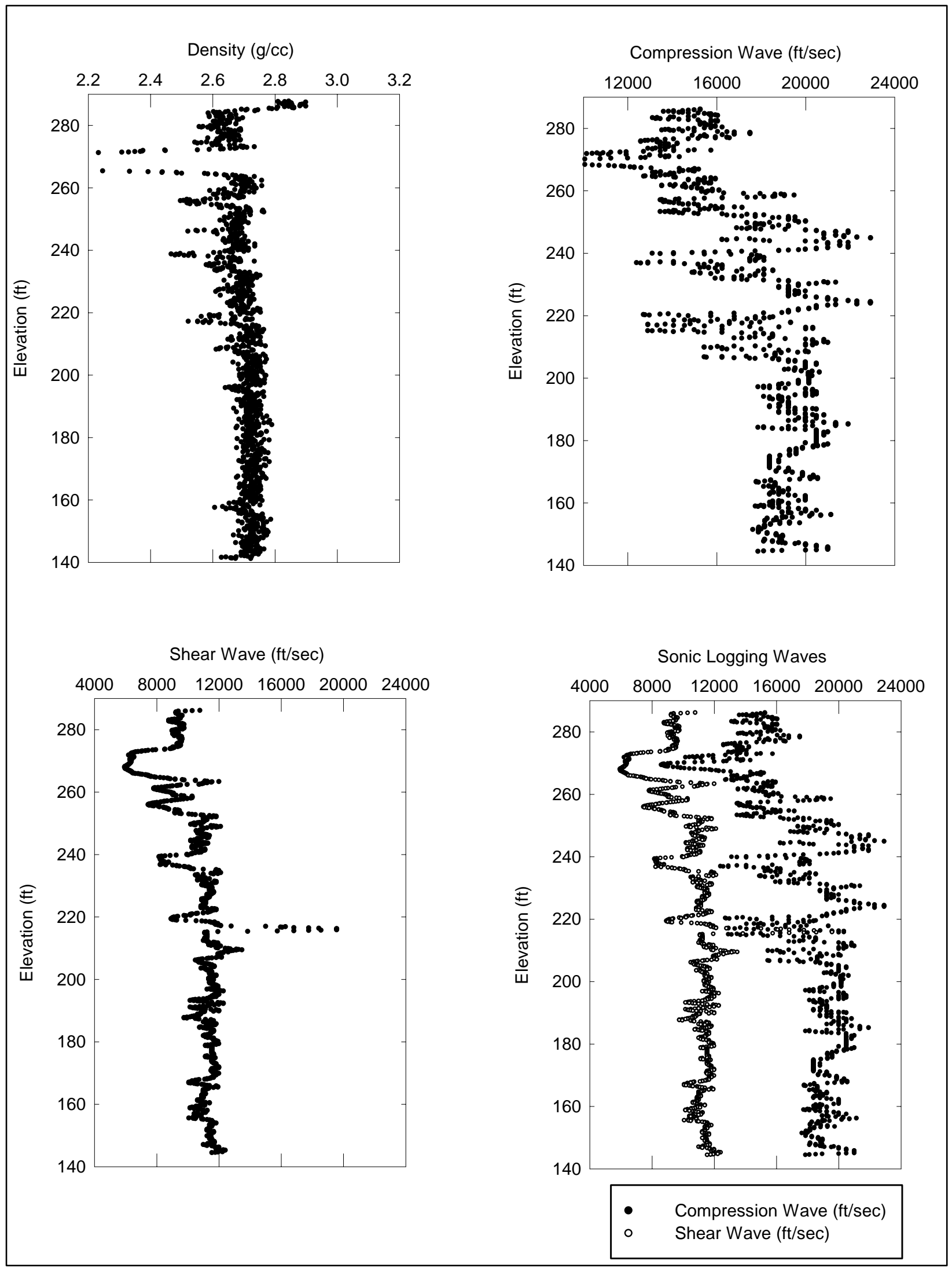

Figure B3. Monolith 2 - Relief Well No. 3 


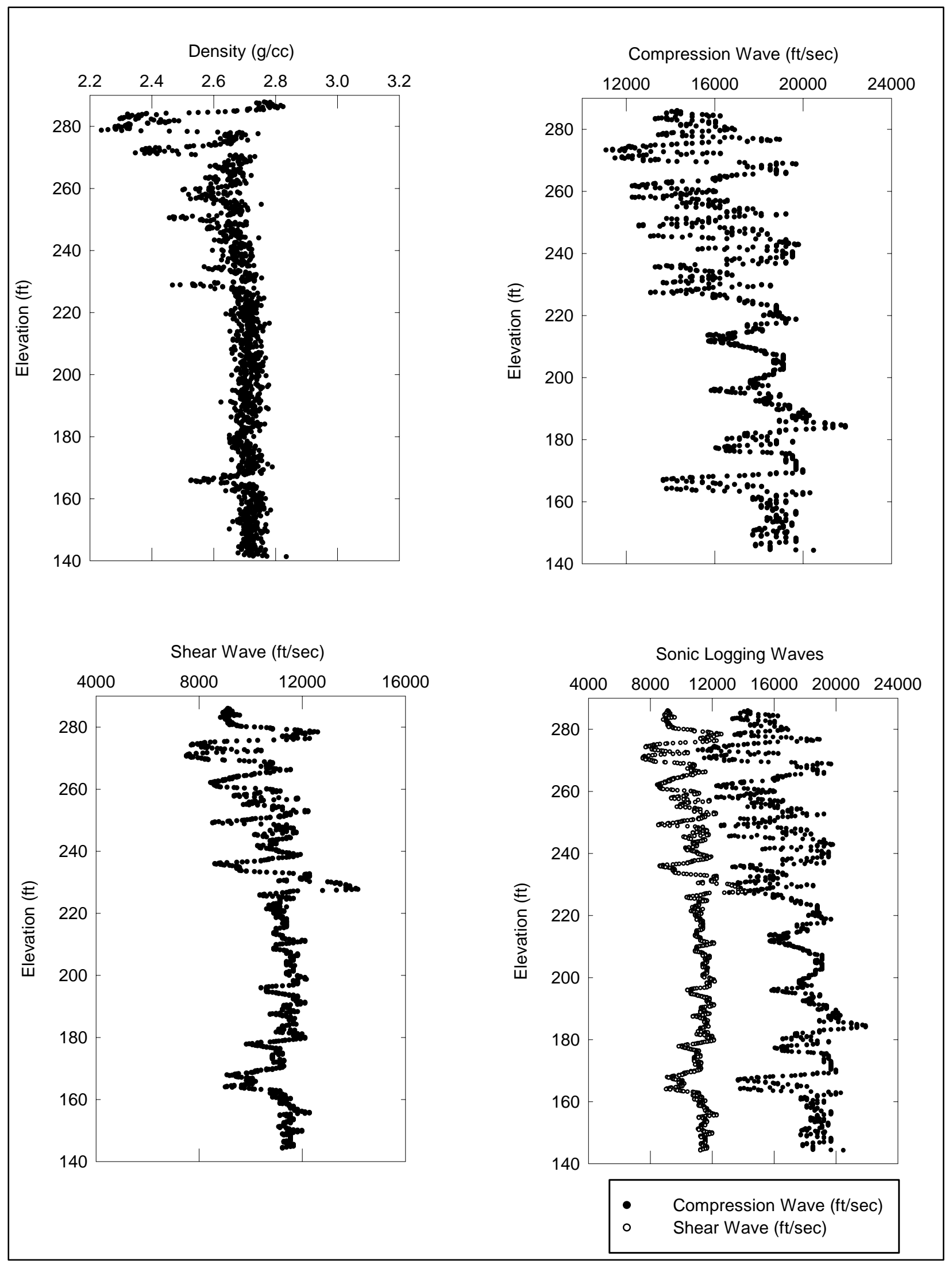

Figure B4. Monolith 2 - Relief Well No. 4 


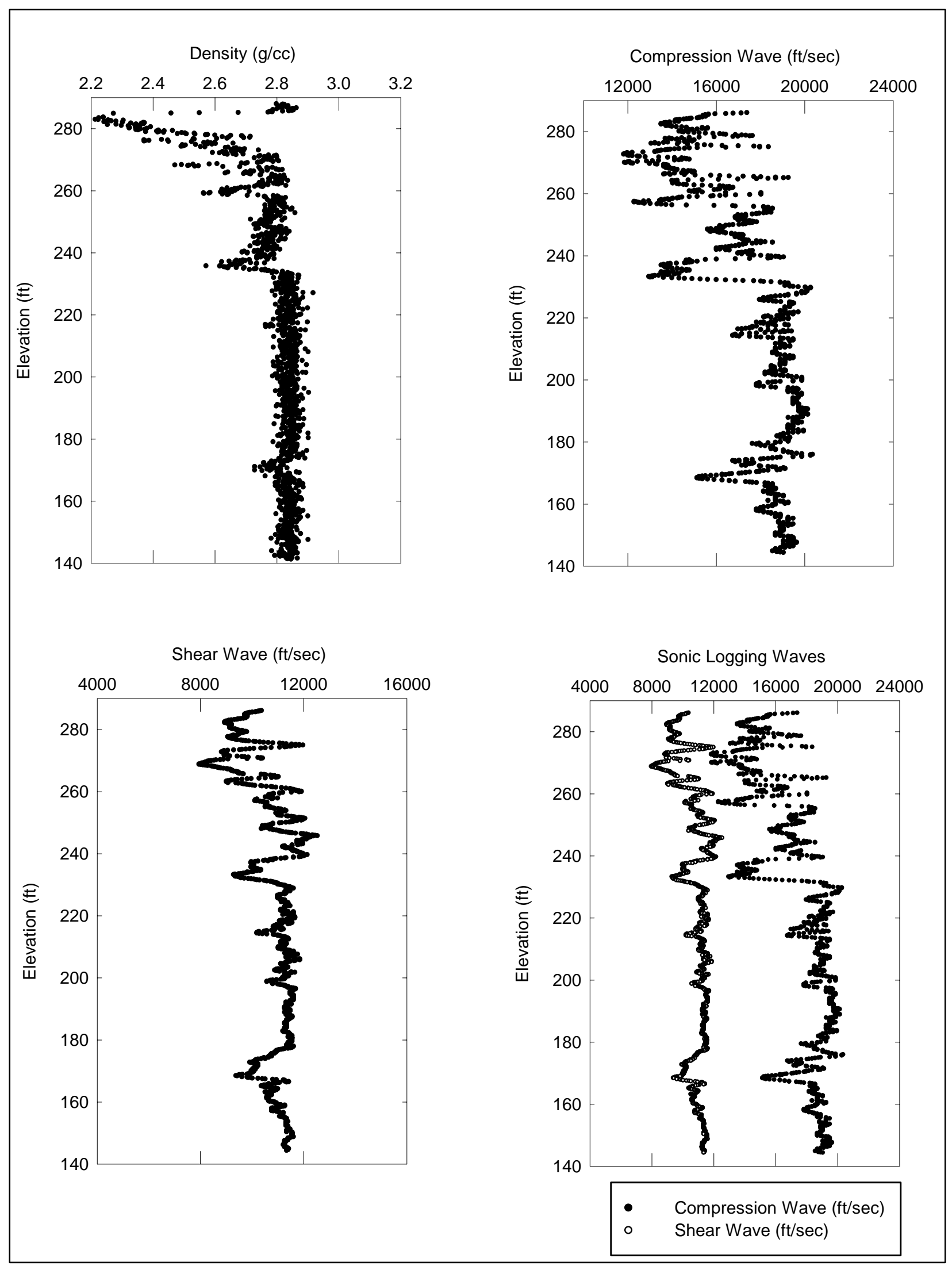

Figure B5. Monolith 2 - Relief Well No. 5 


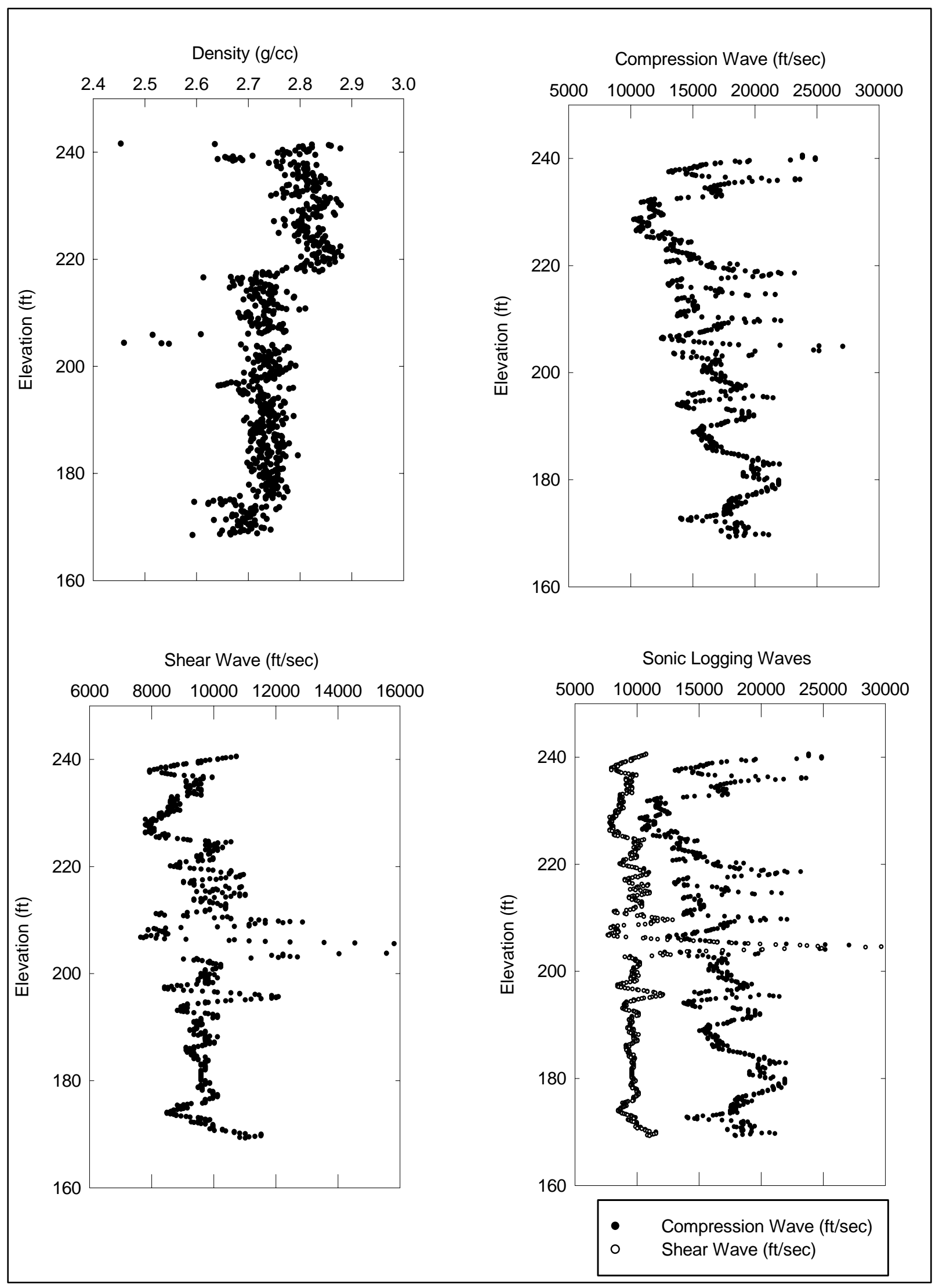

Figure B6. Monolith 11 - Relief Well No. 1 


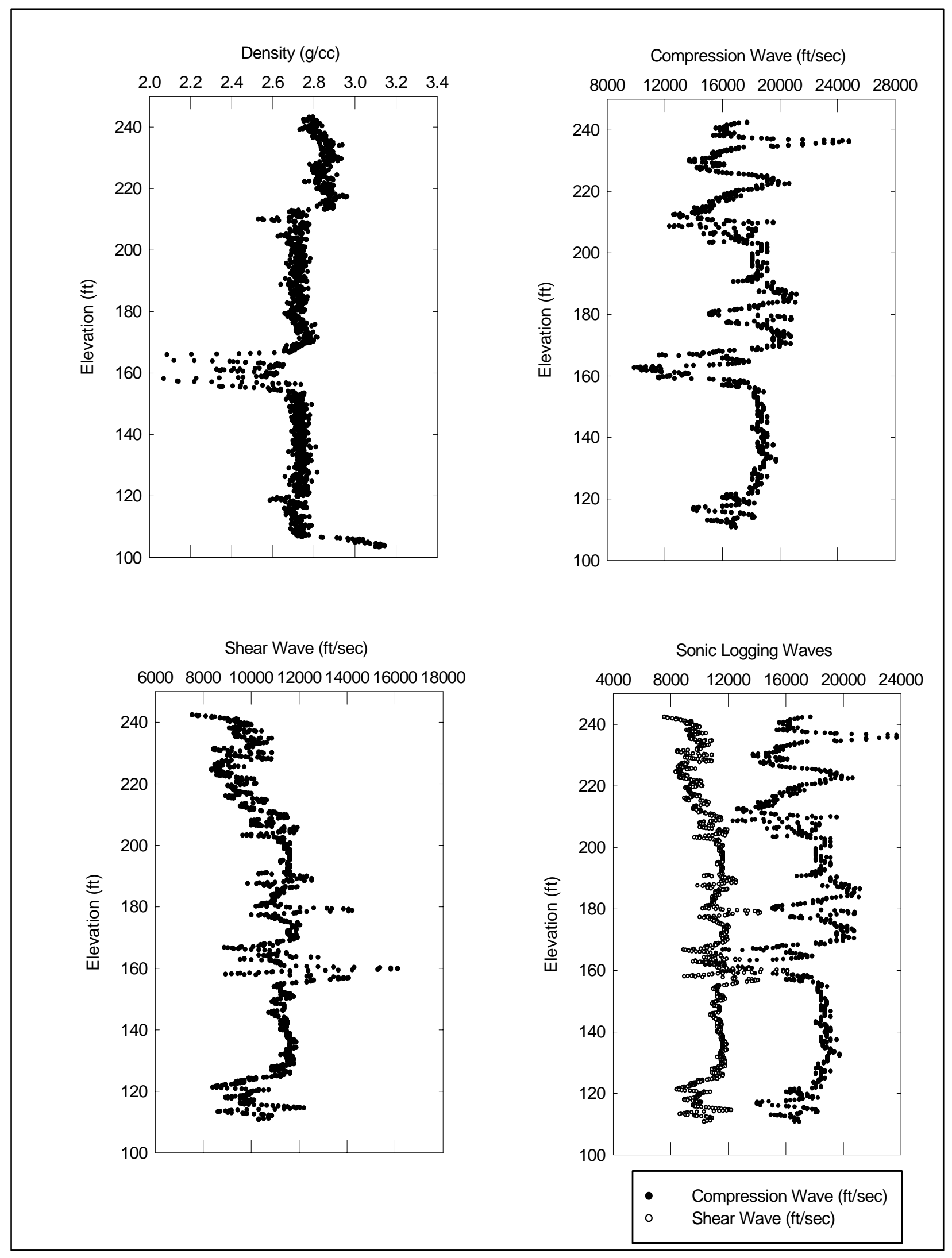

Figure B7. Monolith 11 - Relief Well No. 2 


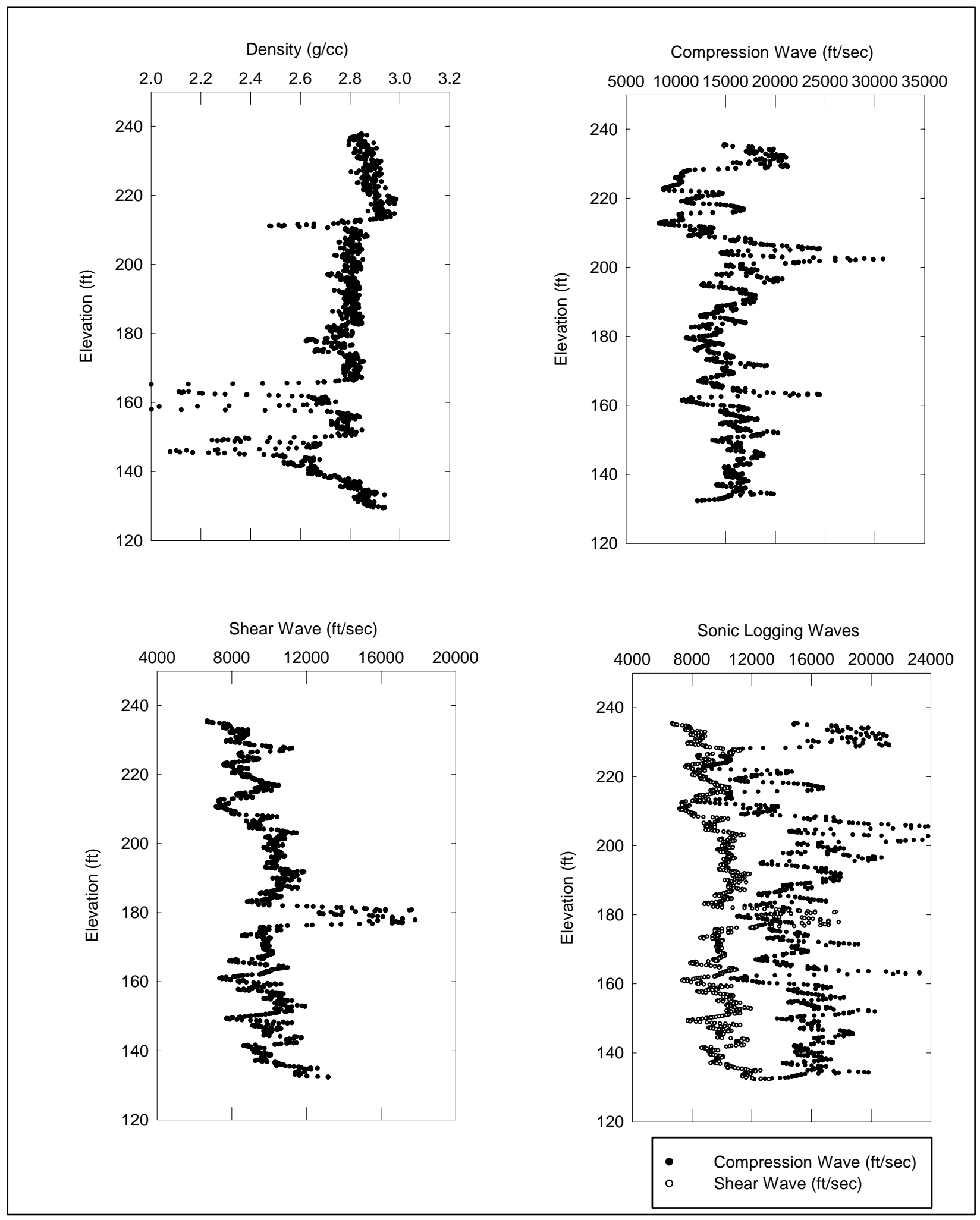

Figure B8. Monolith 11 - Relief Well No. 3 


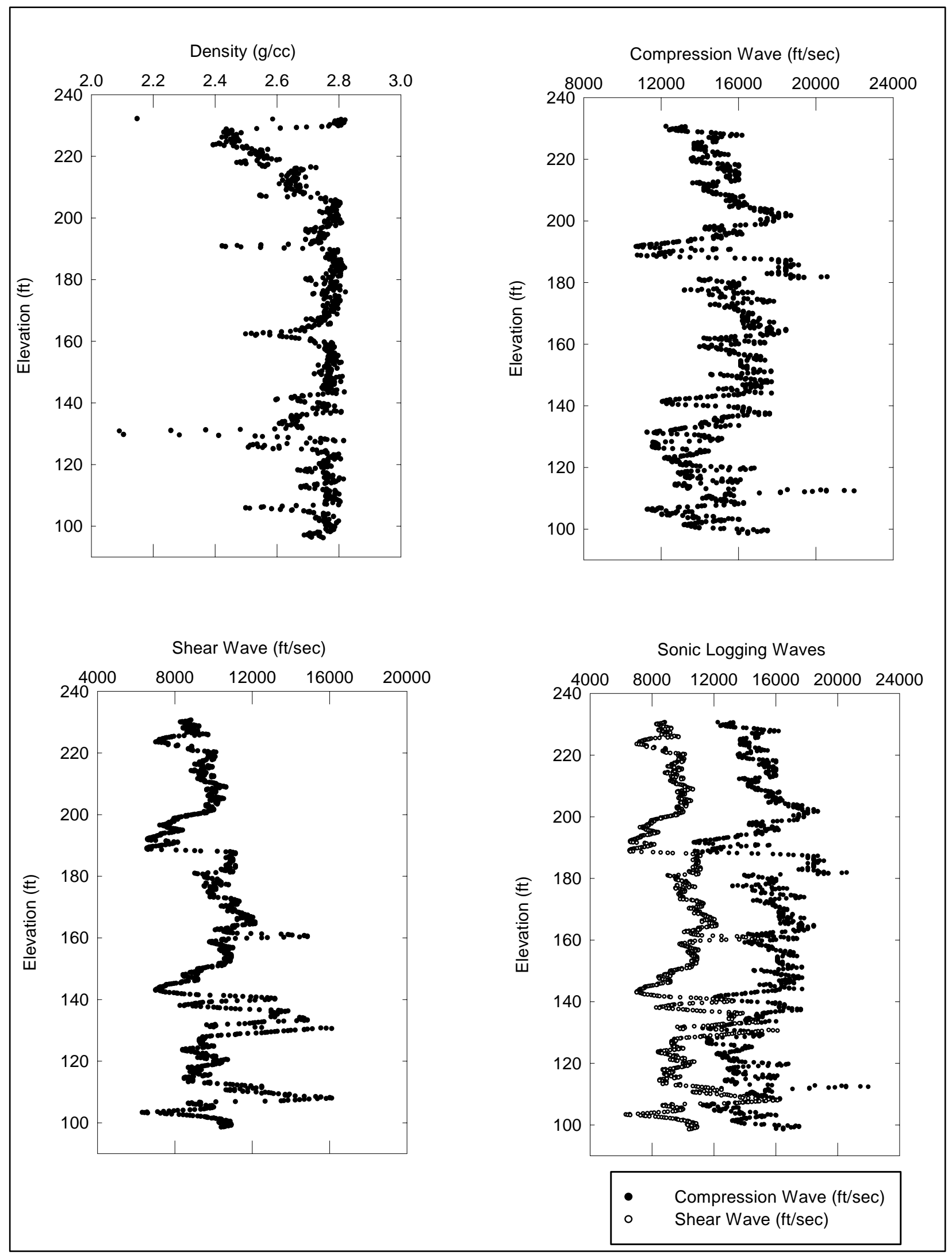

Figure B9. Monolith 11 - Relief Well No. 4 


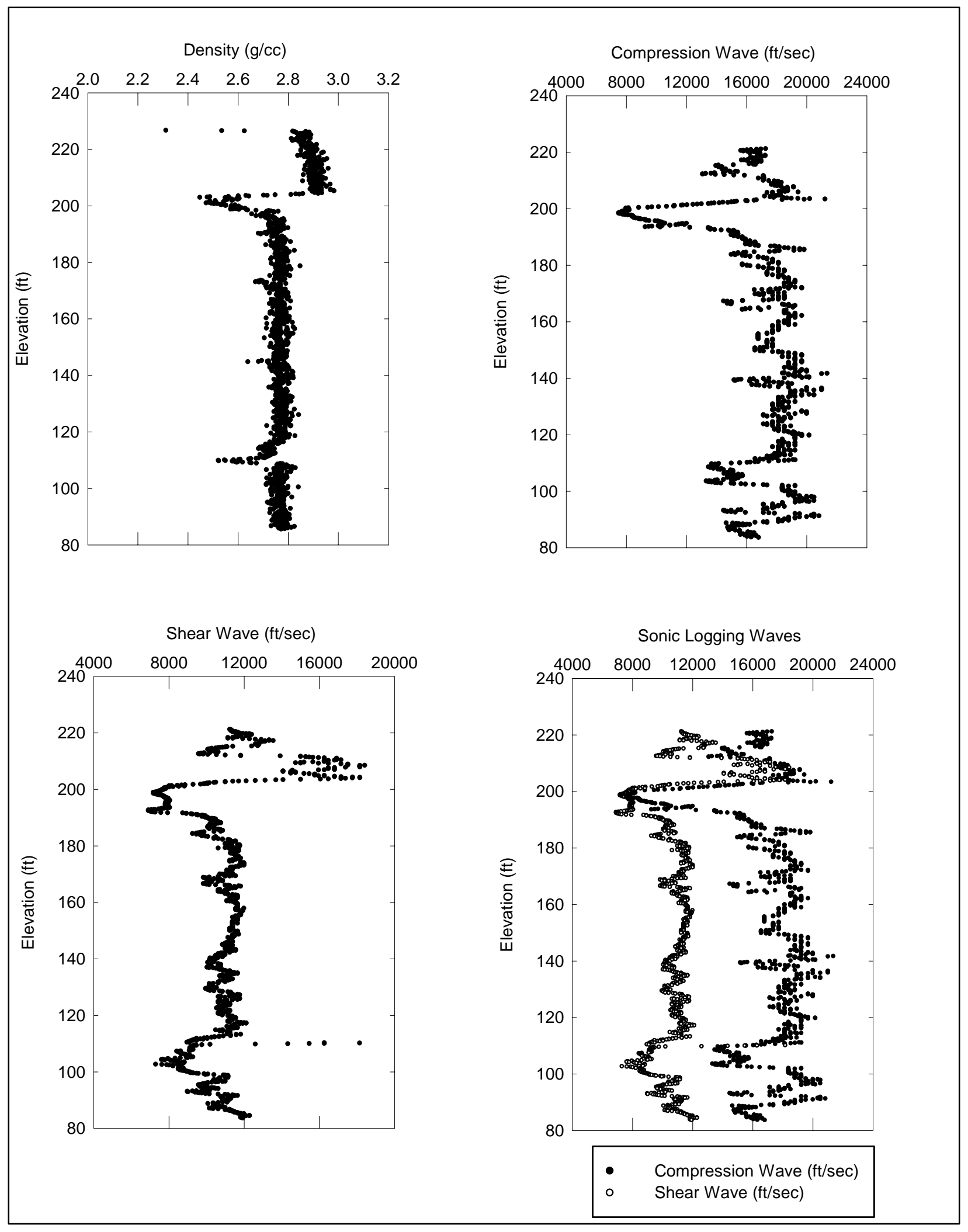

Figure B10. Monolith 11 - Relief Well No. 5 


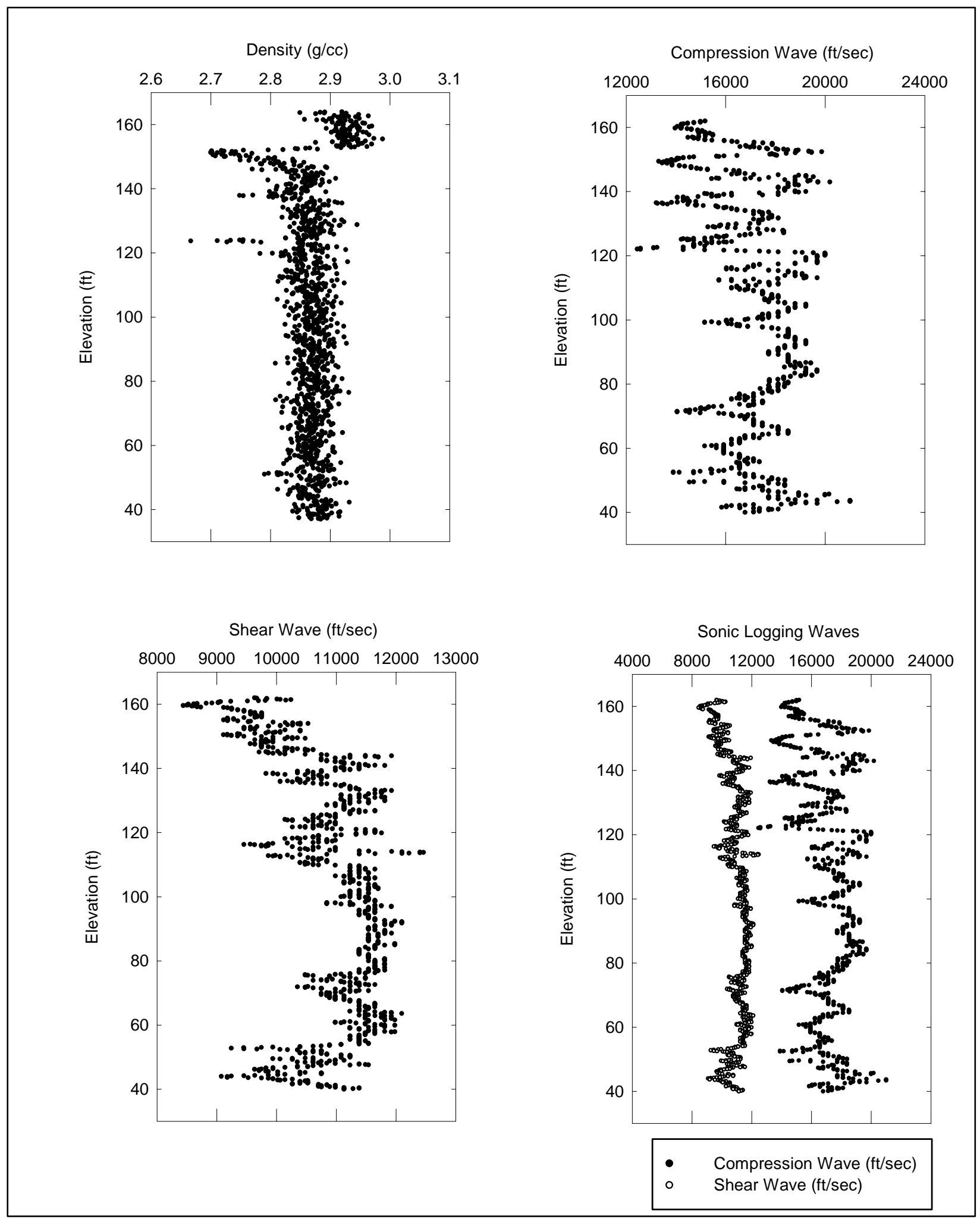

Figure B11. Monolith 14 - Relief Well No. 1 


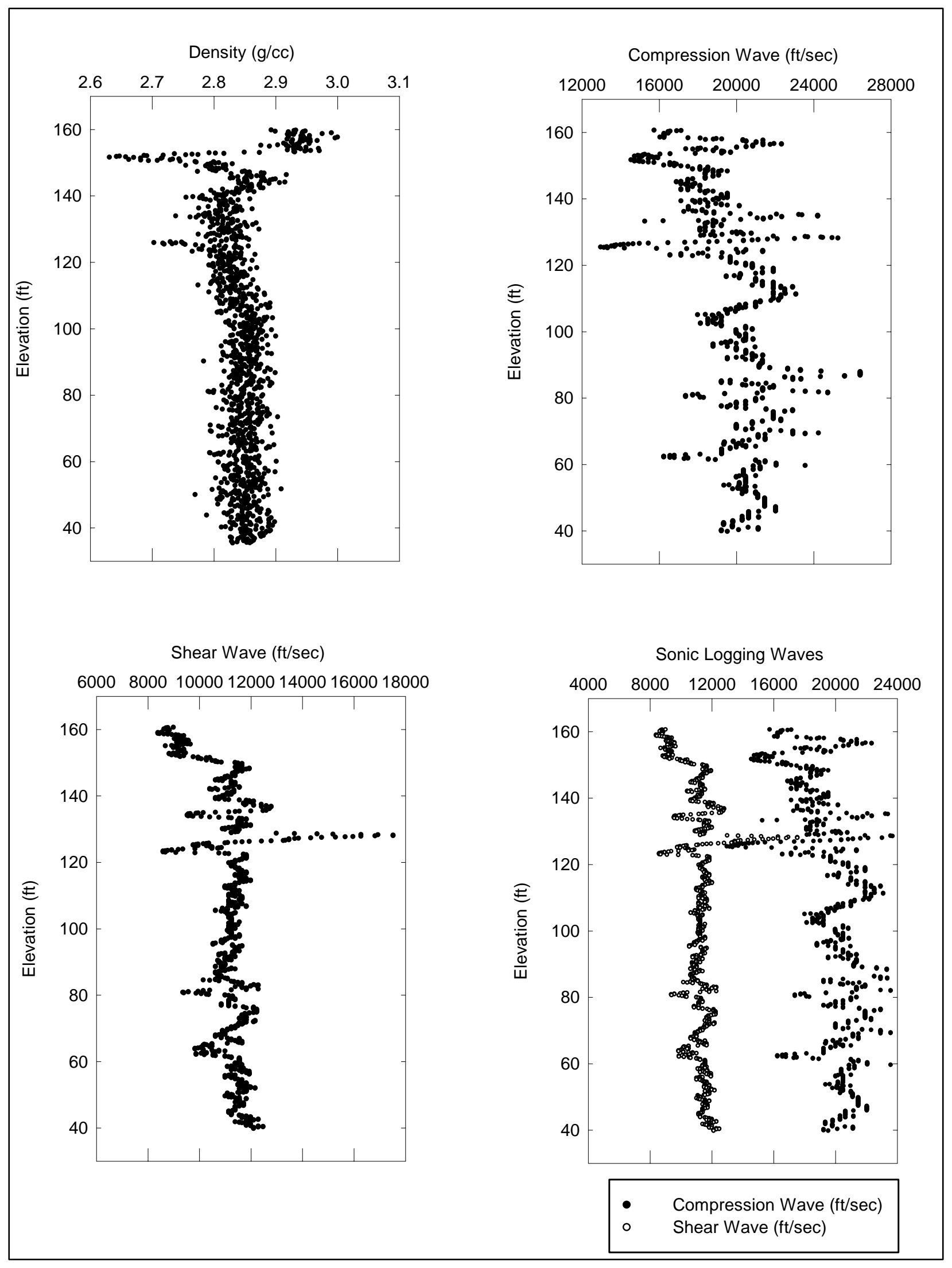

Figure B12. Monolith 14 - Relief Well No. 2 


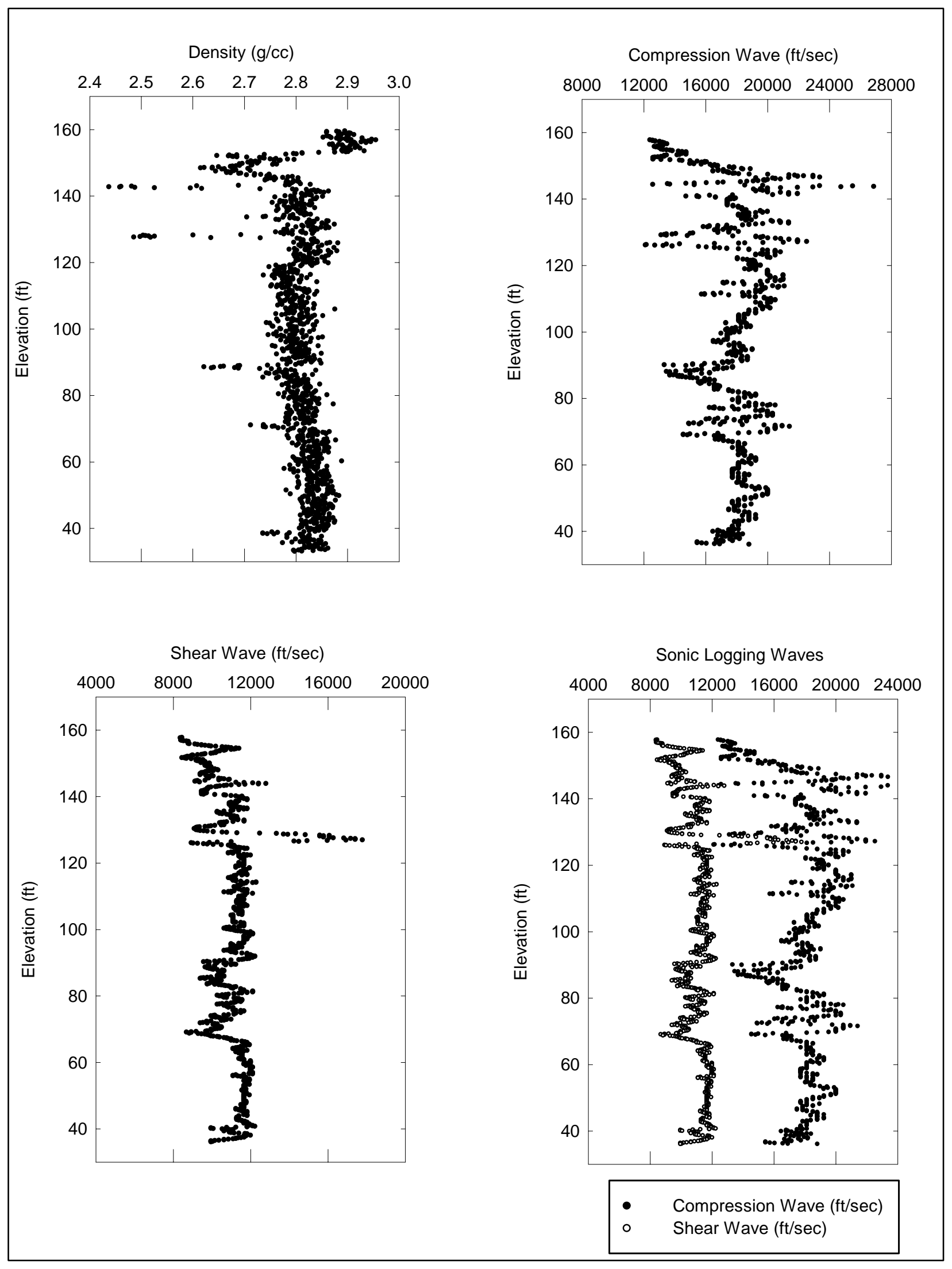

Figure B13. Monolith 14 - Relief Well No. 3 


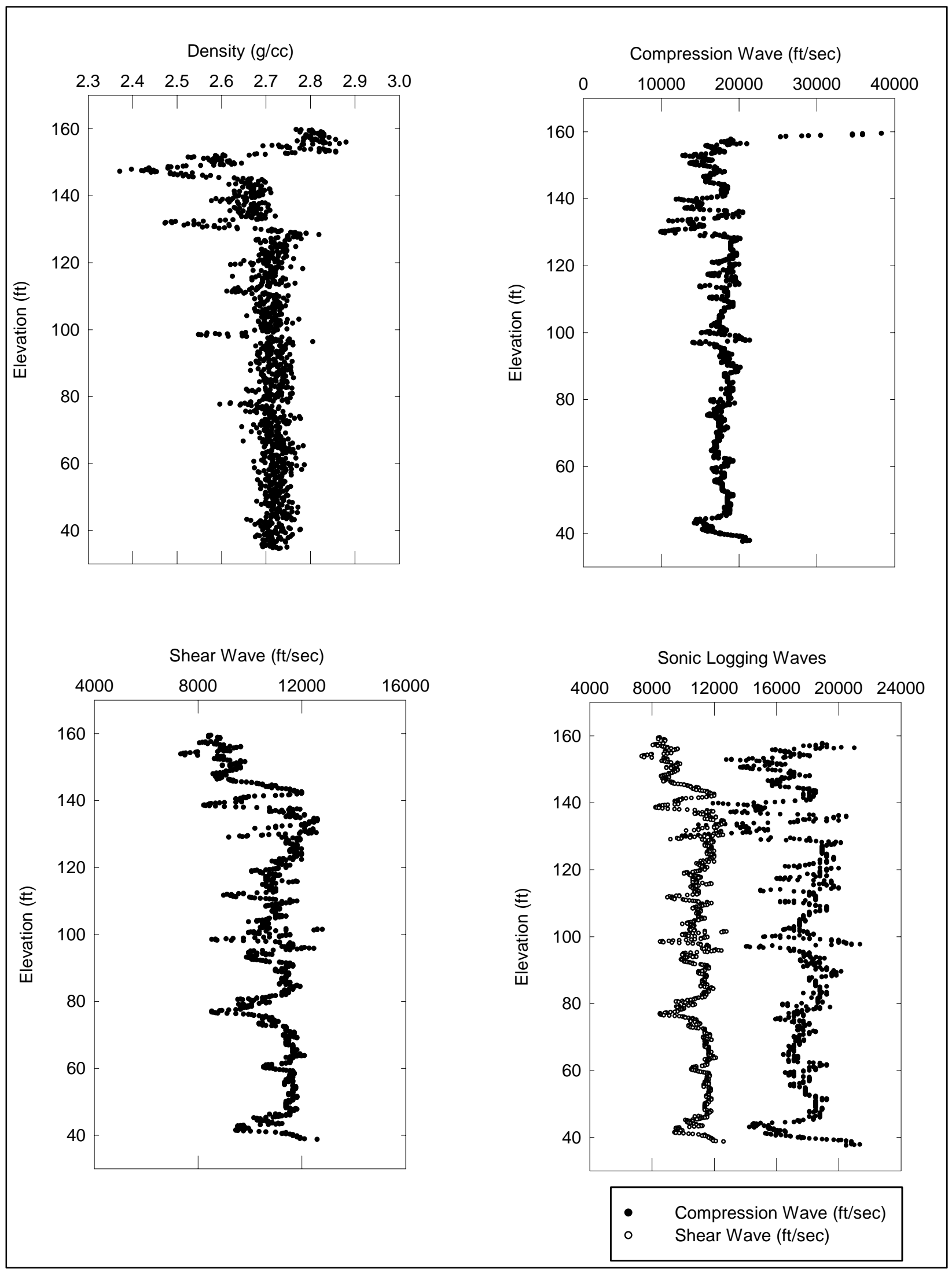

Figure B14. Monolith 14 - Relief Well No. 4 


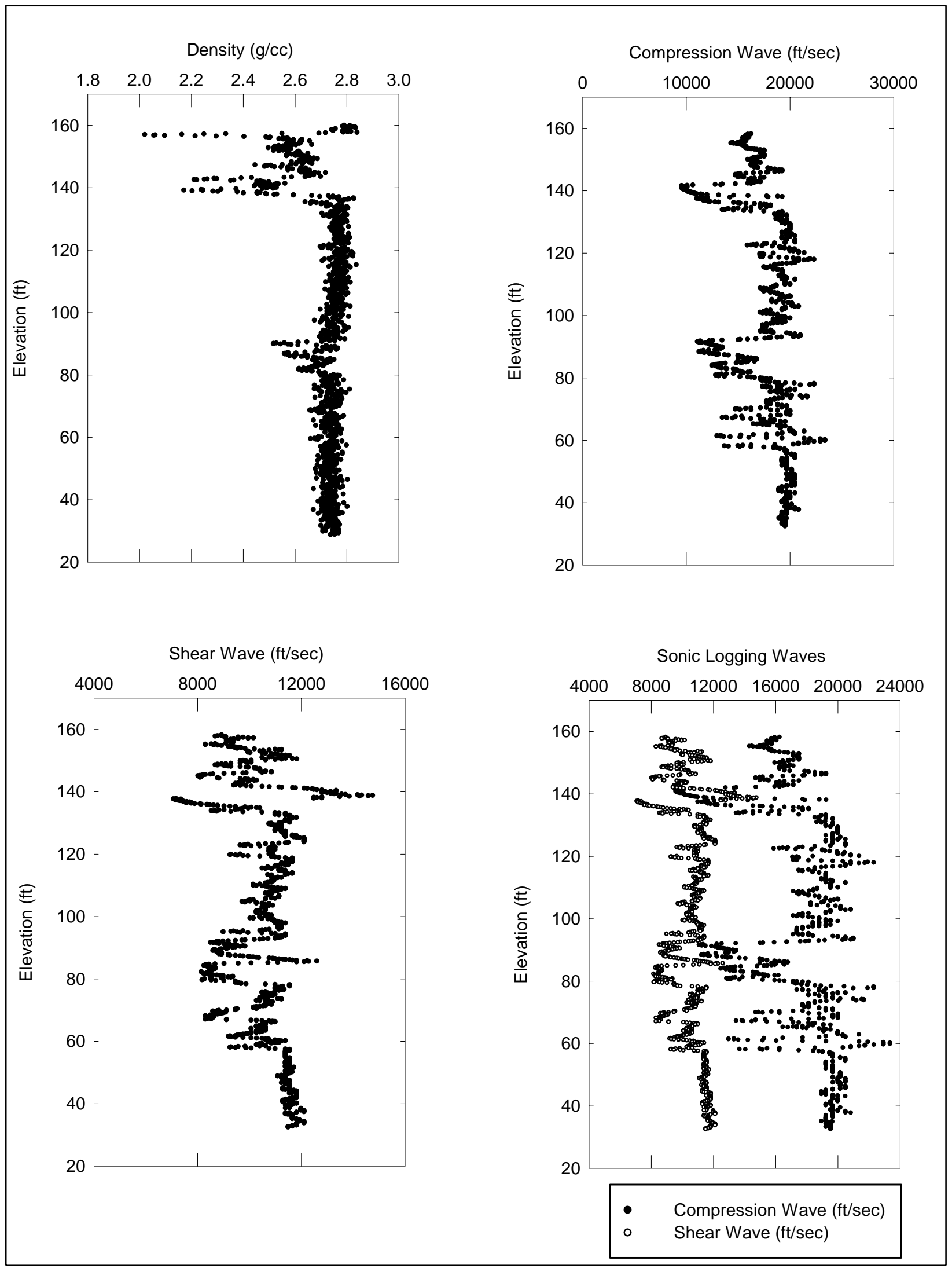

Figure B15. Monolith 15 - Relief Well No. 1 


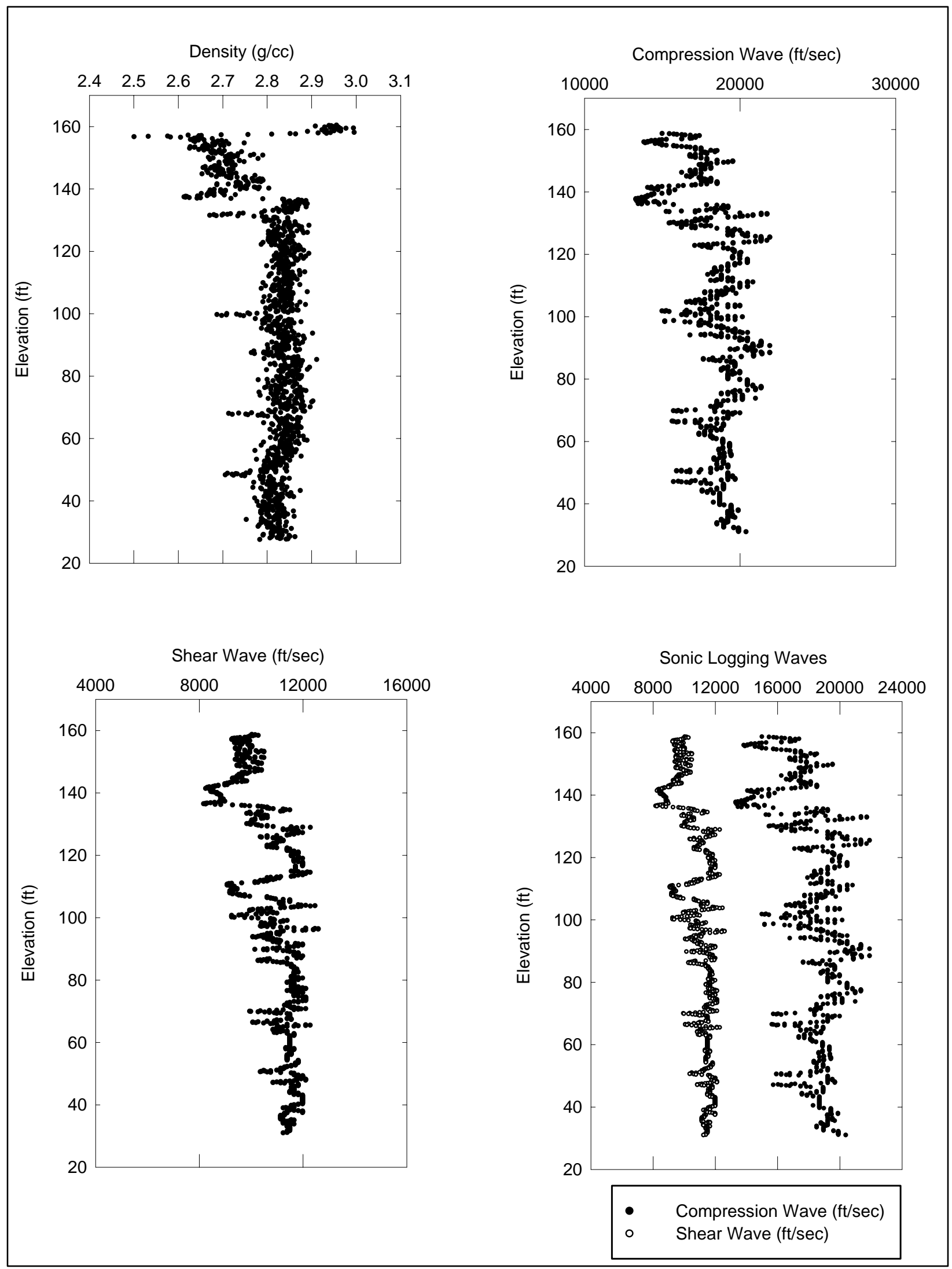

Figure B16. Monolith 15 - Relief Well No. 2 


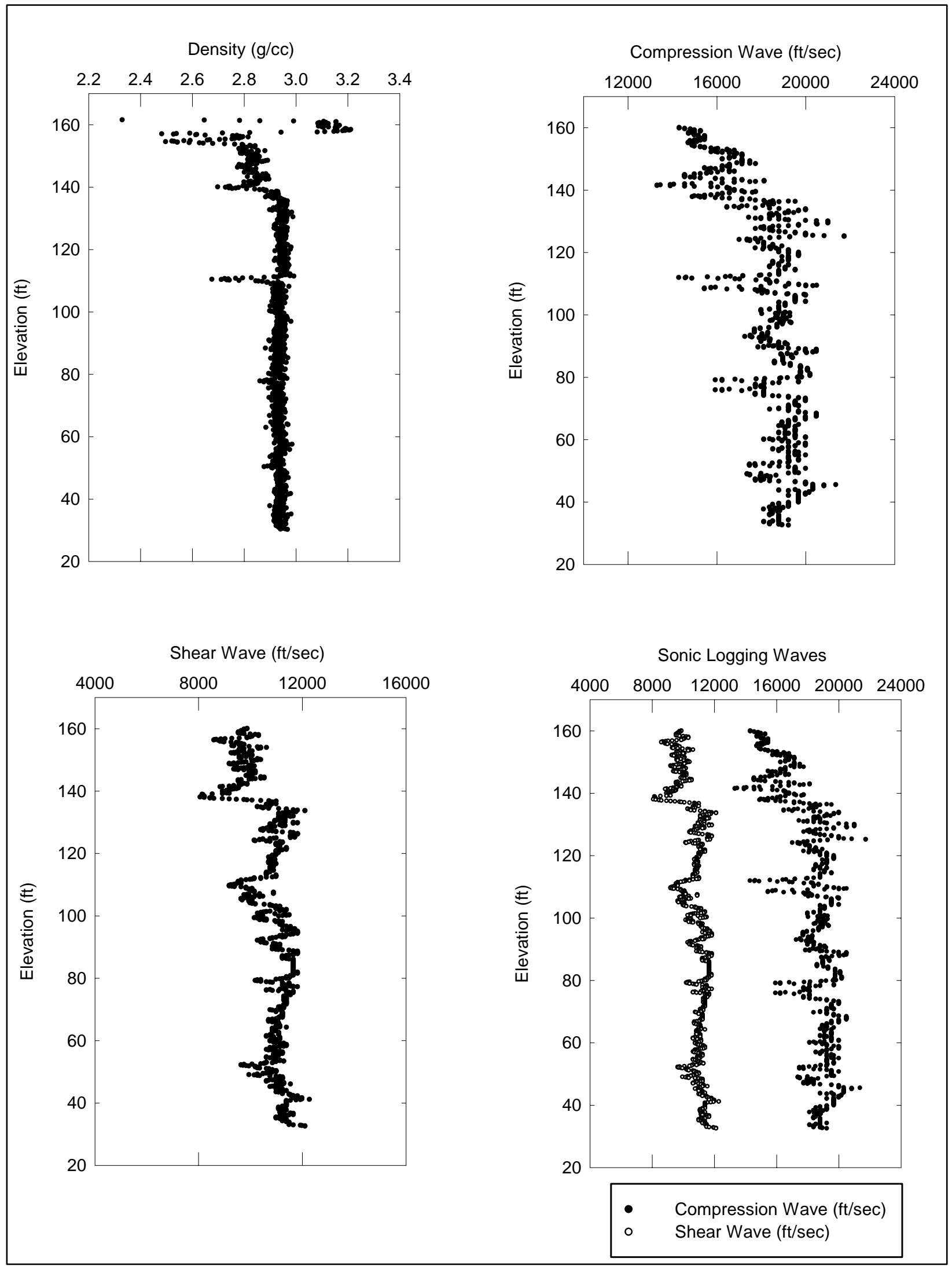

Figure B17. Monolith 15 - Relief Well No. 3 


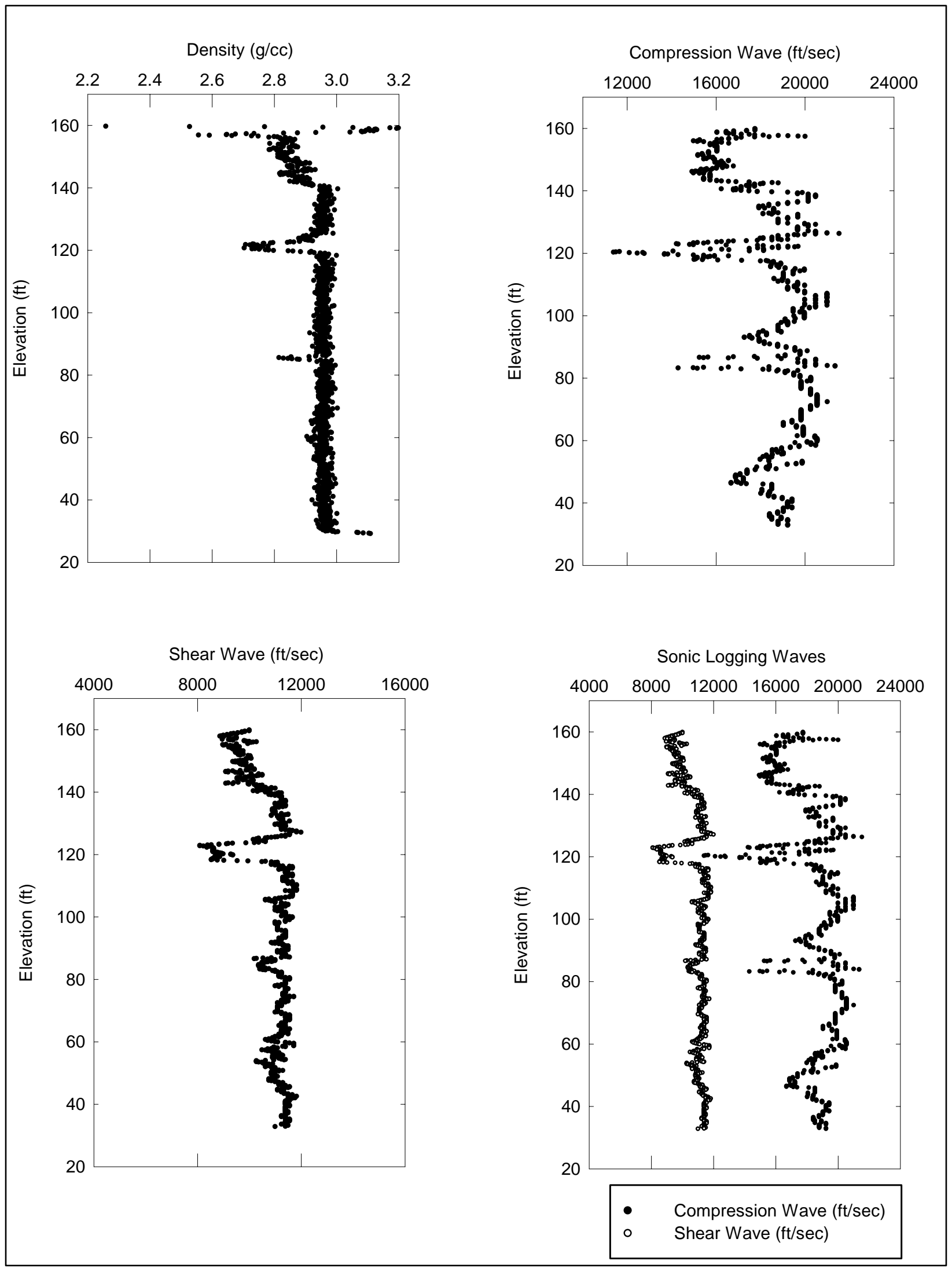

Figure B18. Monolith 15 - Relief Well No. 4 


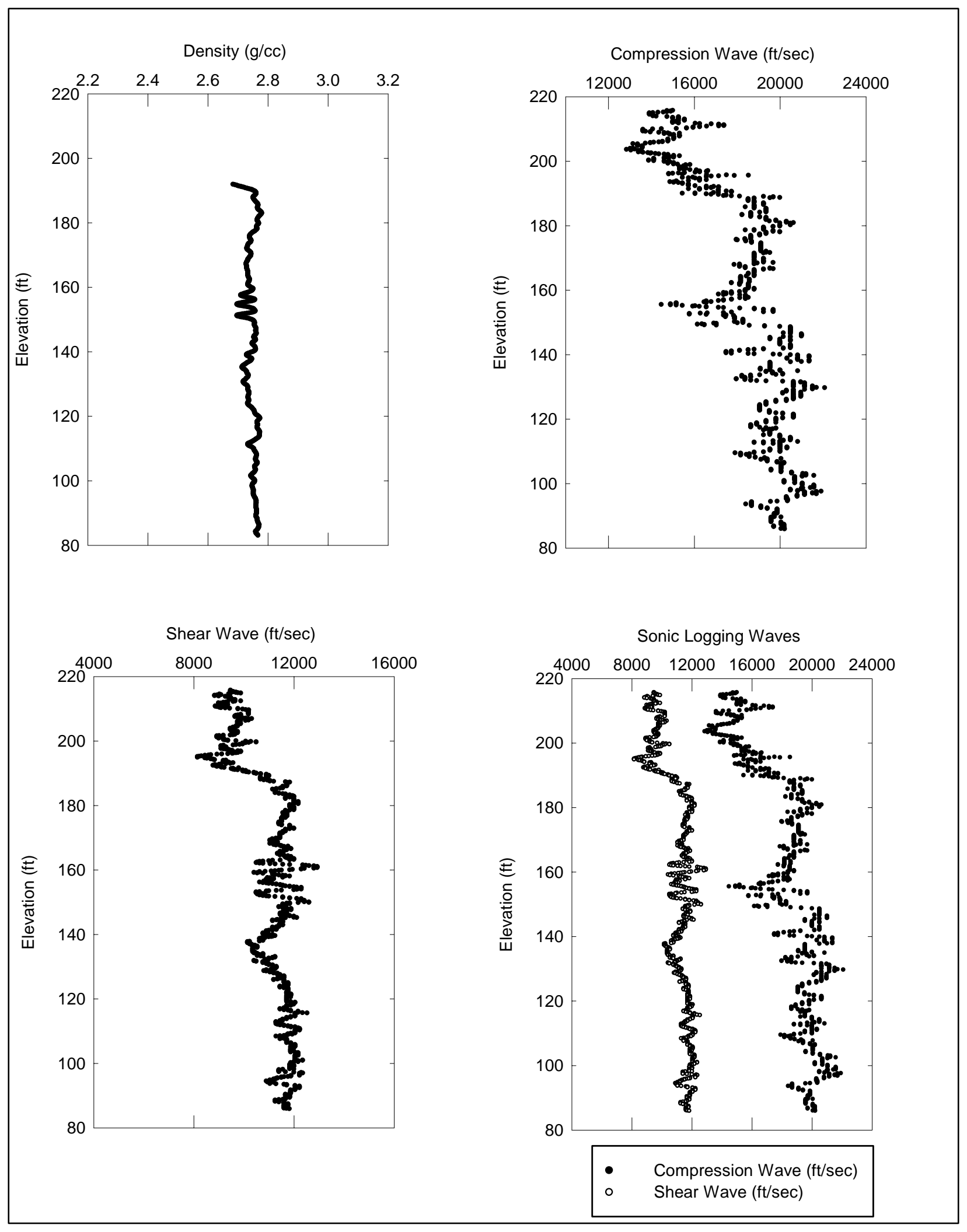

Figure B19. Monolith 21 - Relief Well No. 1 


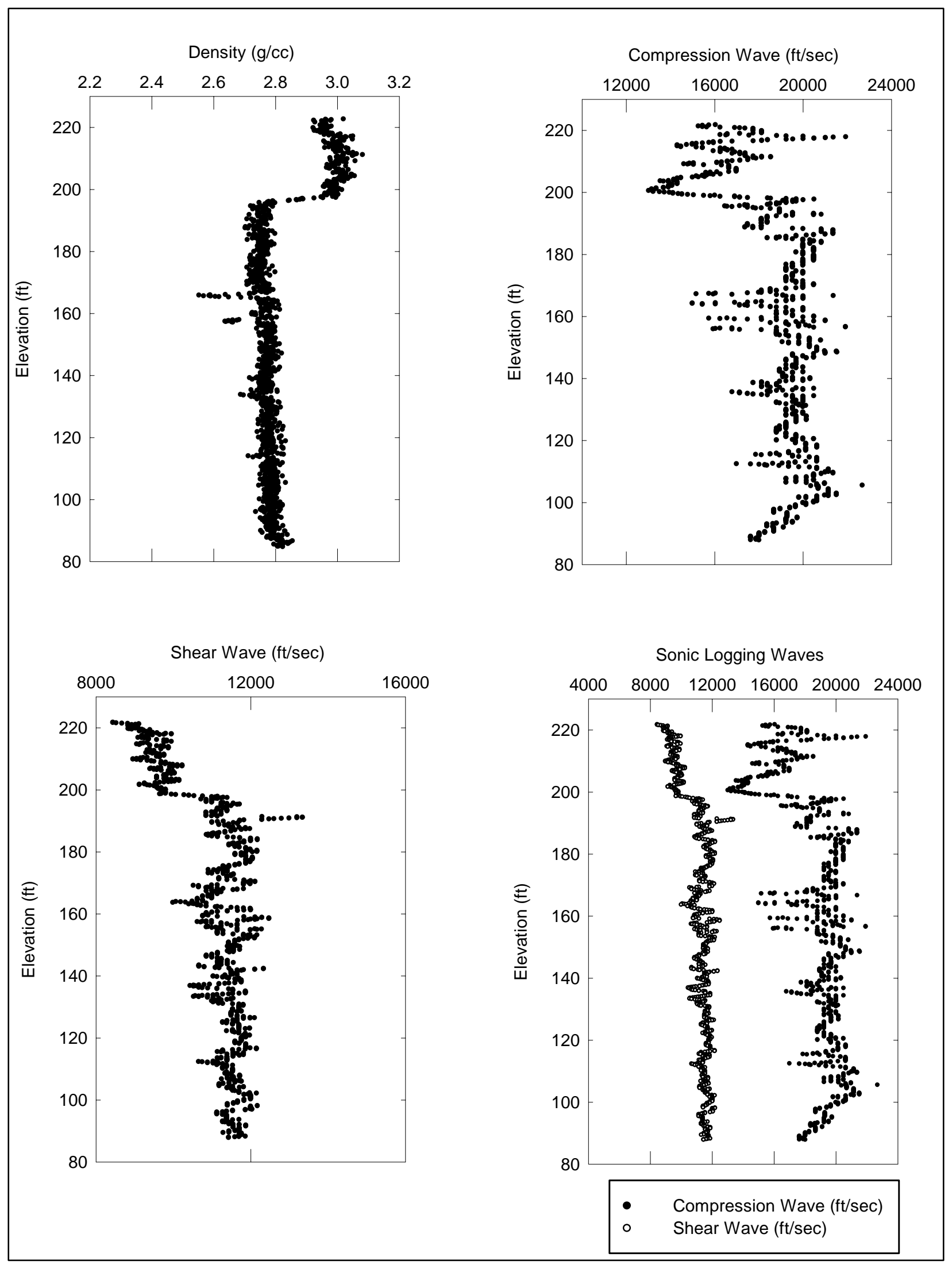

Figure B20. Monolith 21 - Relief Well No. 2 


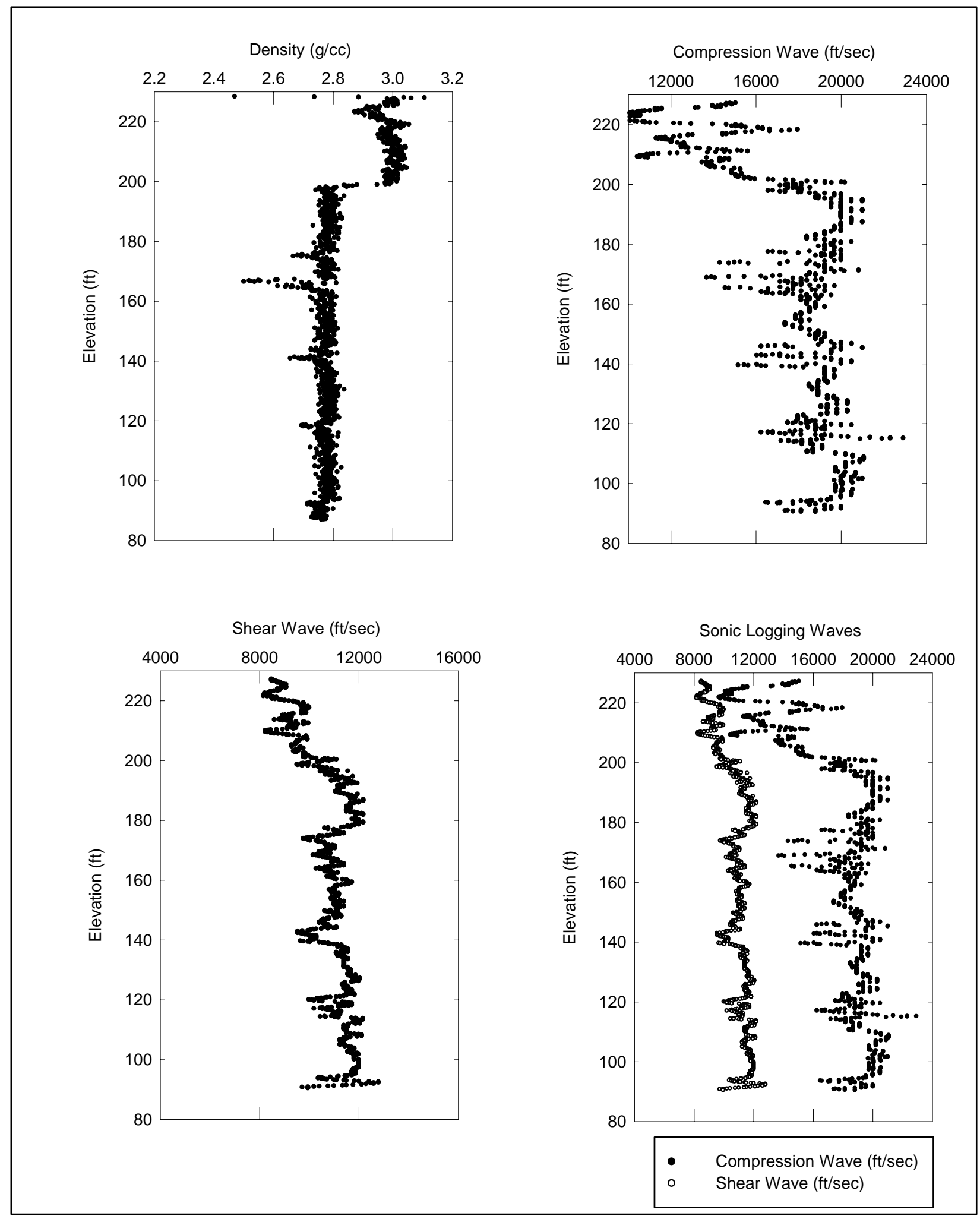

Figure B21. Monolith 21 - Relief Well No. 3 


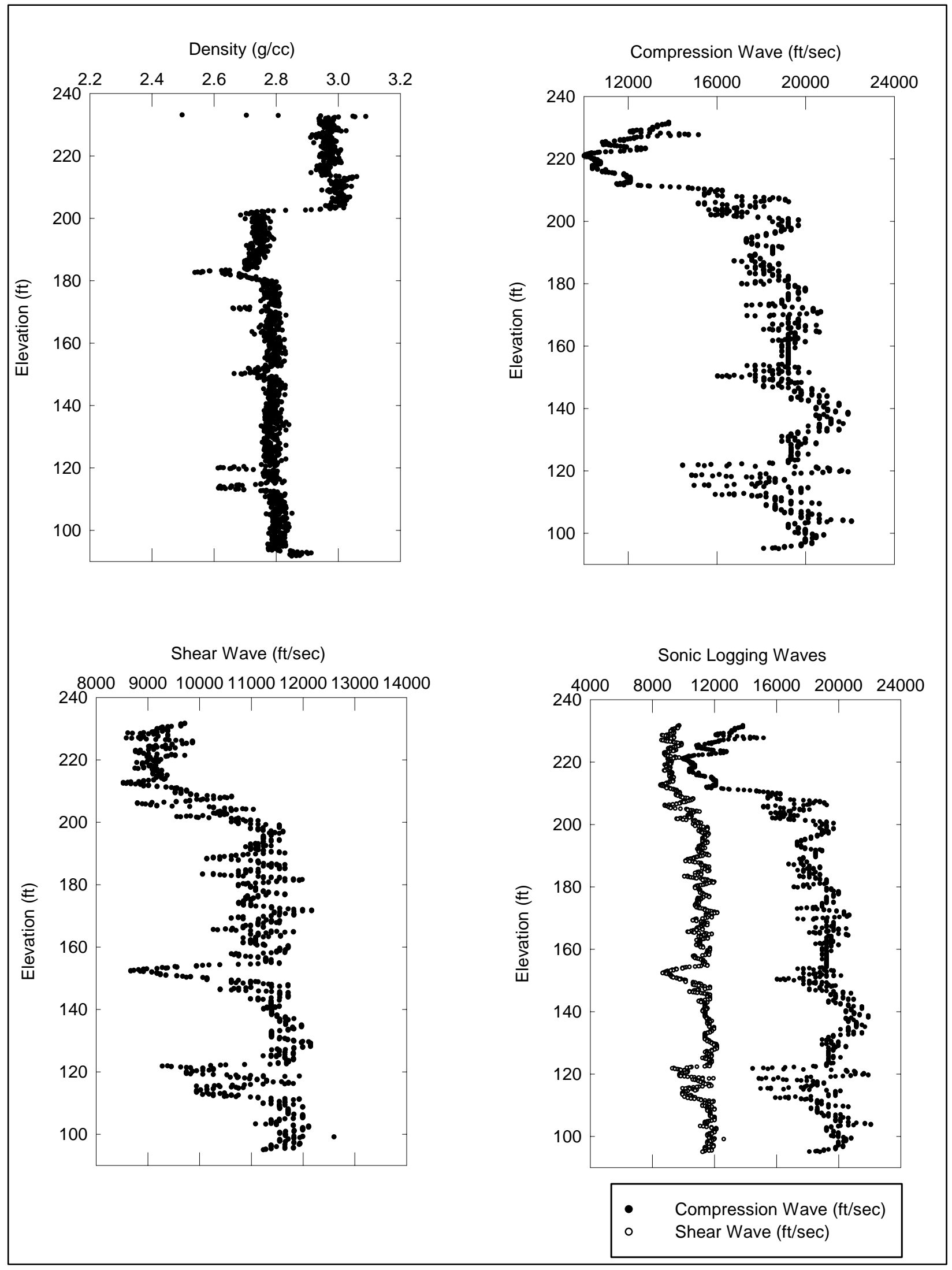

Figure B22. Monolith 21 - Relief Well No. 4 


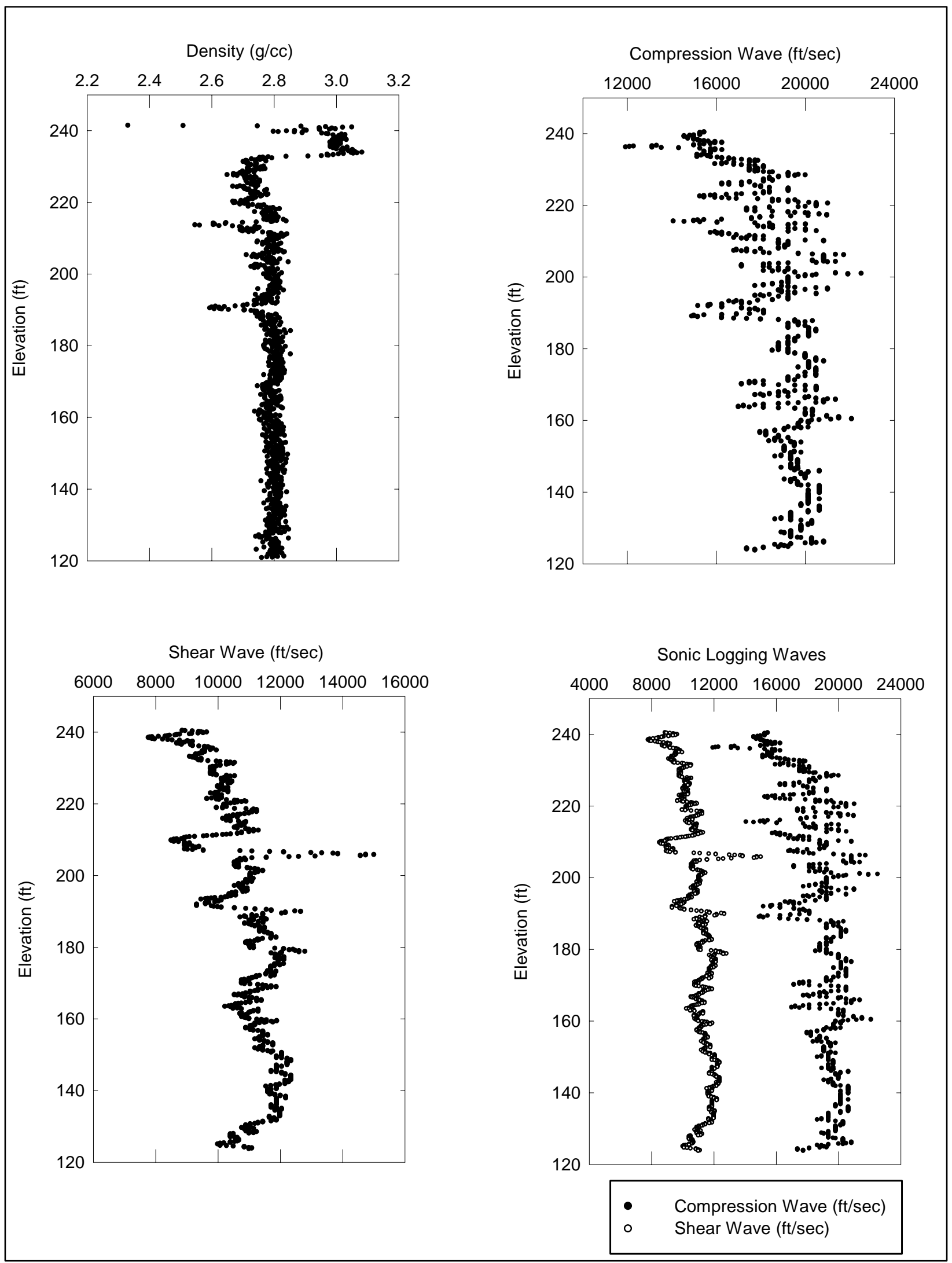

Figure B23. Monolith 22 - Relief Well No. 2 


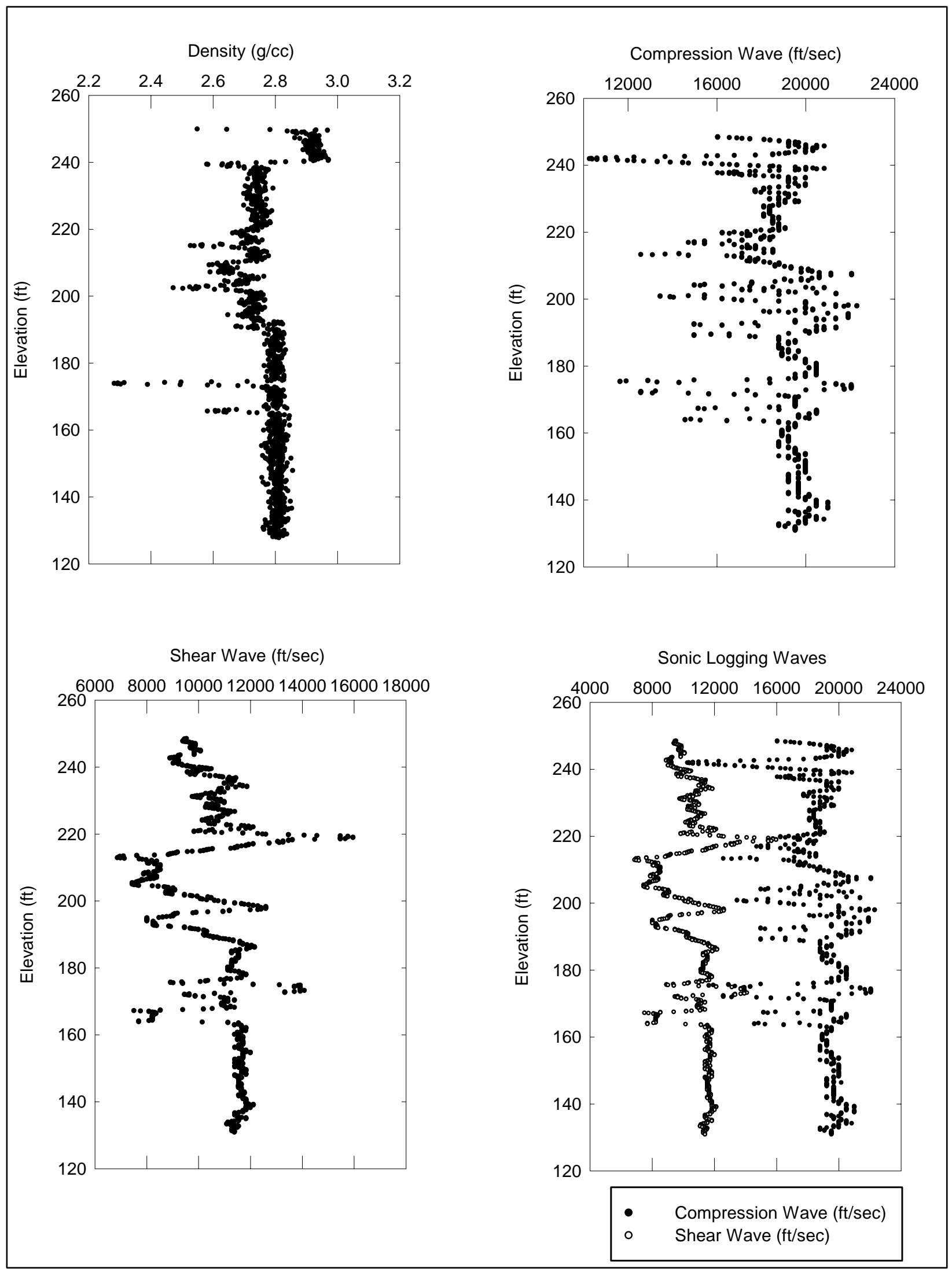

Figure B24. Monolith 22 - Relief Well No. 3 


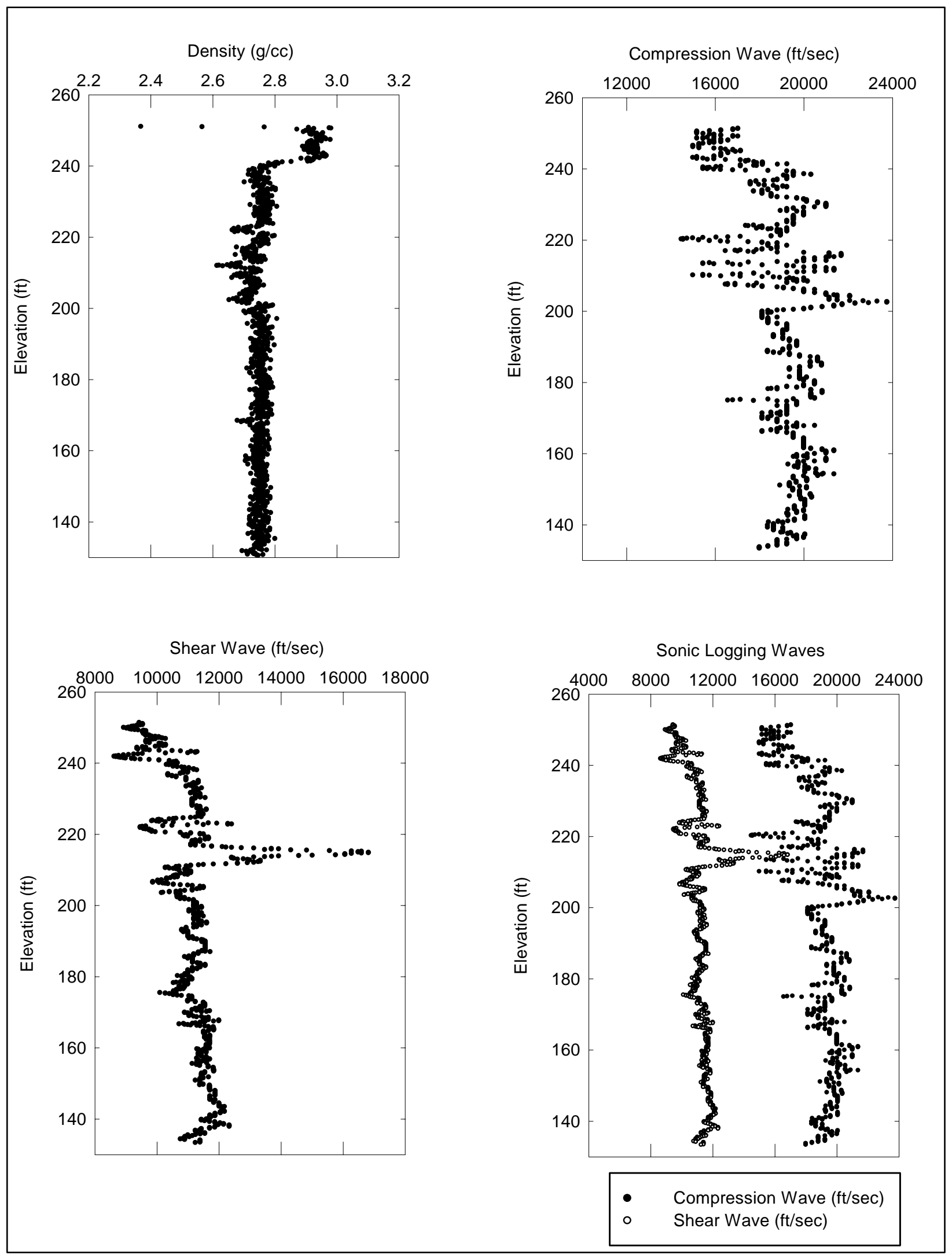

Figure B25. Monolith 22 - Relief Well No. 4 


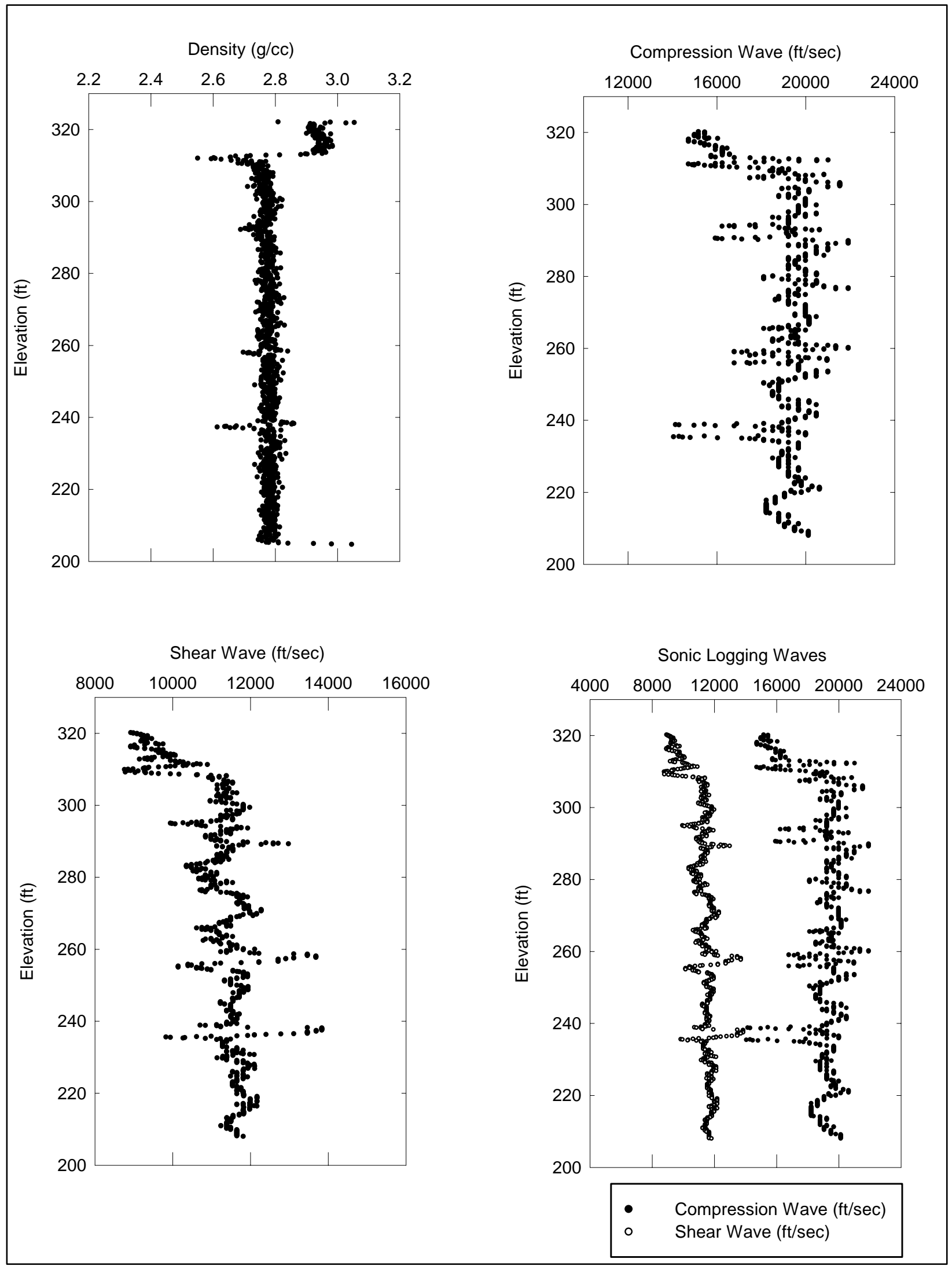

Figure B26. Monolith 27 - Relief Well No. 1 


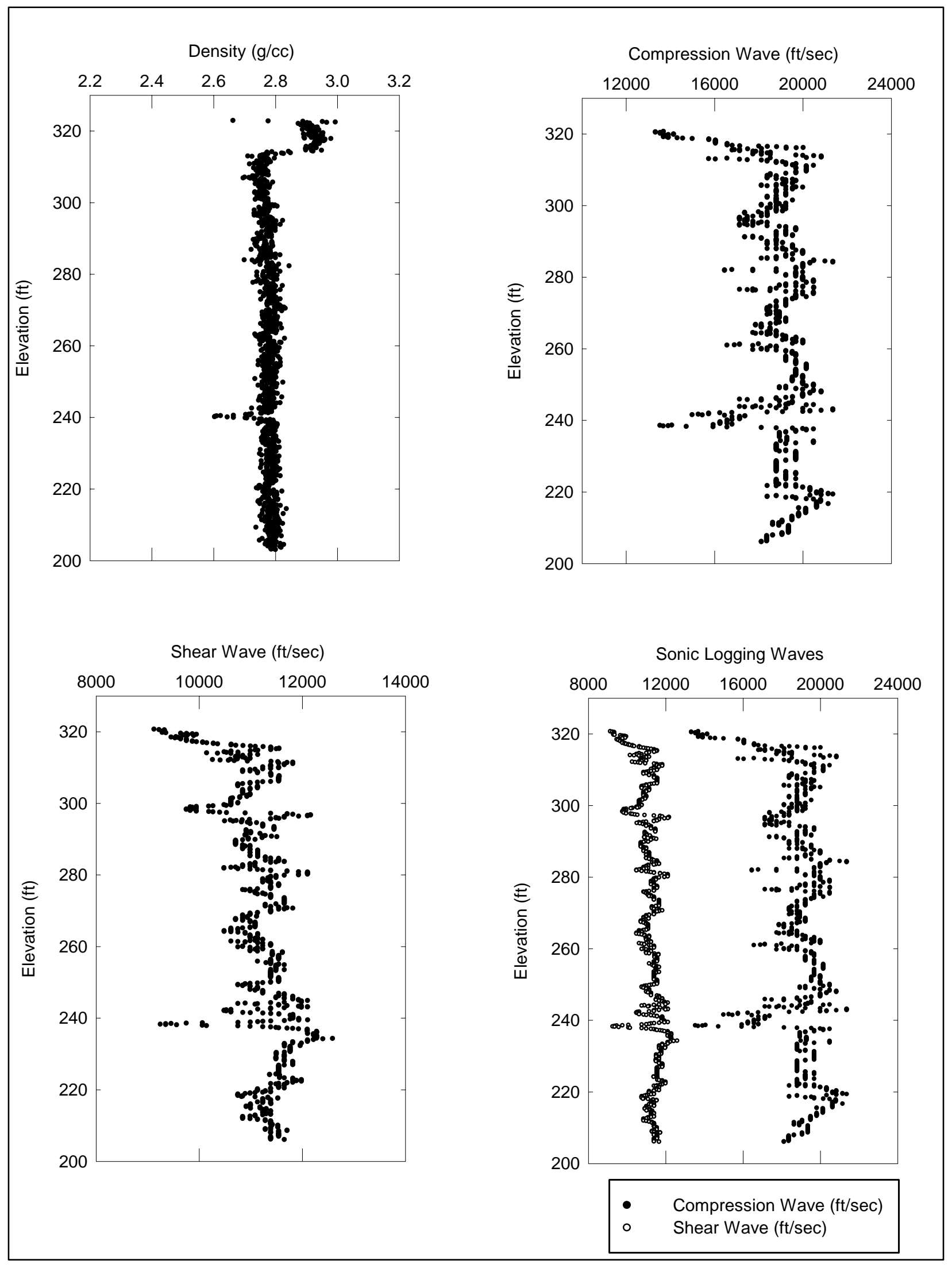

Figure B27. Monolith 27 - Relief Well No. 2 


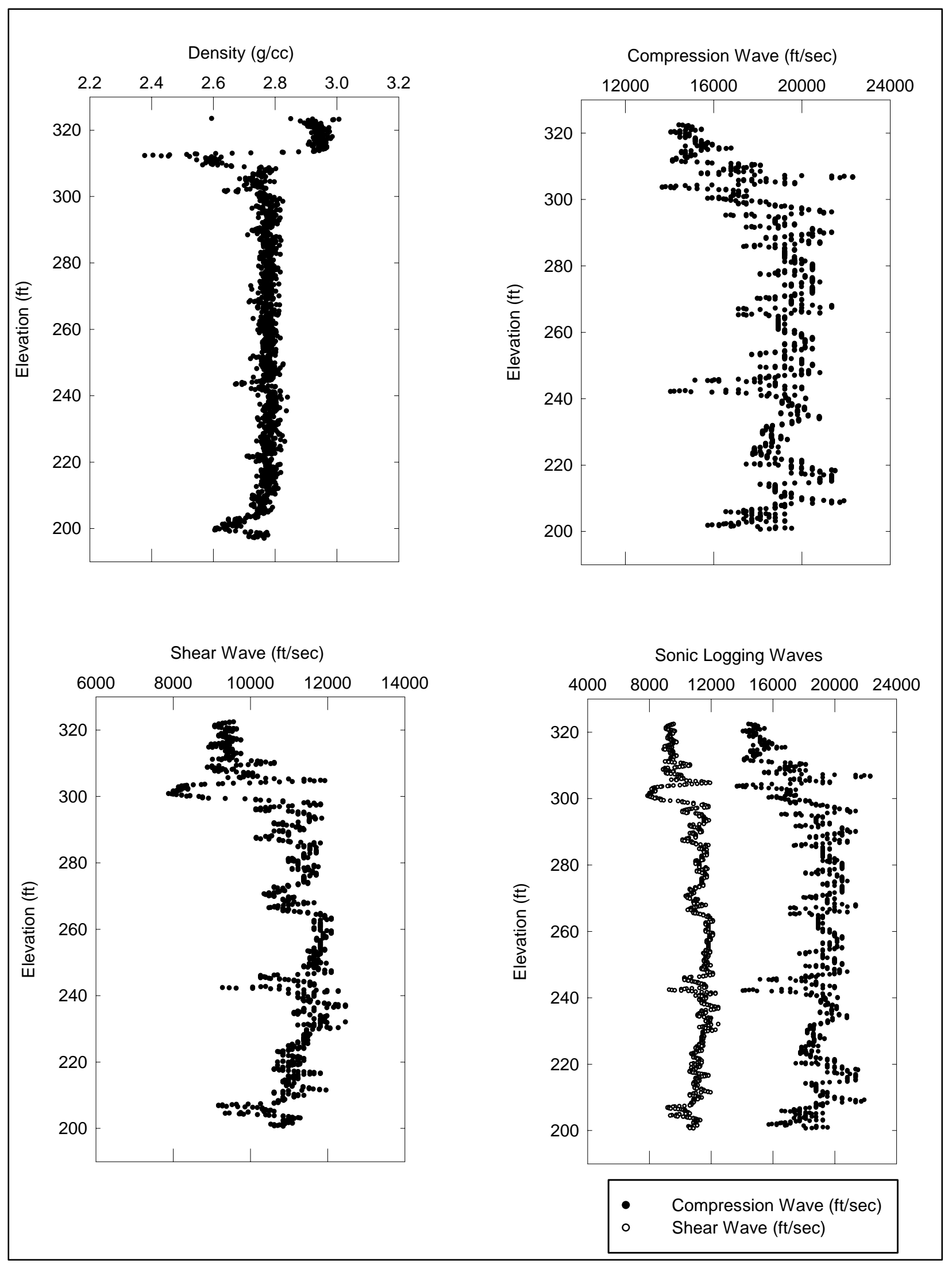

Figure B28. Monolith 27 - Relief Well No. 3 


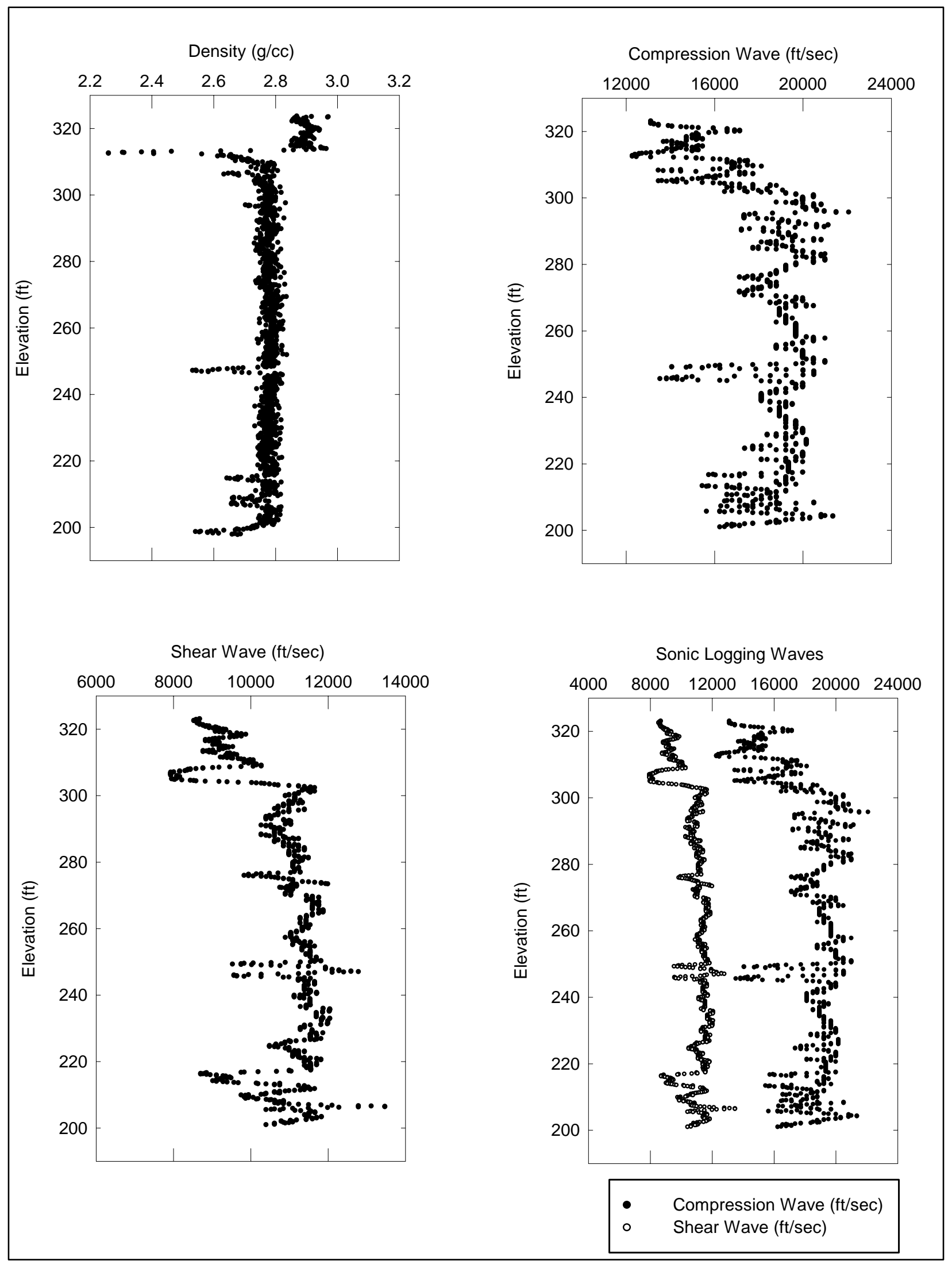

Figure B29. Monolith 27 - Relief Well No. 4 


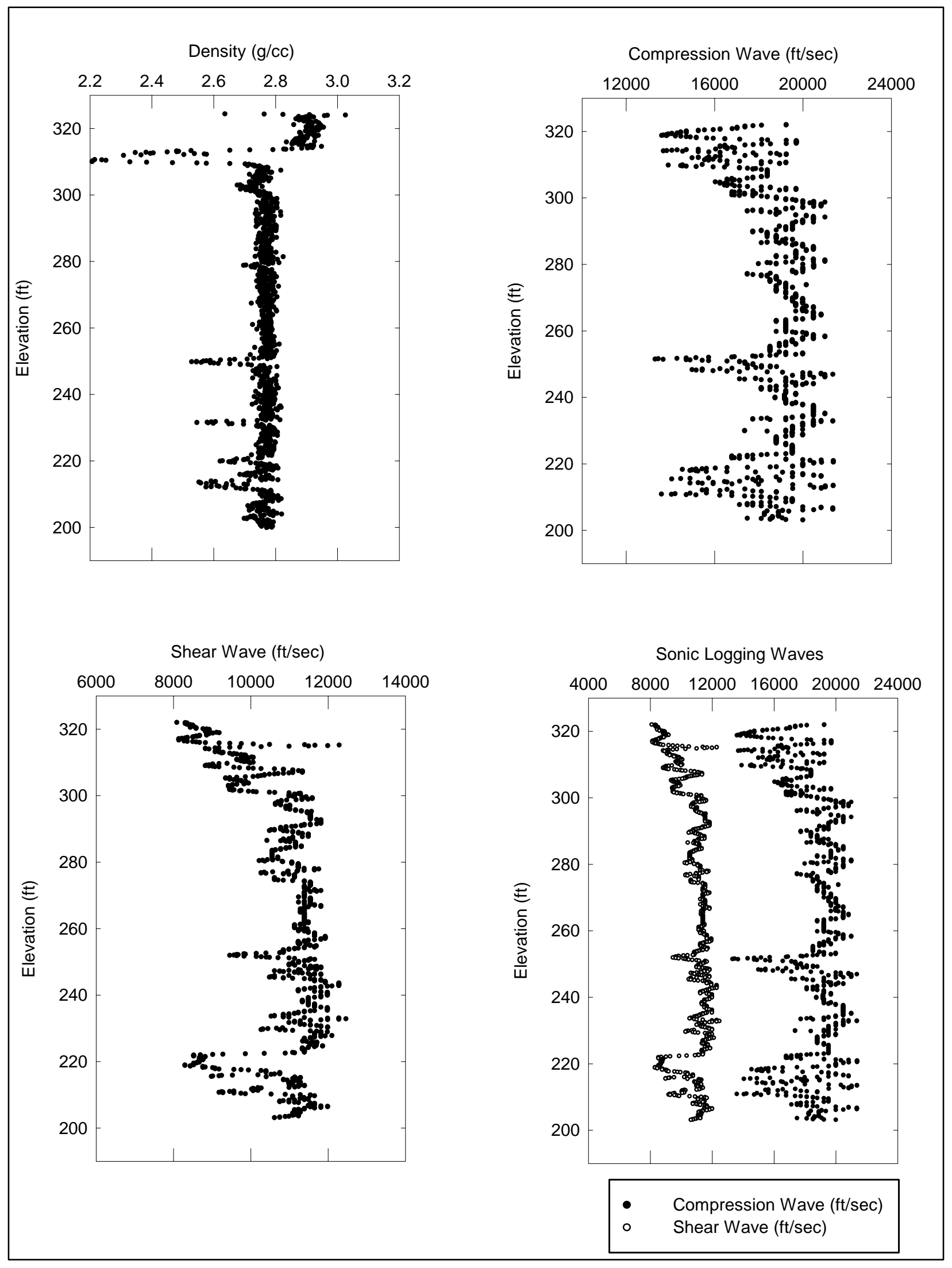

Figure B30. Monolith 27 - Relief Well No. 5 


\section{Appendix C Monolith Average P- and S-Wave Crosshole Velocities}




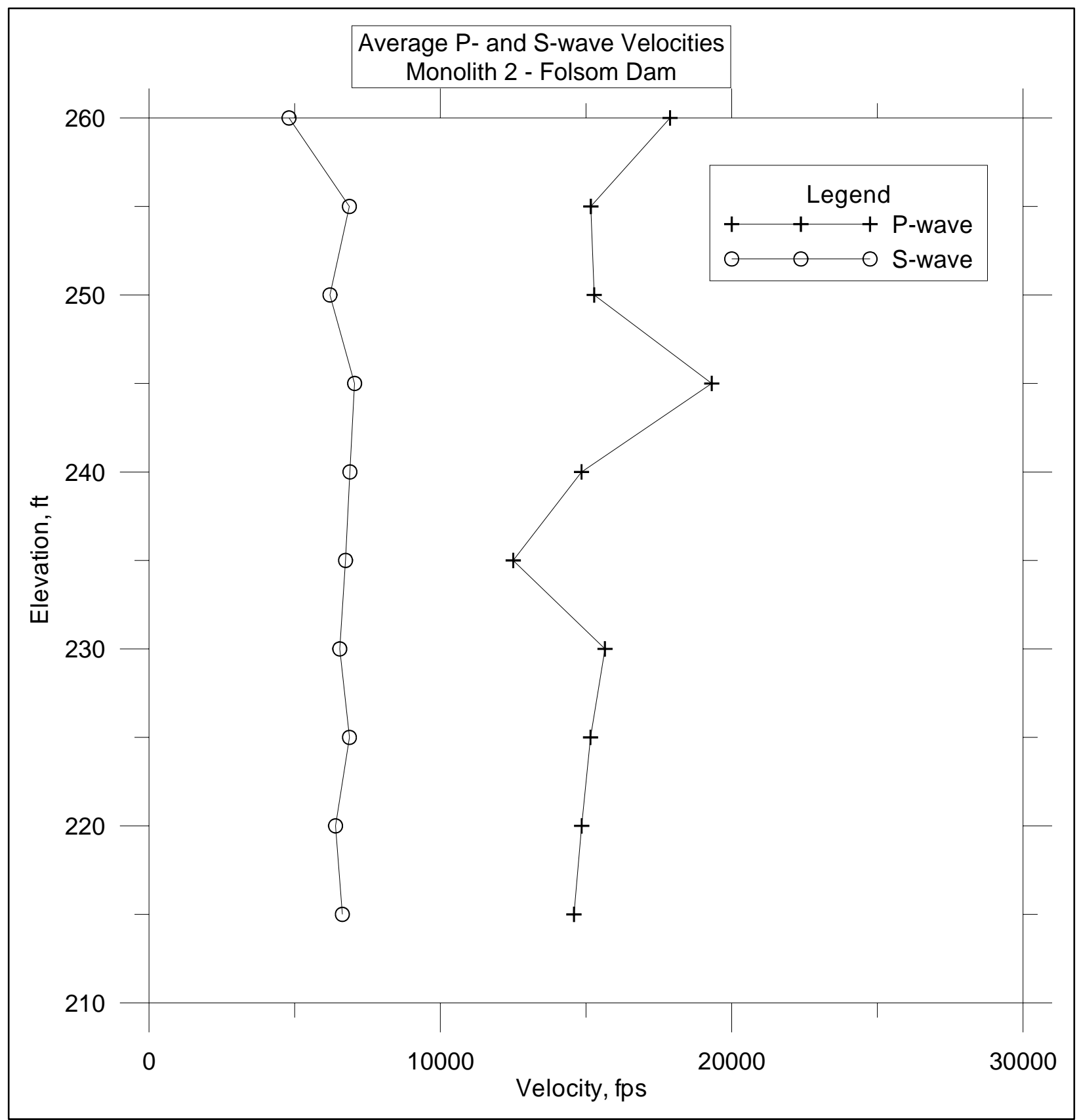

Figure C1. Average P- and S-wave crosshole velocities, Monolith 2 


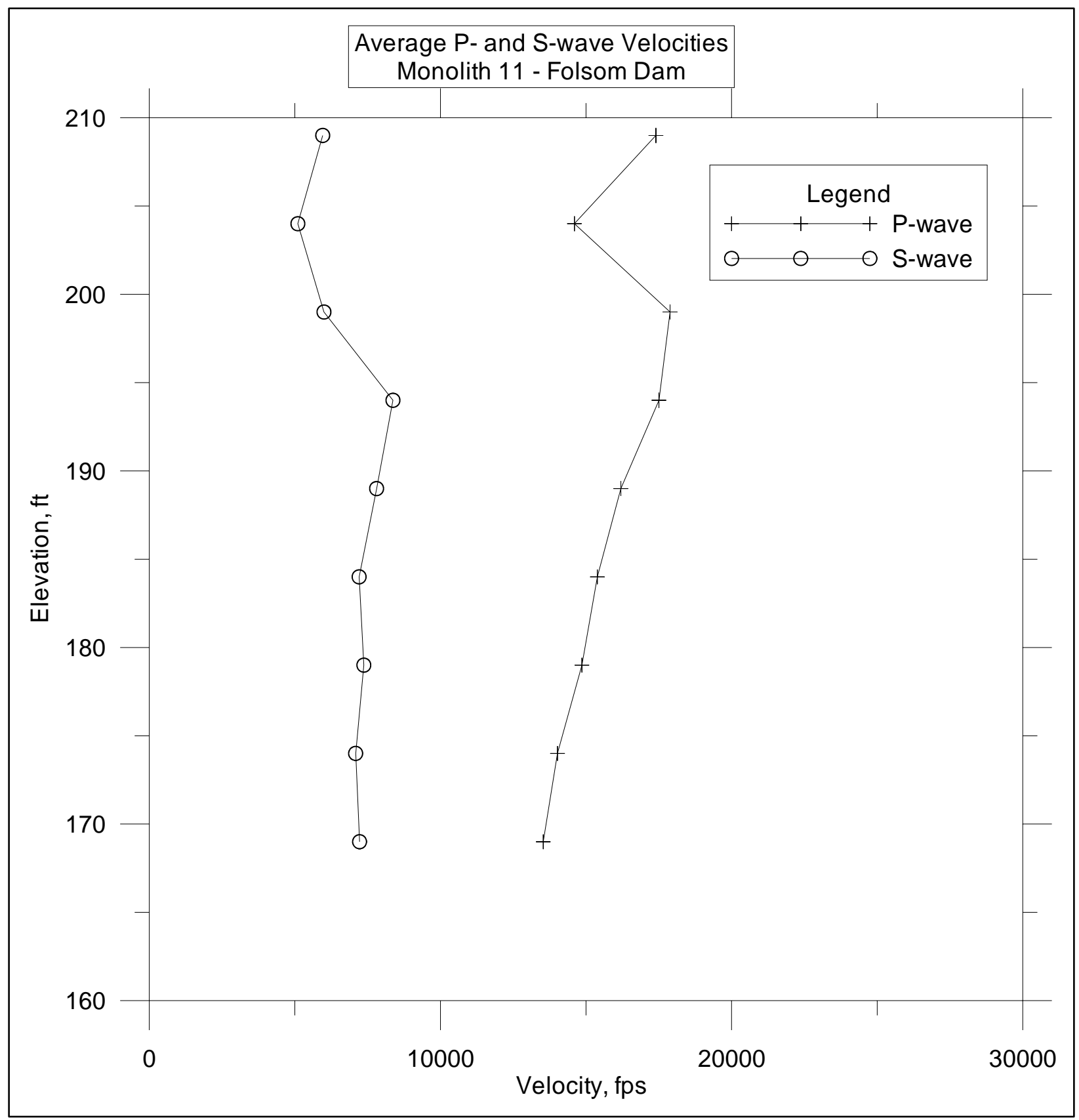

Figure C2. Average P- and S-wave crosshole velocities, Monolith 11 


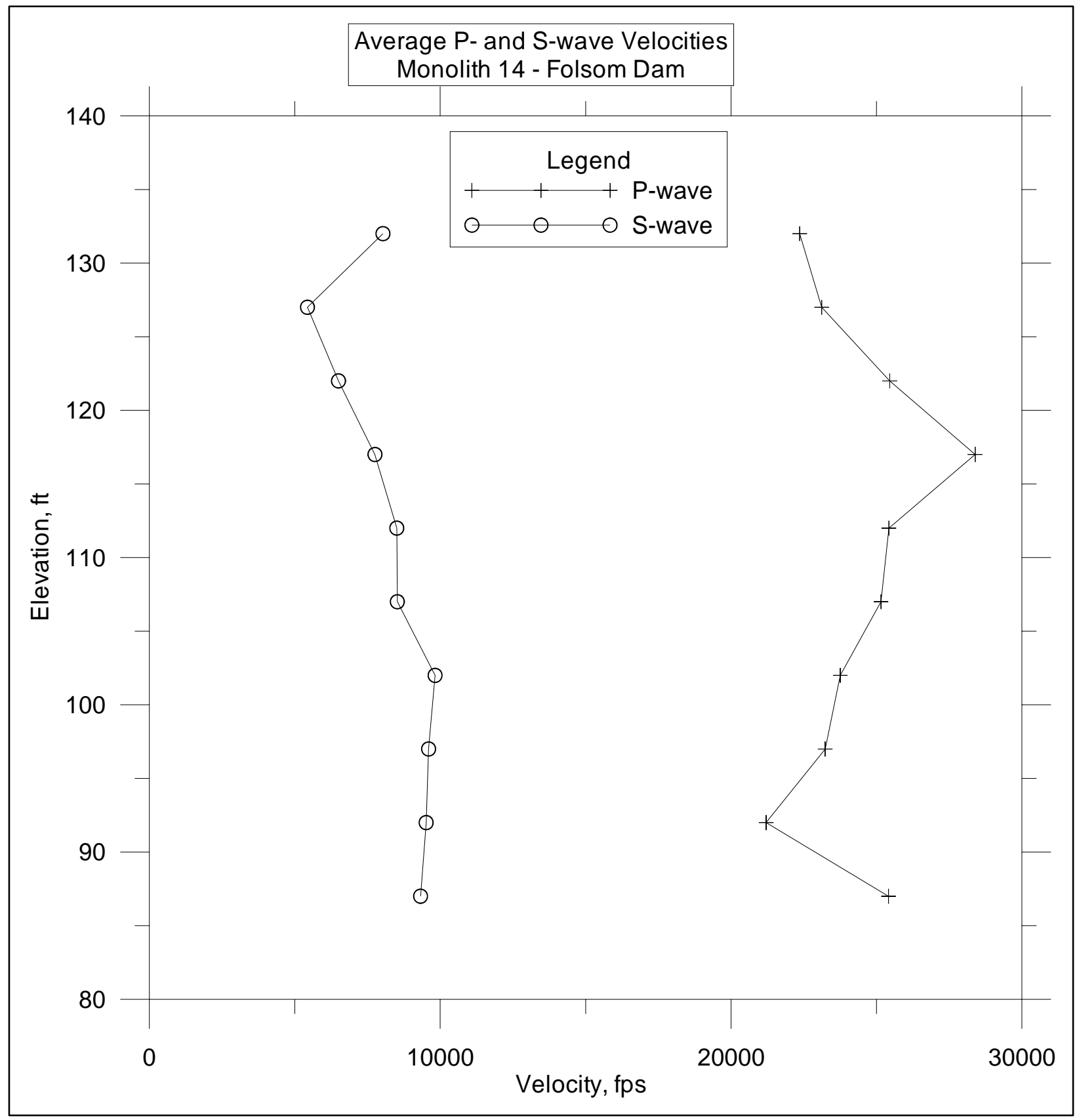

Figure C3. Average P- and S-wave crosshole velocities, Monolith 14 


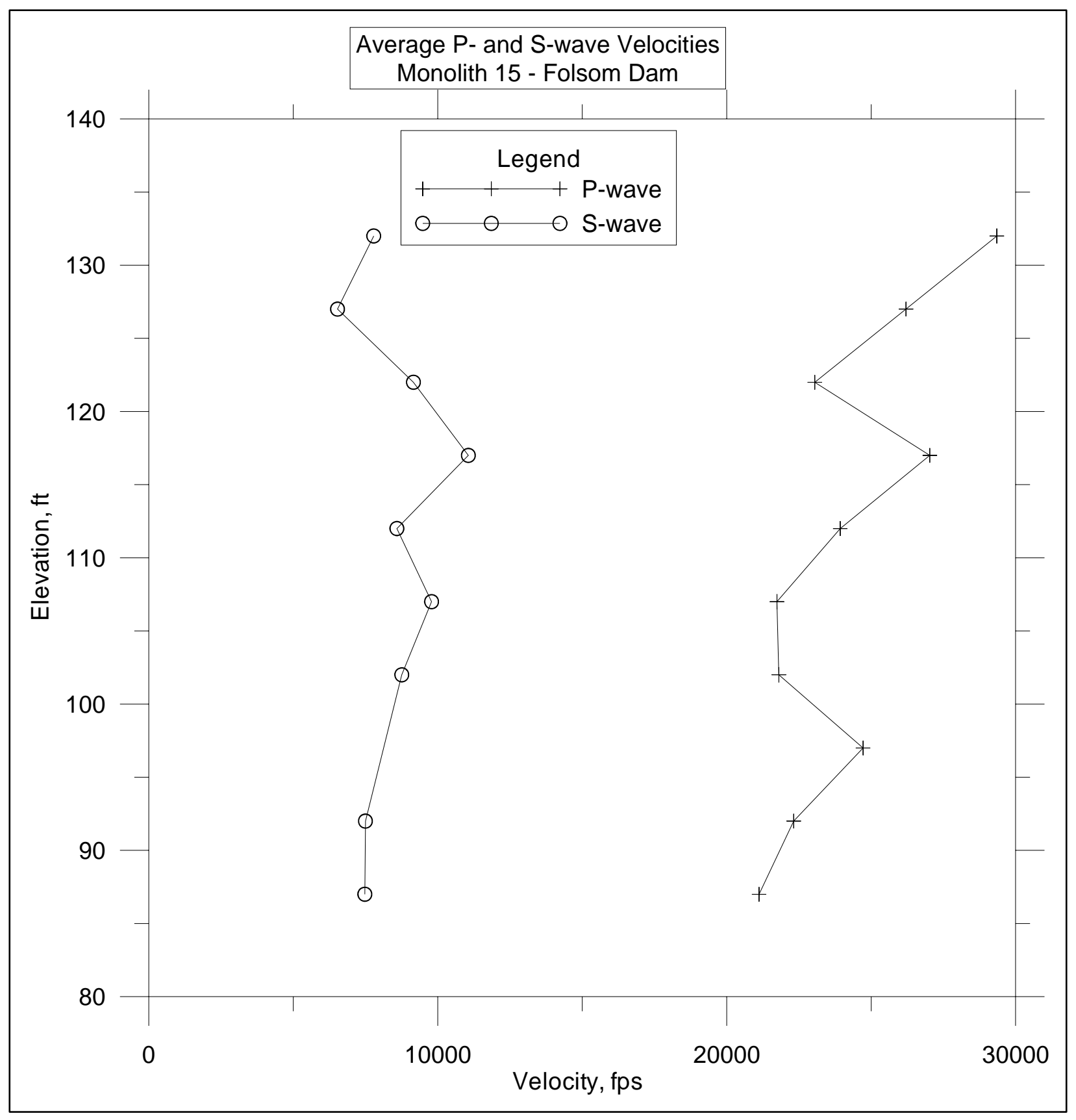

Figure C4. Average P- and S-wave crosshole velocities, Monolith 15 


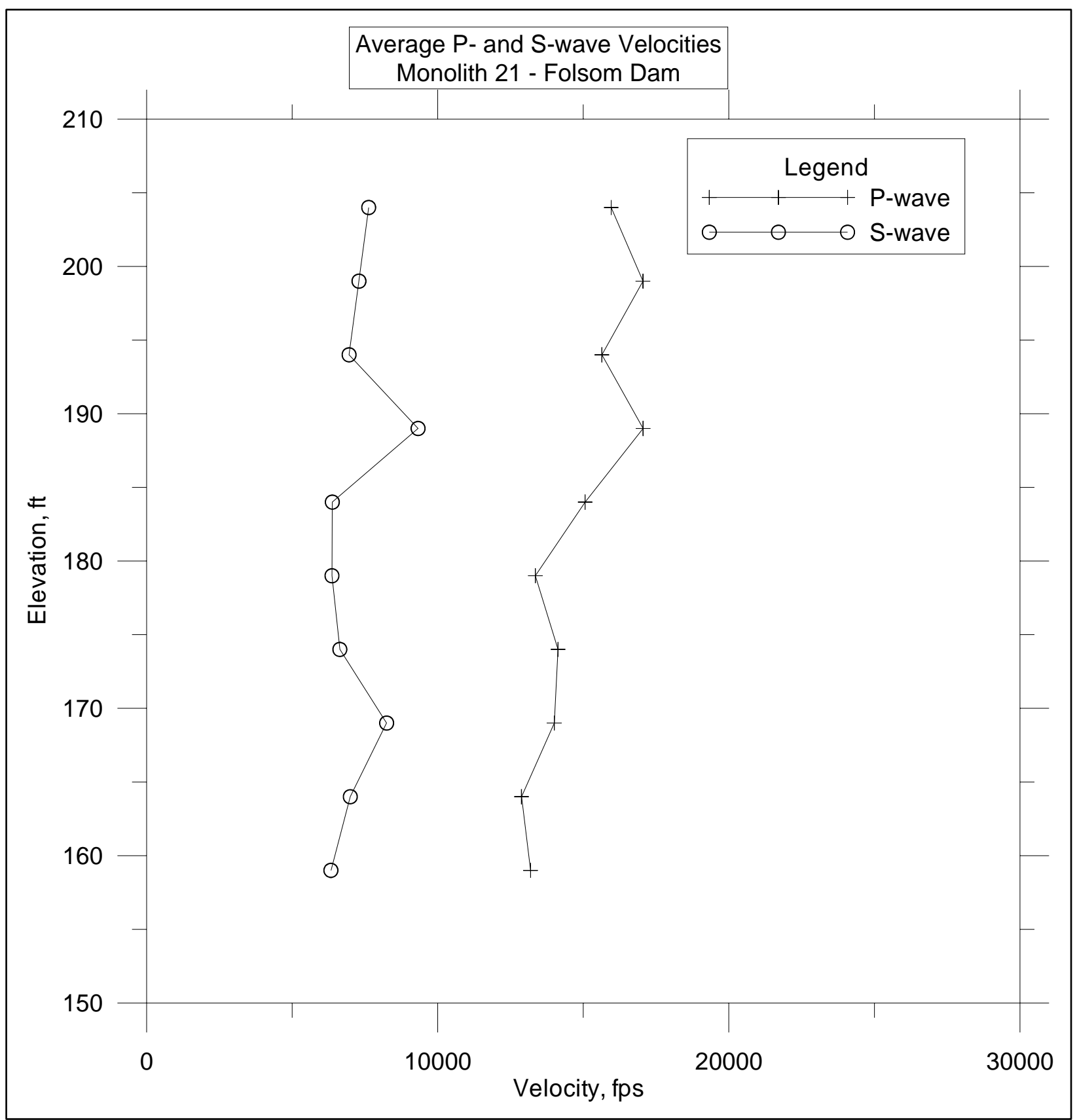

Figure C5. Average P- and S-wave crosshole velocities, Monolith 21 


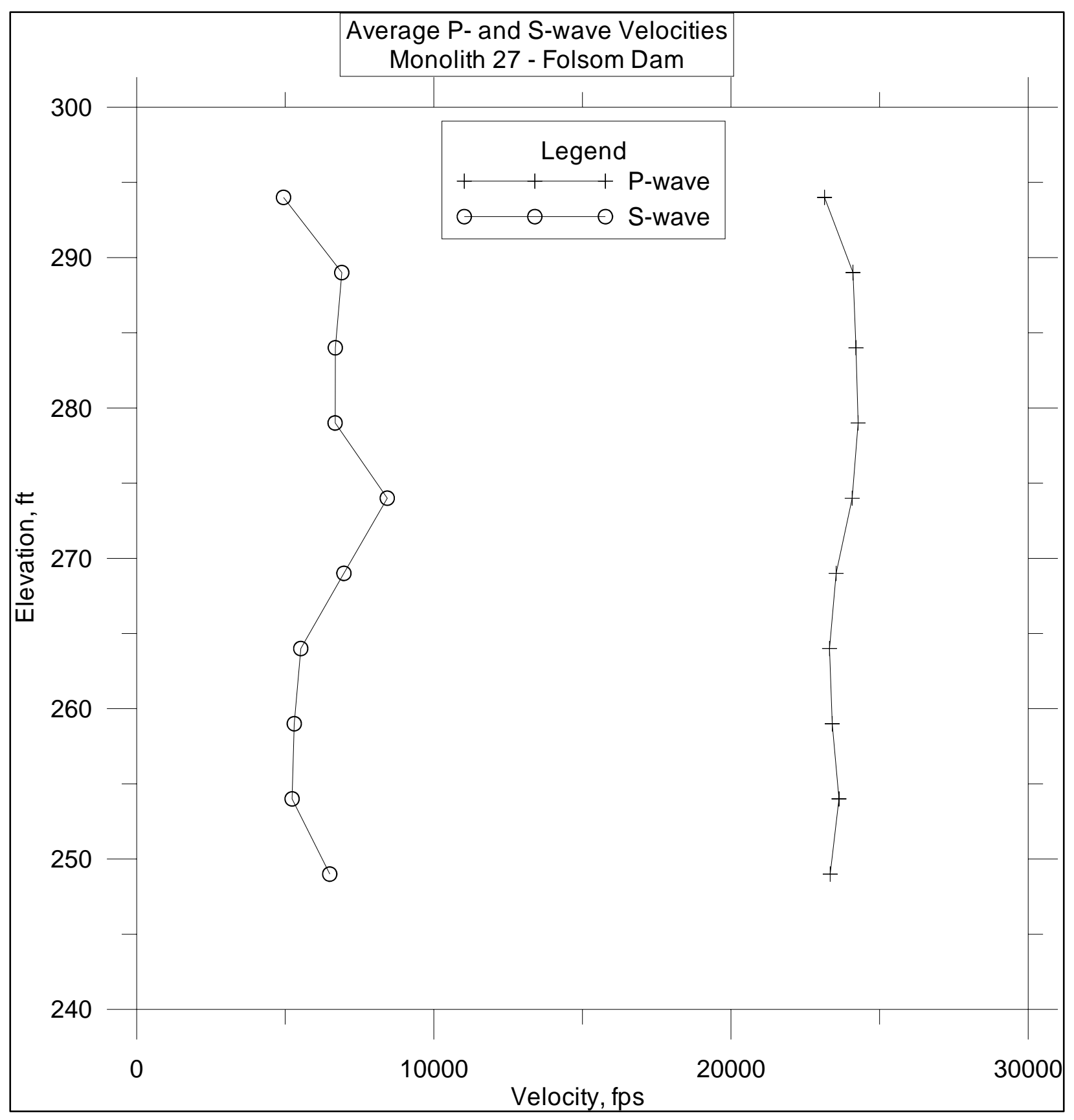

Figure C6. Average P- and S-wave crosshole velocities, Monolith 27 


\section{Appendix D Computed Elastic Moduli Based on Sonic Logging}




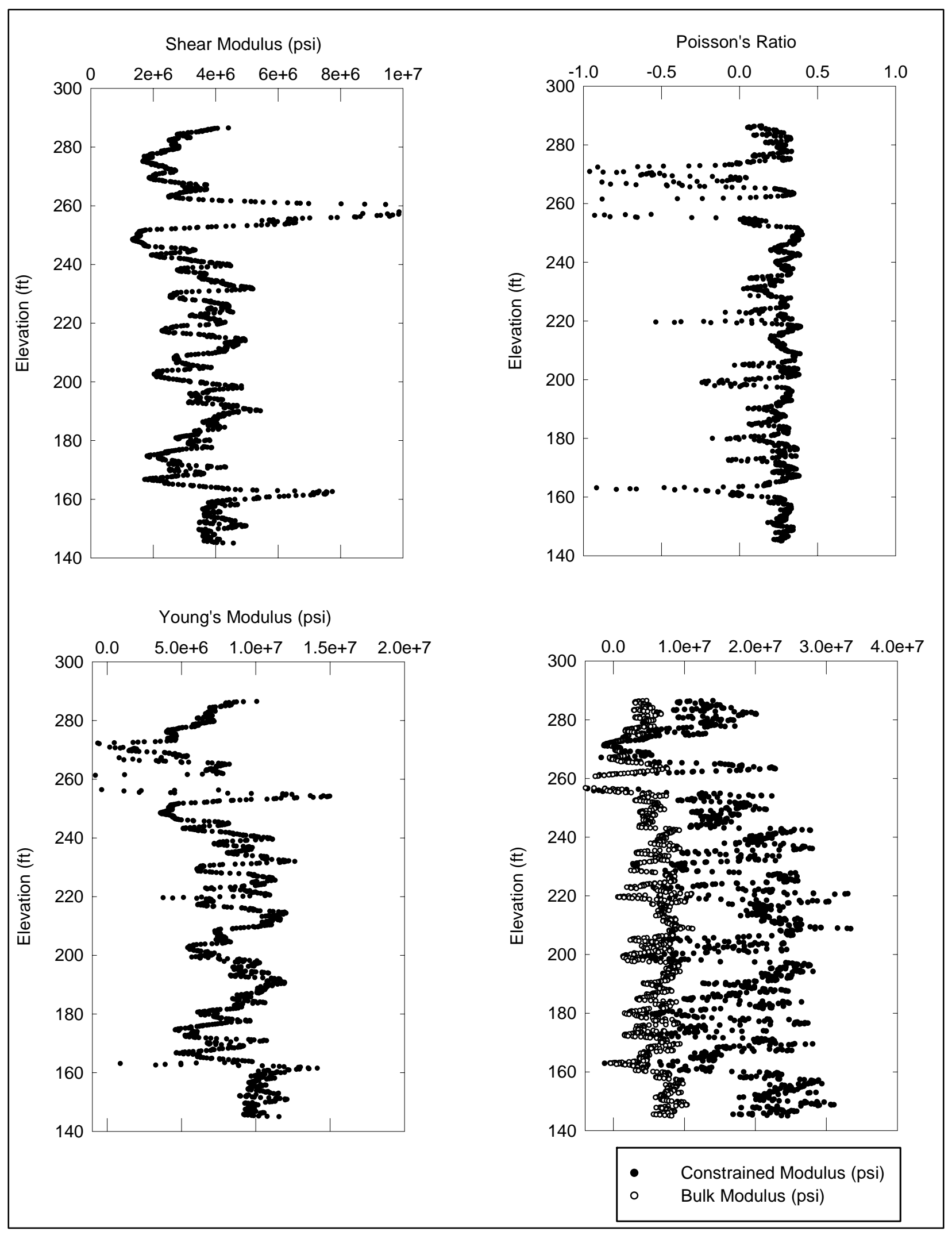

Figure D1. Monolith 2 - Relief Well No. 1 


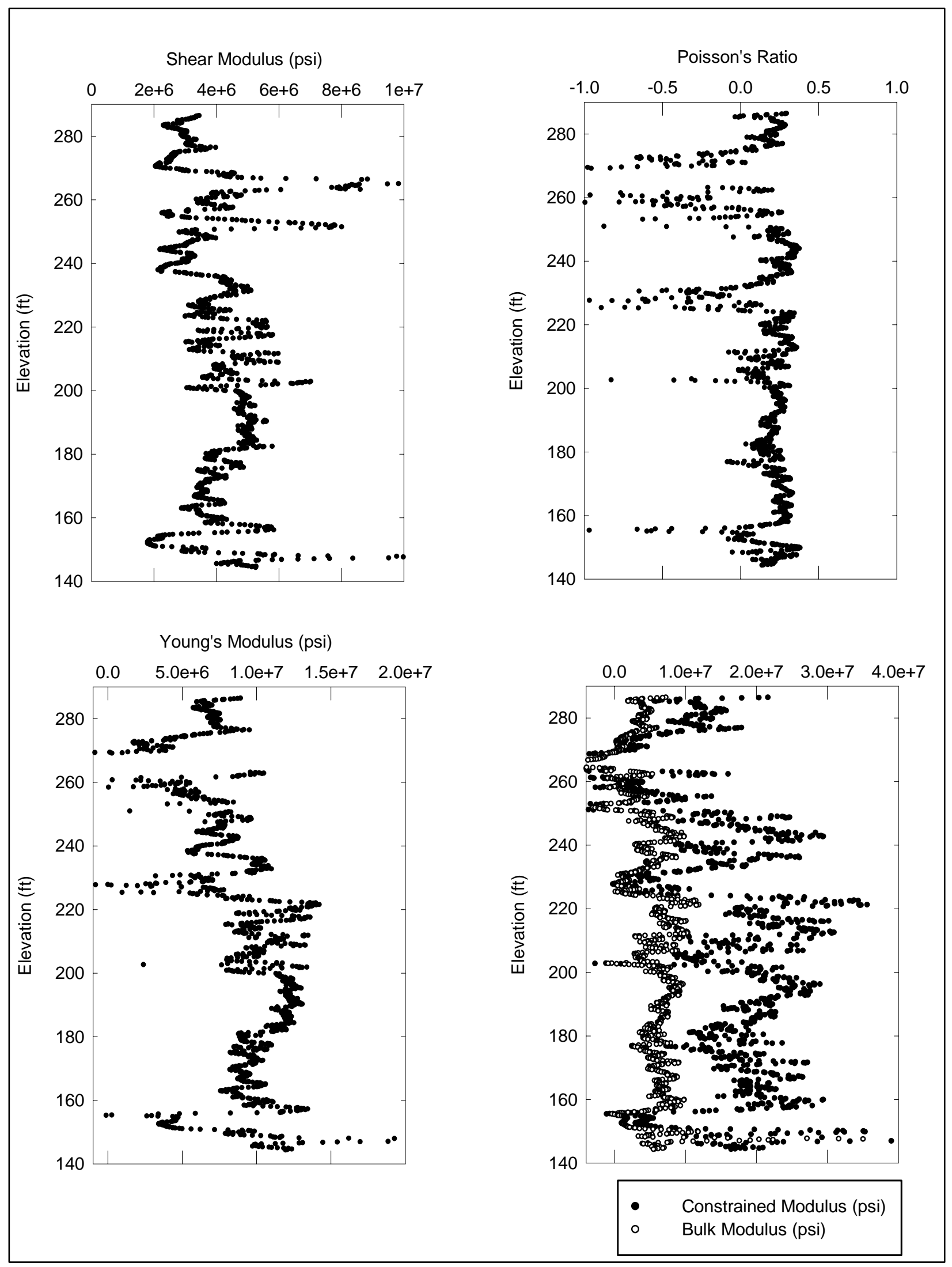

Figure D2. Monolith 2 - Relief Well No. 2 


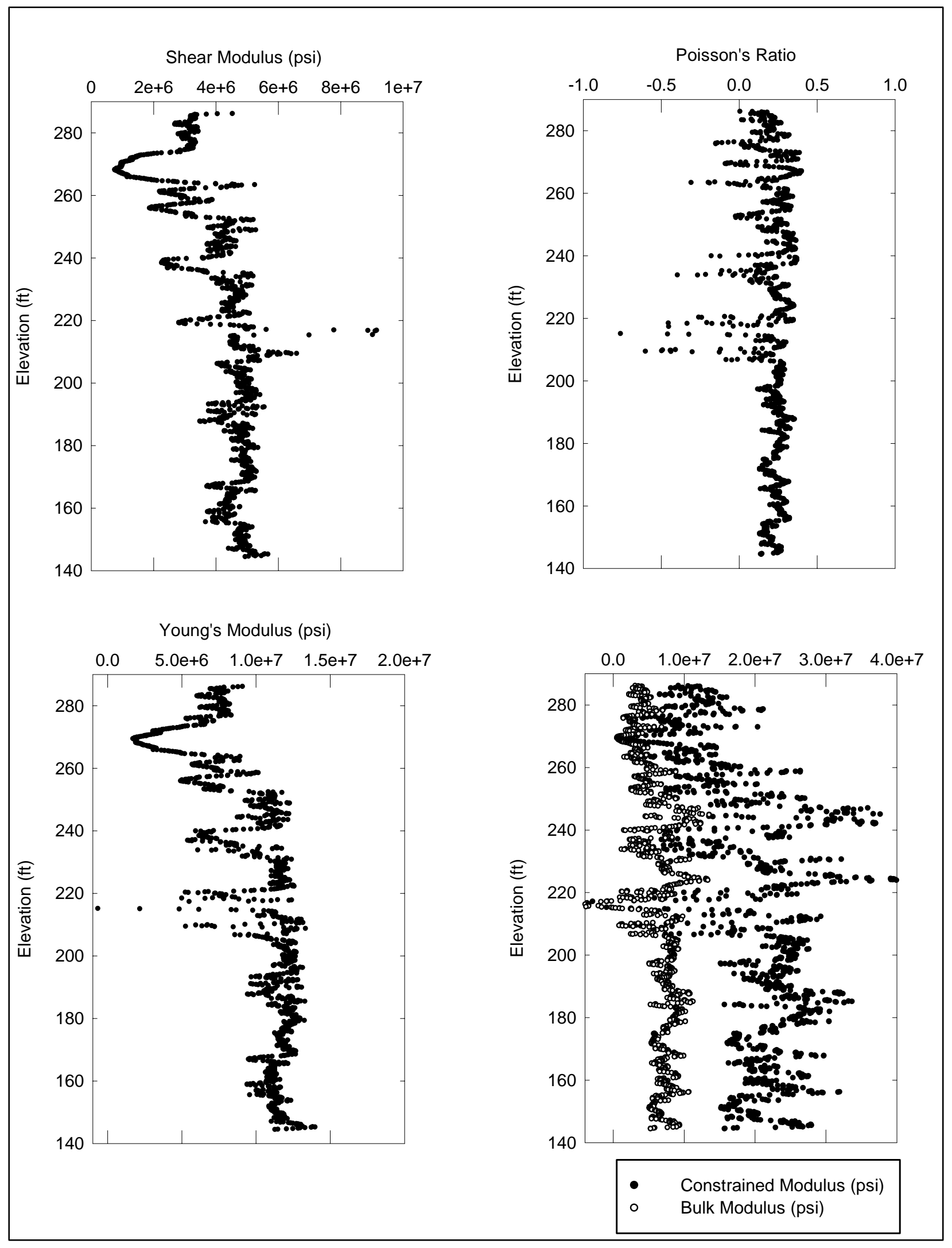

Figure D3. Monolith 2 - Relief Well No. 3 


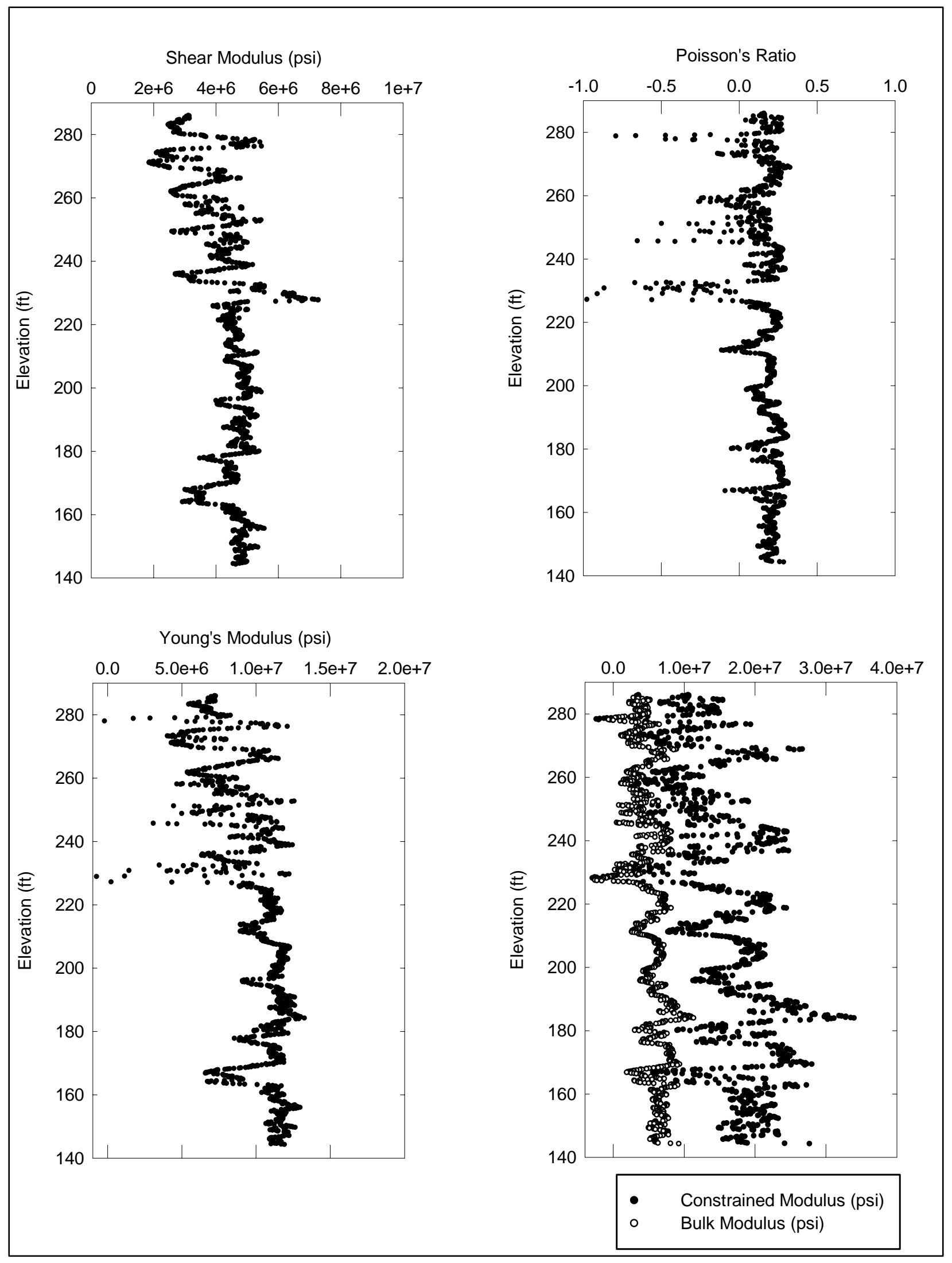

Figure D4. Monolith 2 - Relief Well No. 4 


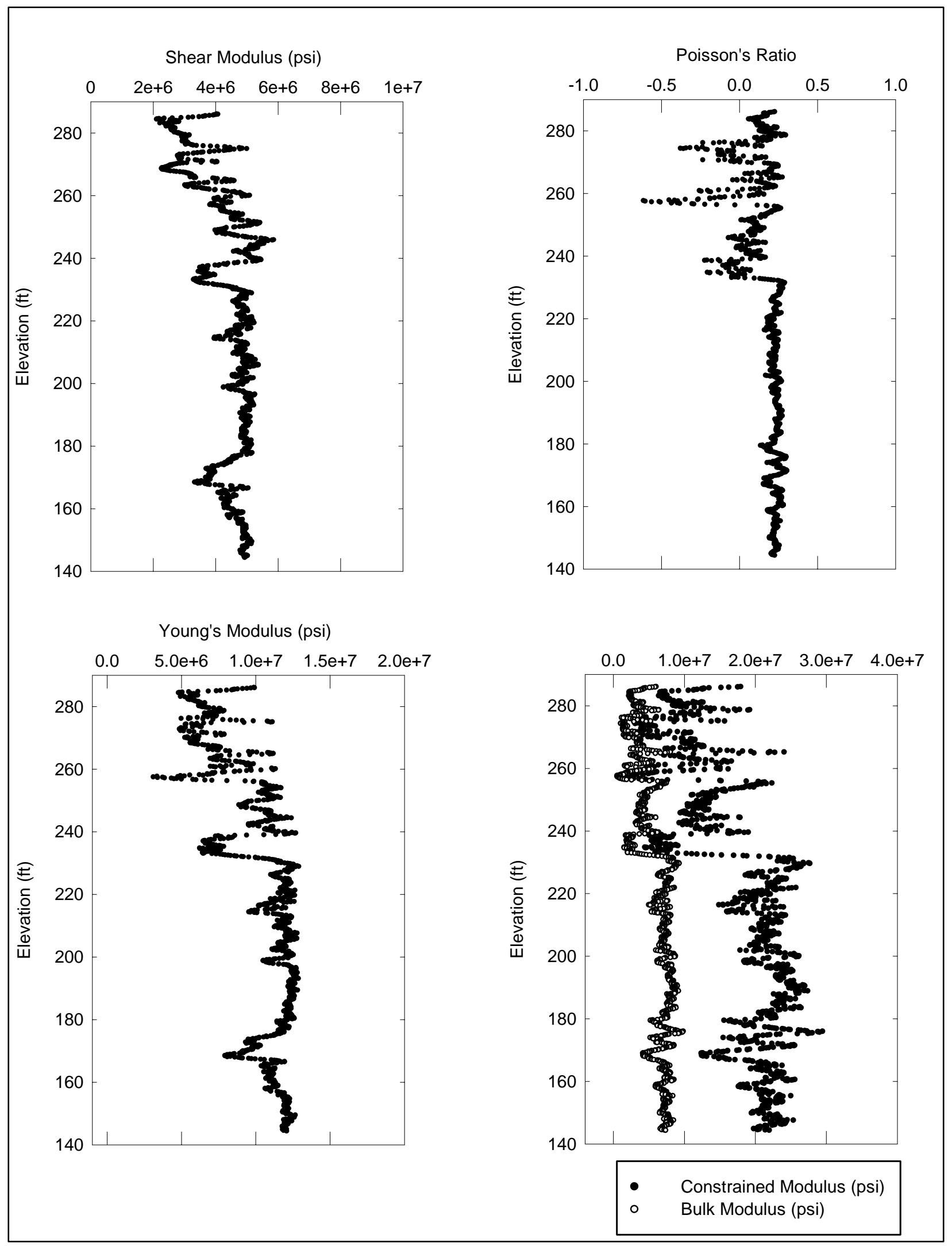

Figure D5. Monolith 2 - Relief Well No. 5 


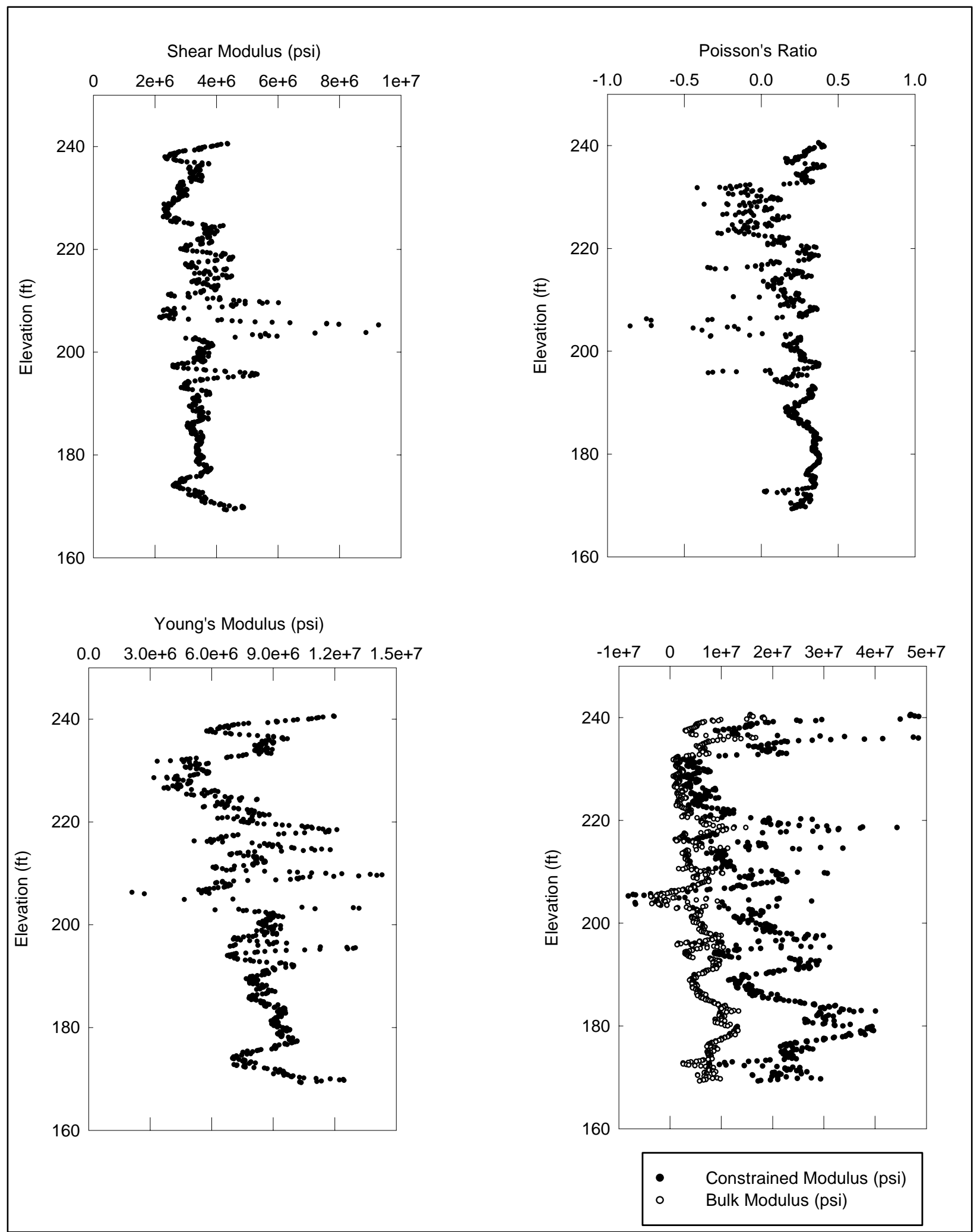

Figure D6. Monolith 11 - Relief Well No. 1 


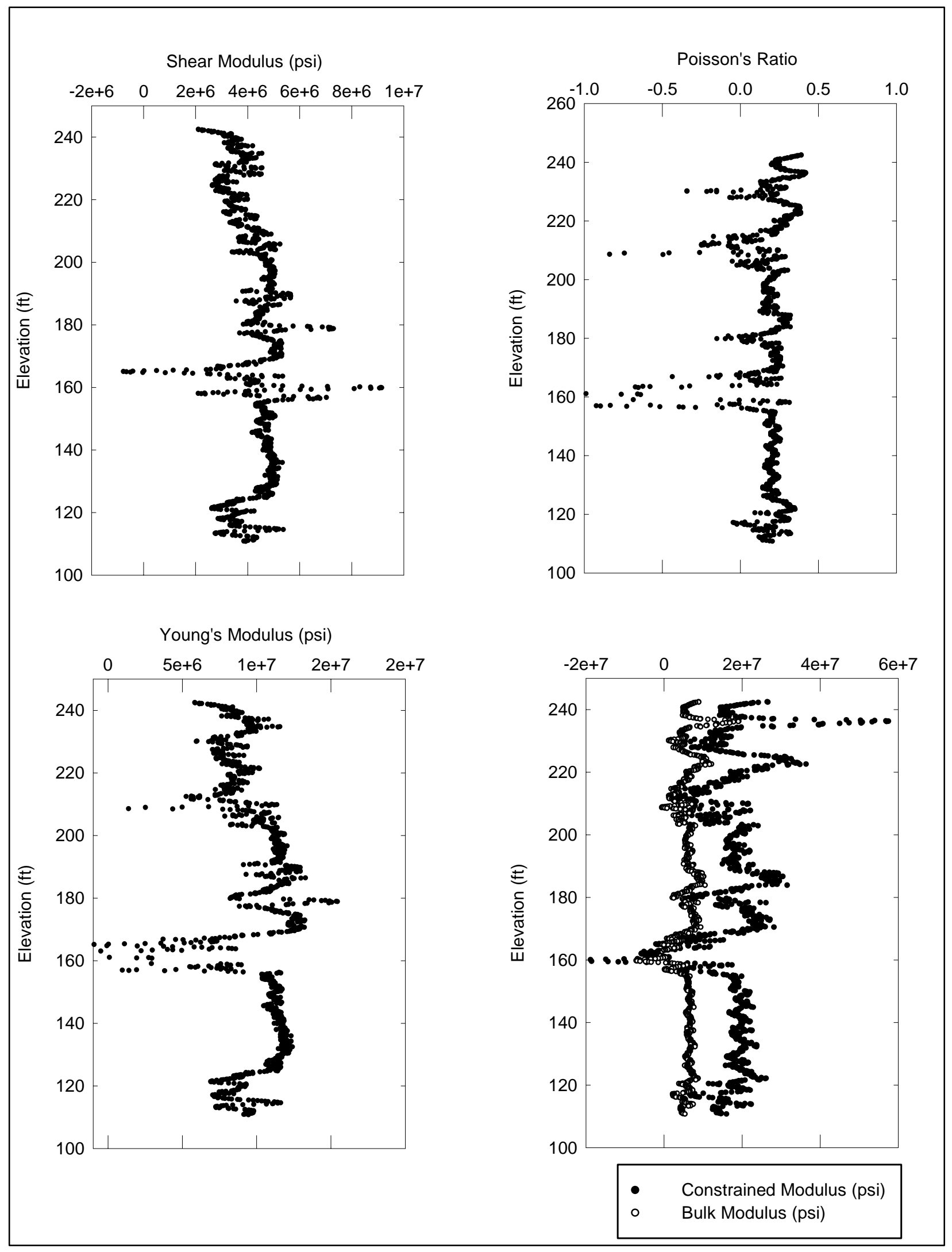

Figure D7. Monolith 11 - Relief Well No. 2 


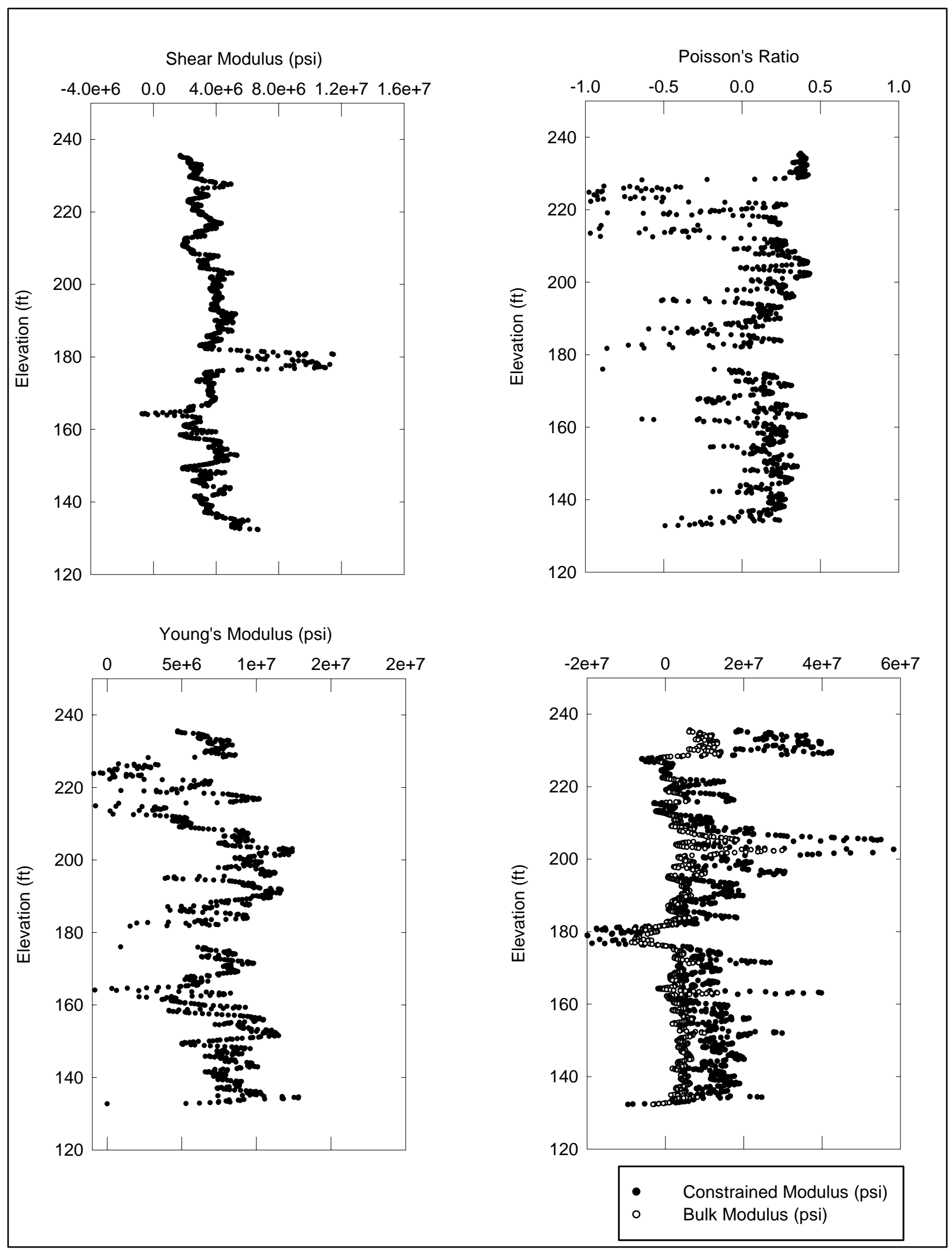

Figure D8. Monolith 11 - Relief Well No. 3 


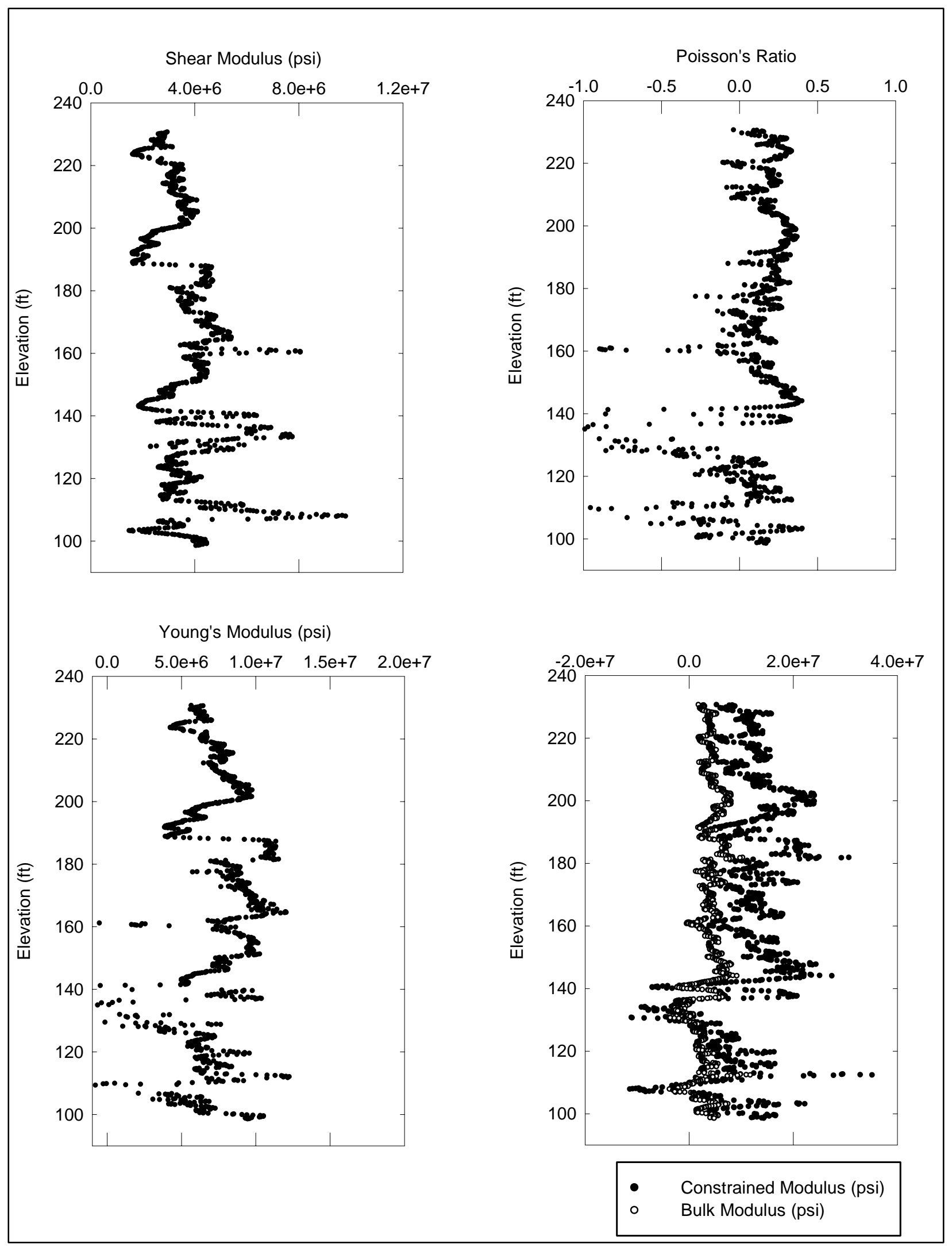

Figure D9. Monolith 11 - Relief Well No. 4 


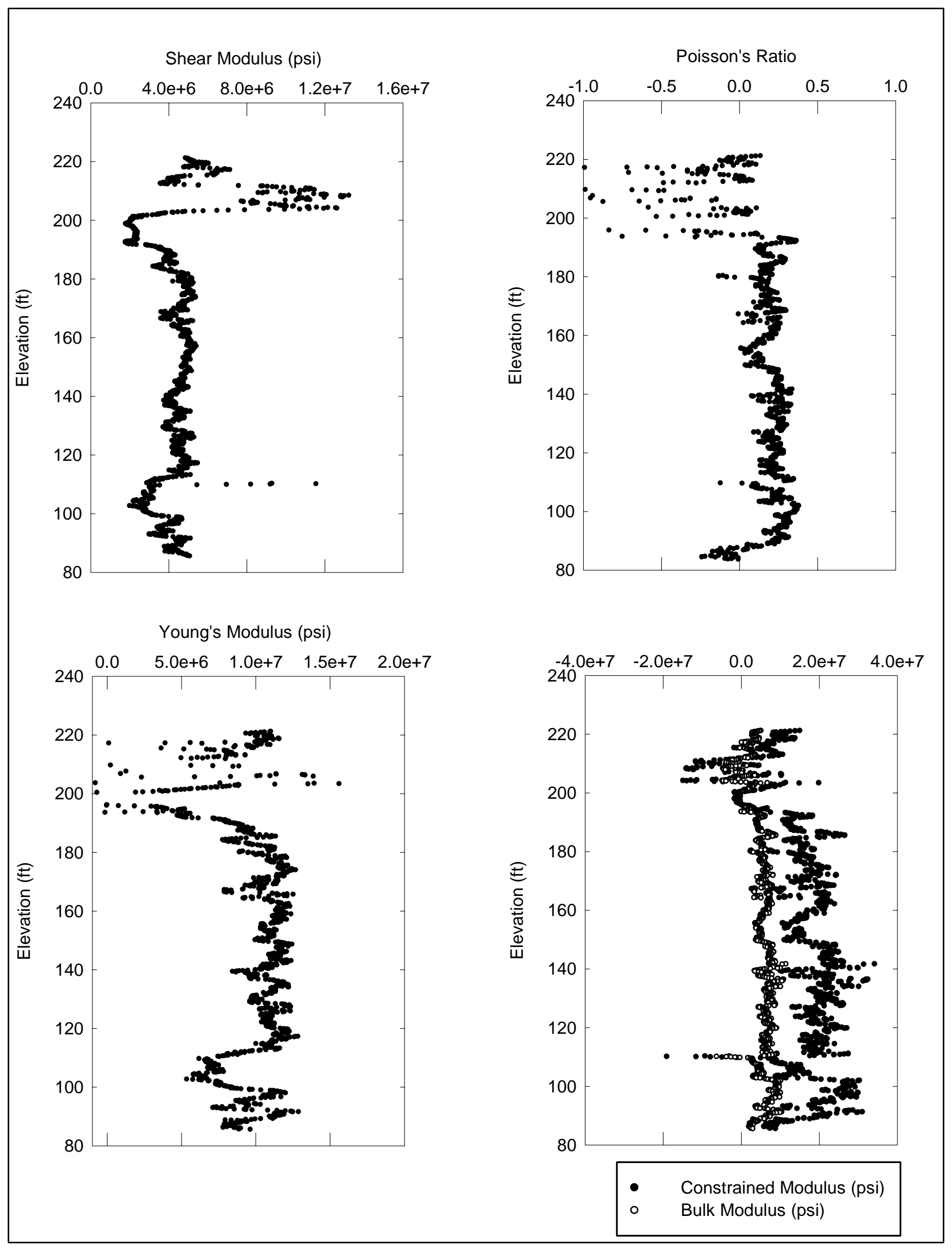

Figure D10. Monolith 11 - Relief Well No. 5 


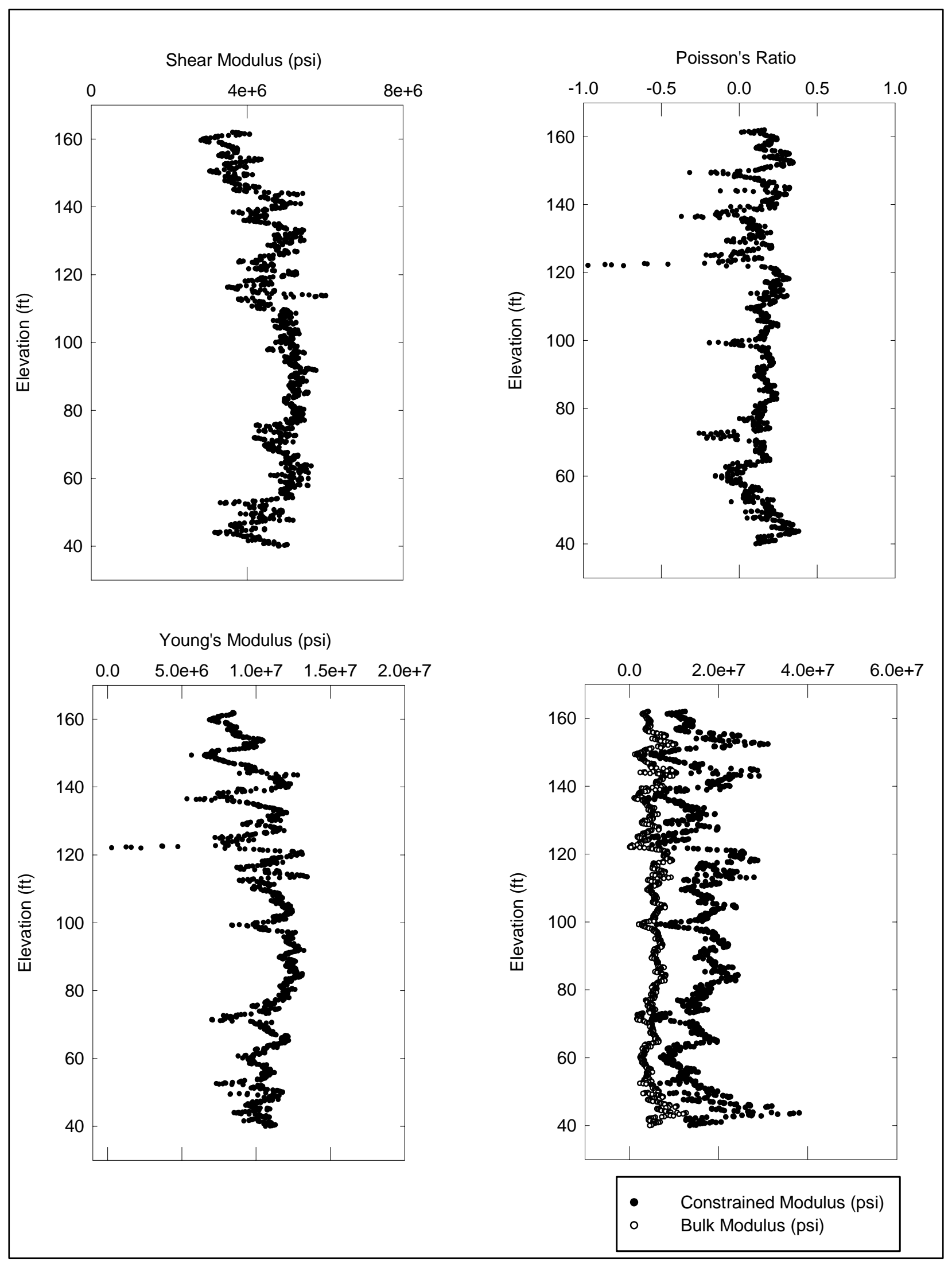

Figure D11. Monolith 14 - Relief Well No. 1 


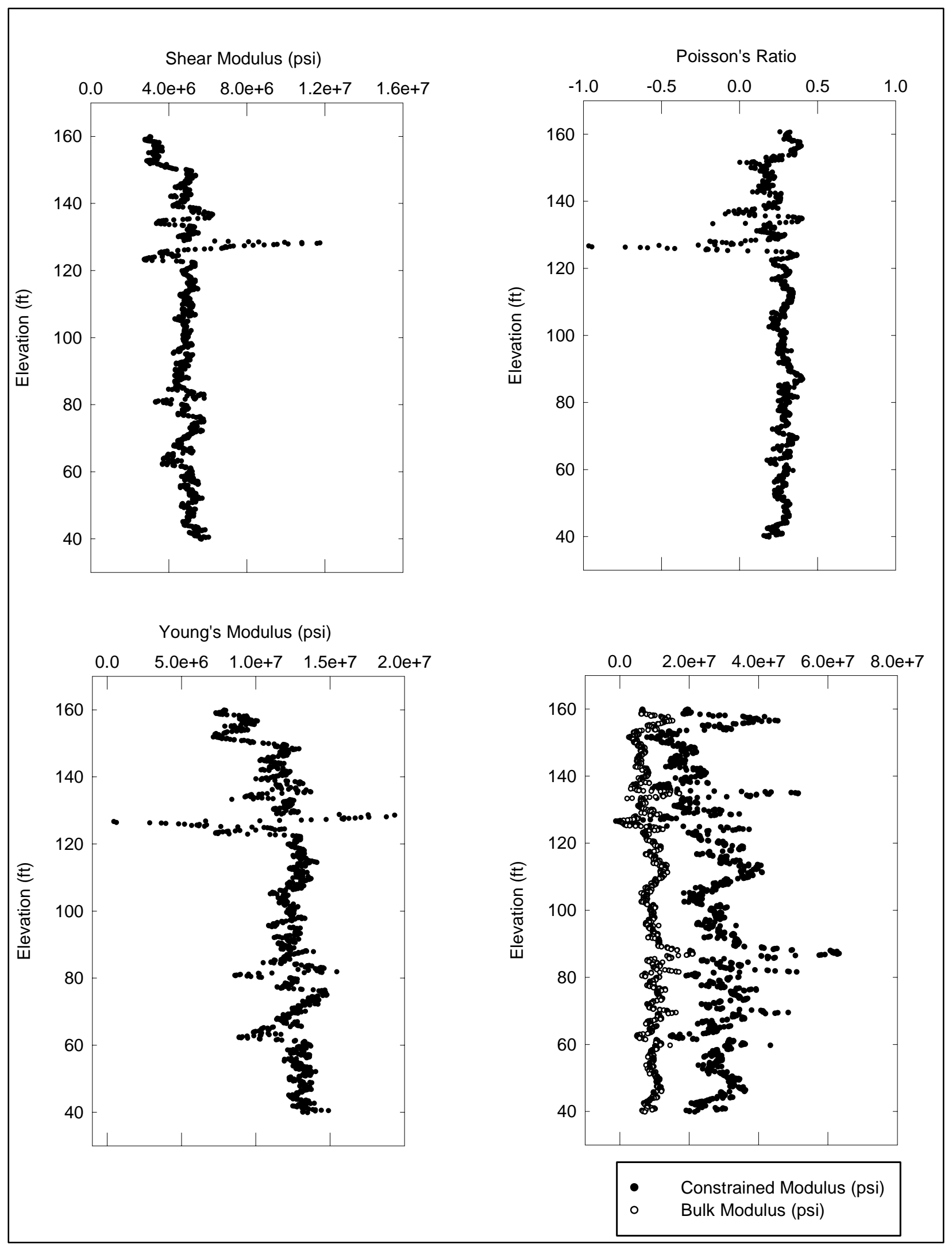

Figure D12. Monolith 14 - Relief Well No. 2 


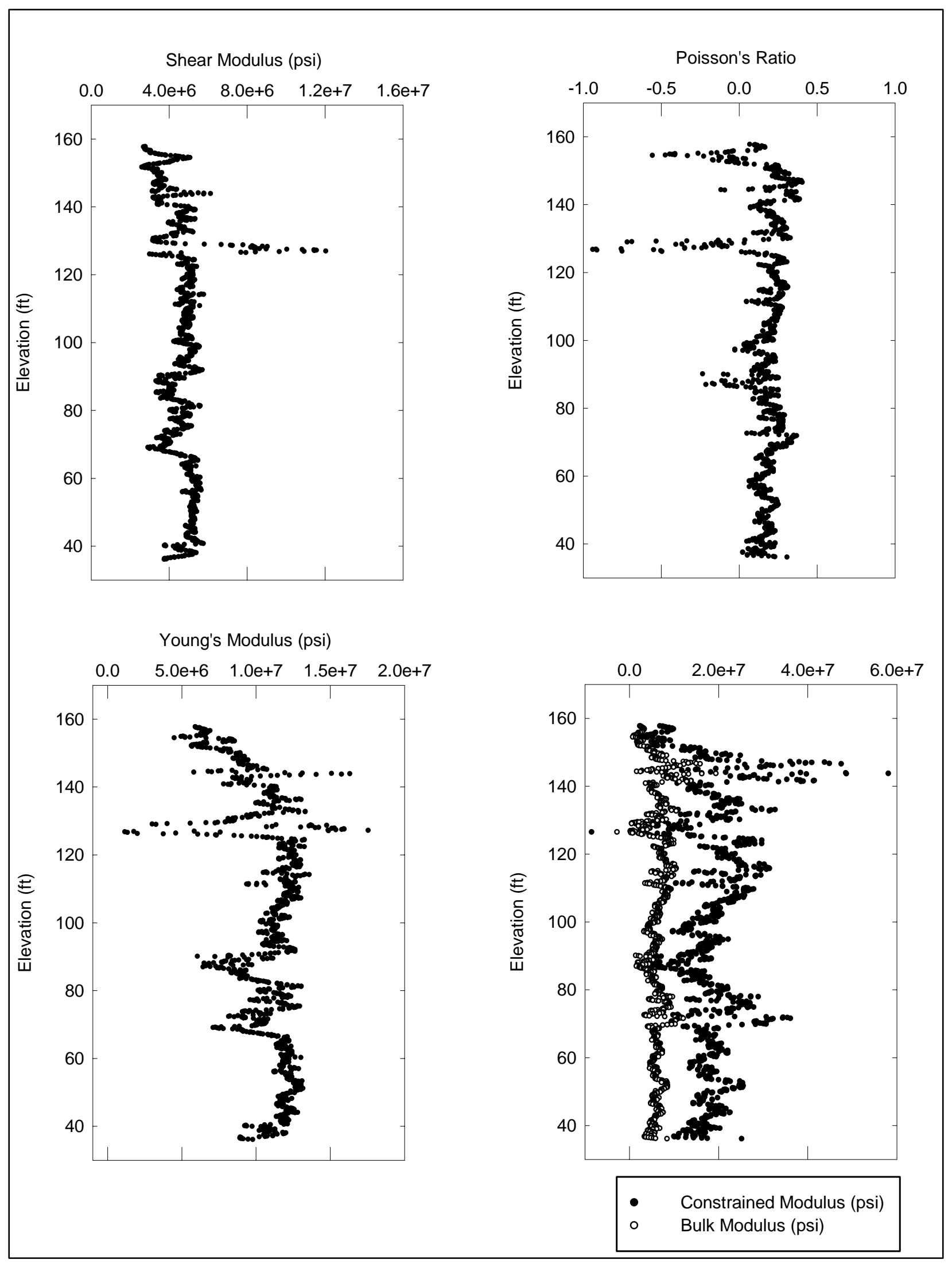

Figure D13. Monolith 14 - Relief Well No. 3 


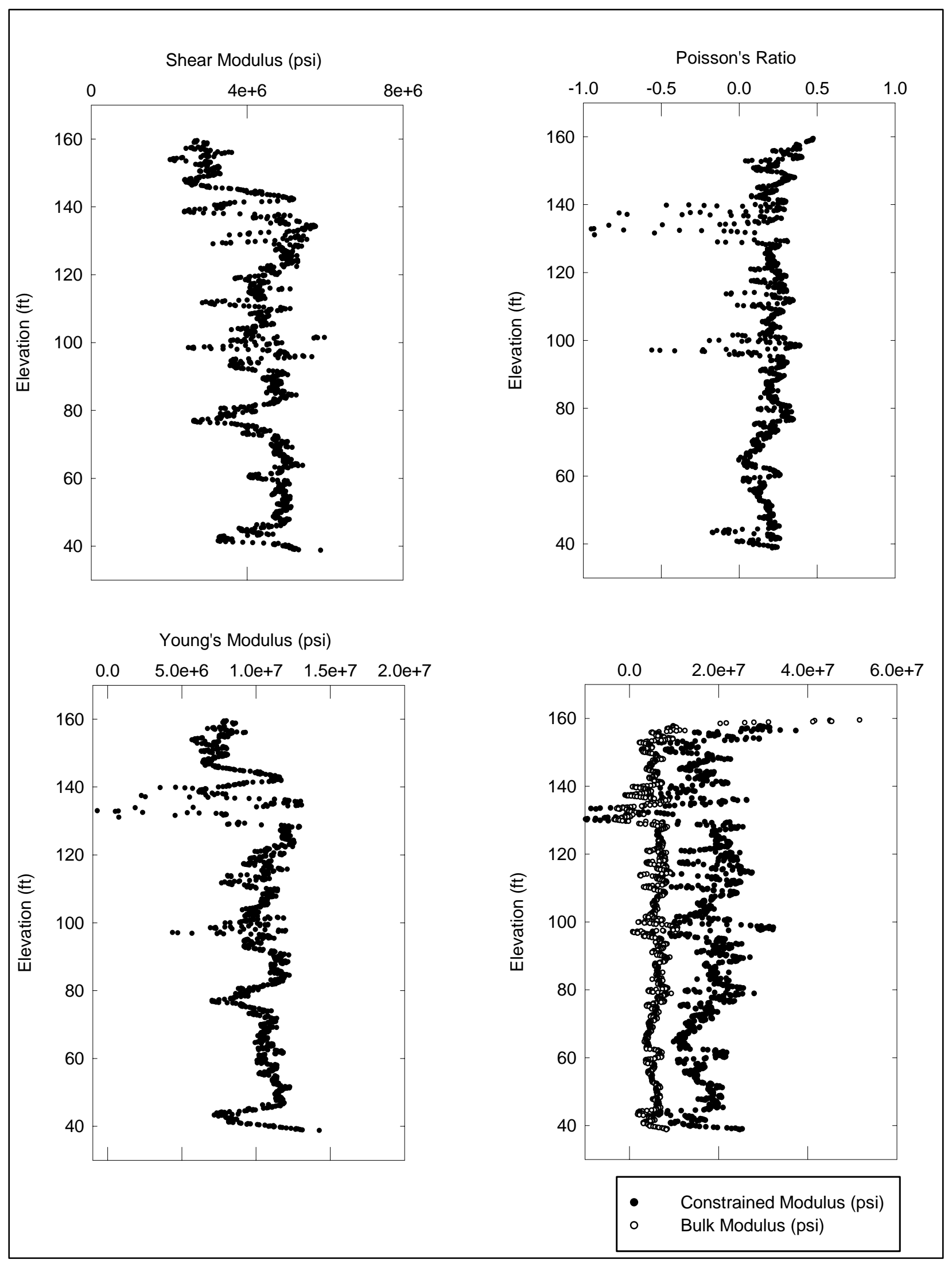

Figure D14. Monolith 14 - Relief Well No. 4 


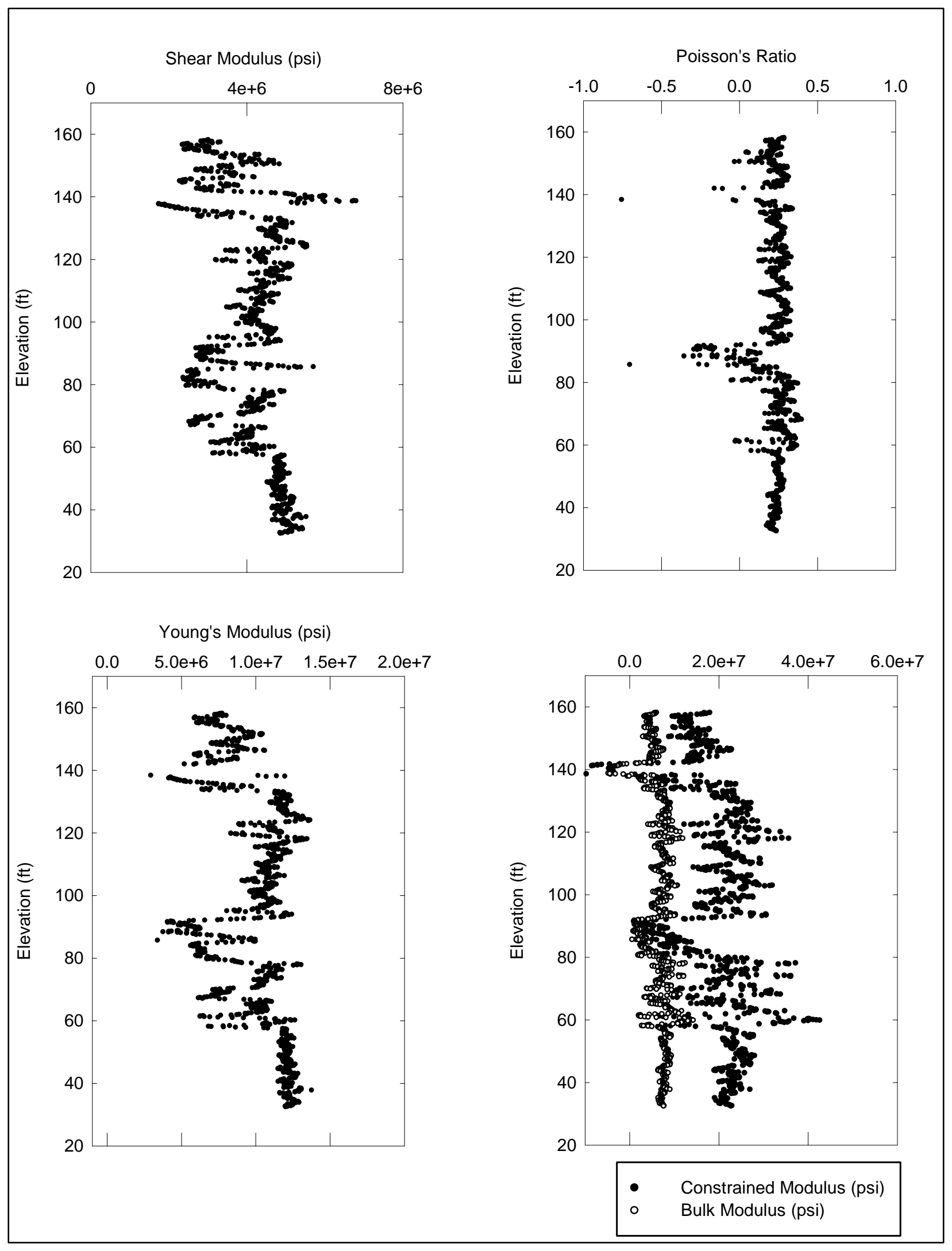

Figure D15. Monolith 15 - Relief Well No. 1 


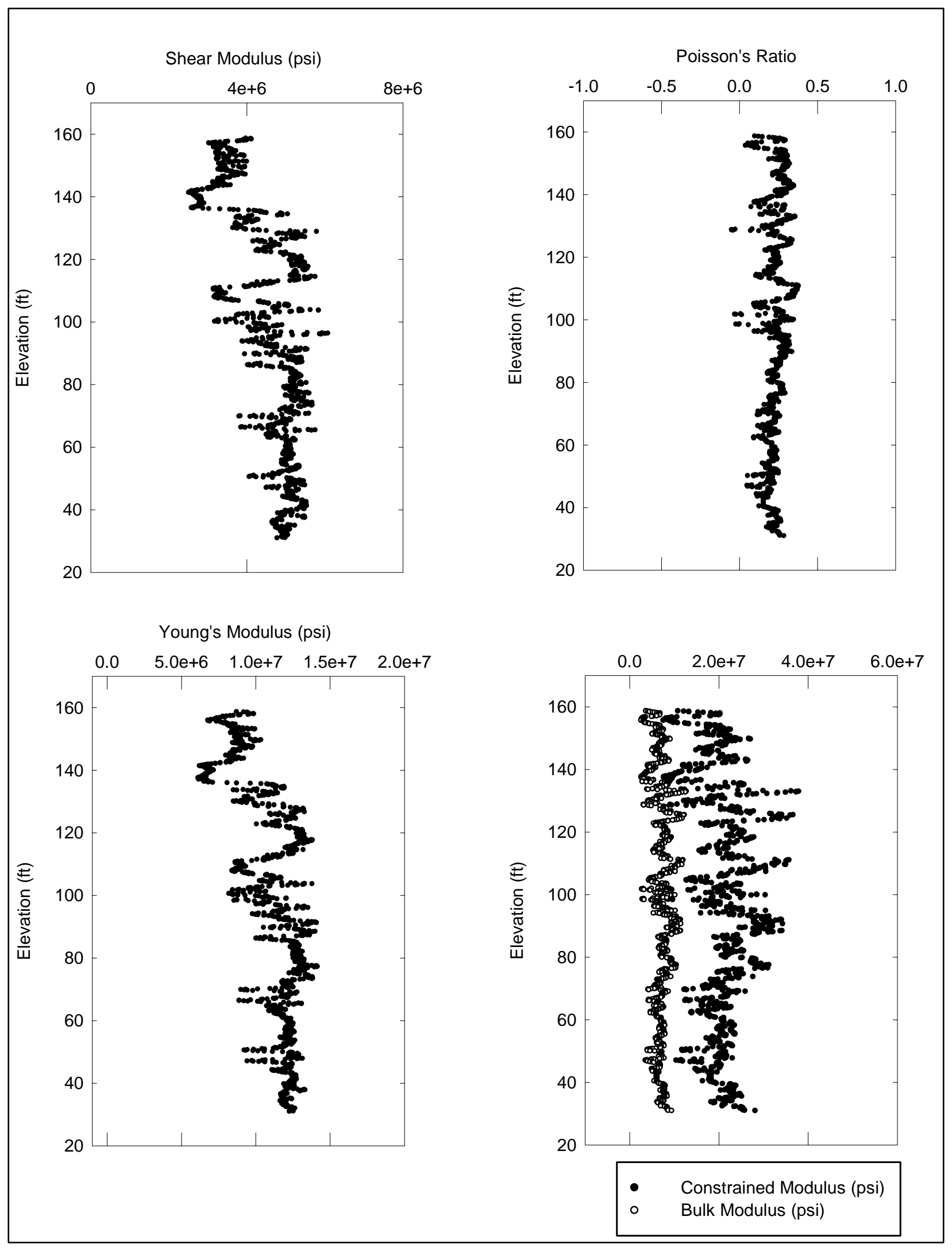

Figure D16. Monolith 15 - Relief Well No. 2 


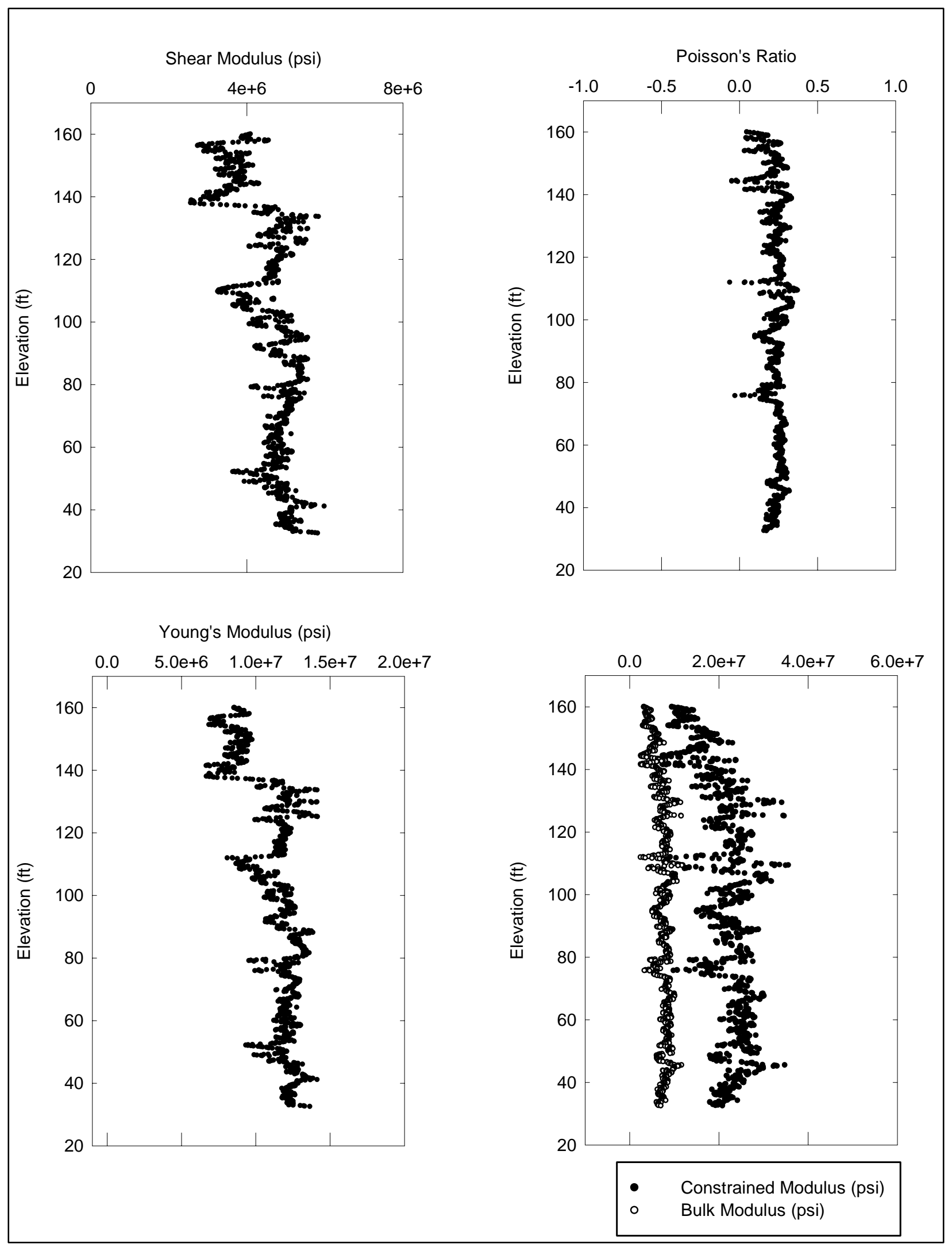

Figure D17. Monolith 15 - Relief Well No. 3 


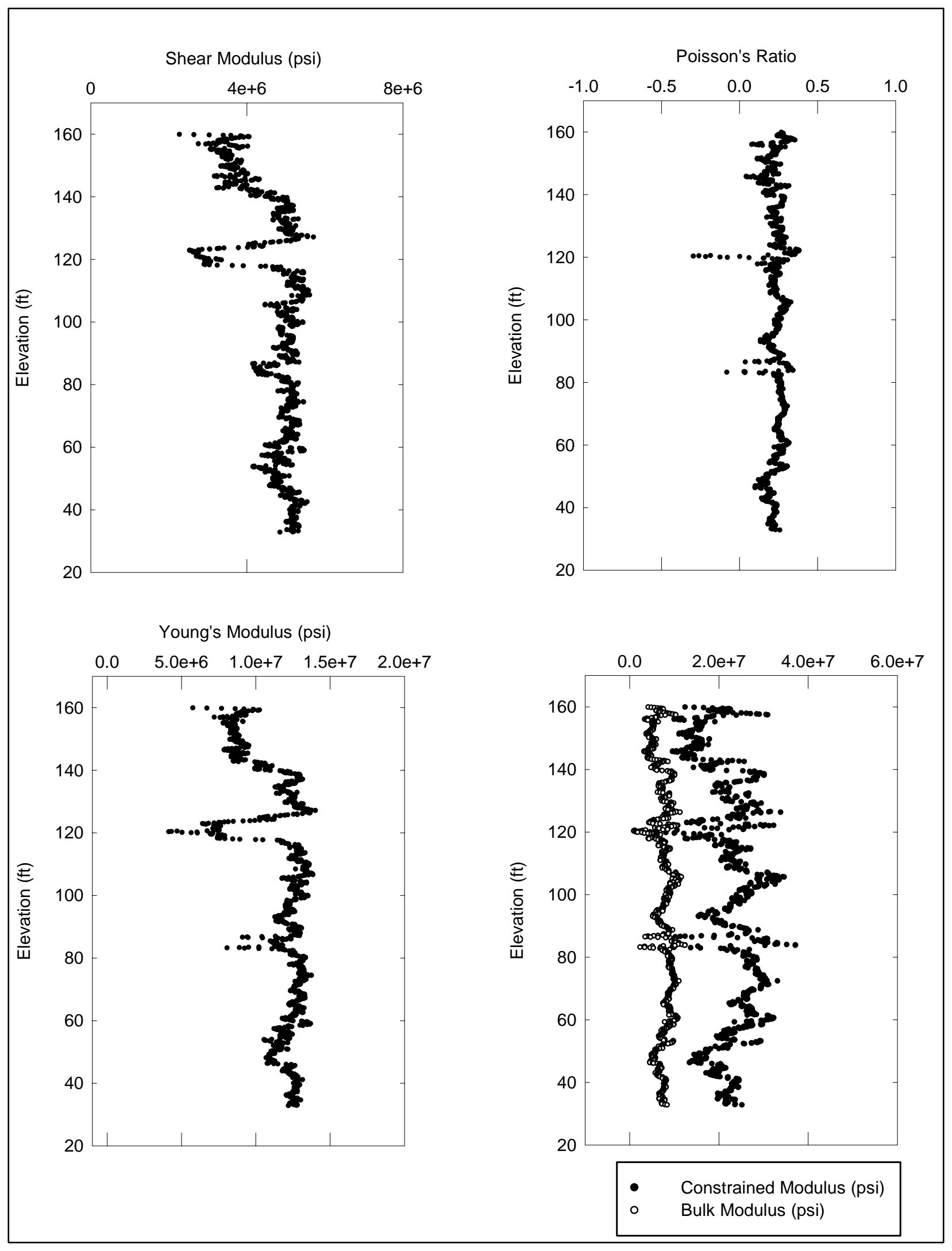

Figure D18. Monolith 15 - Relief Well No. 4 


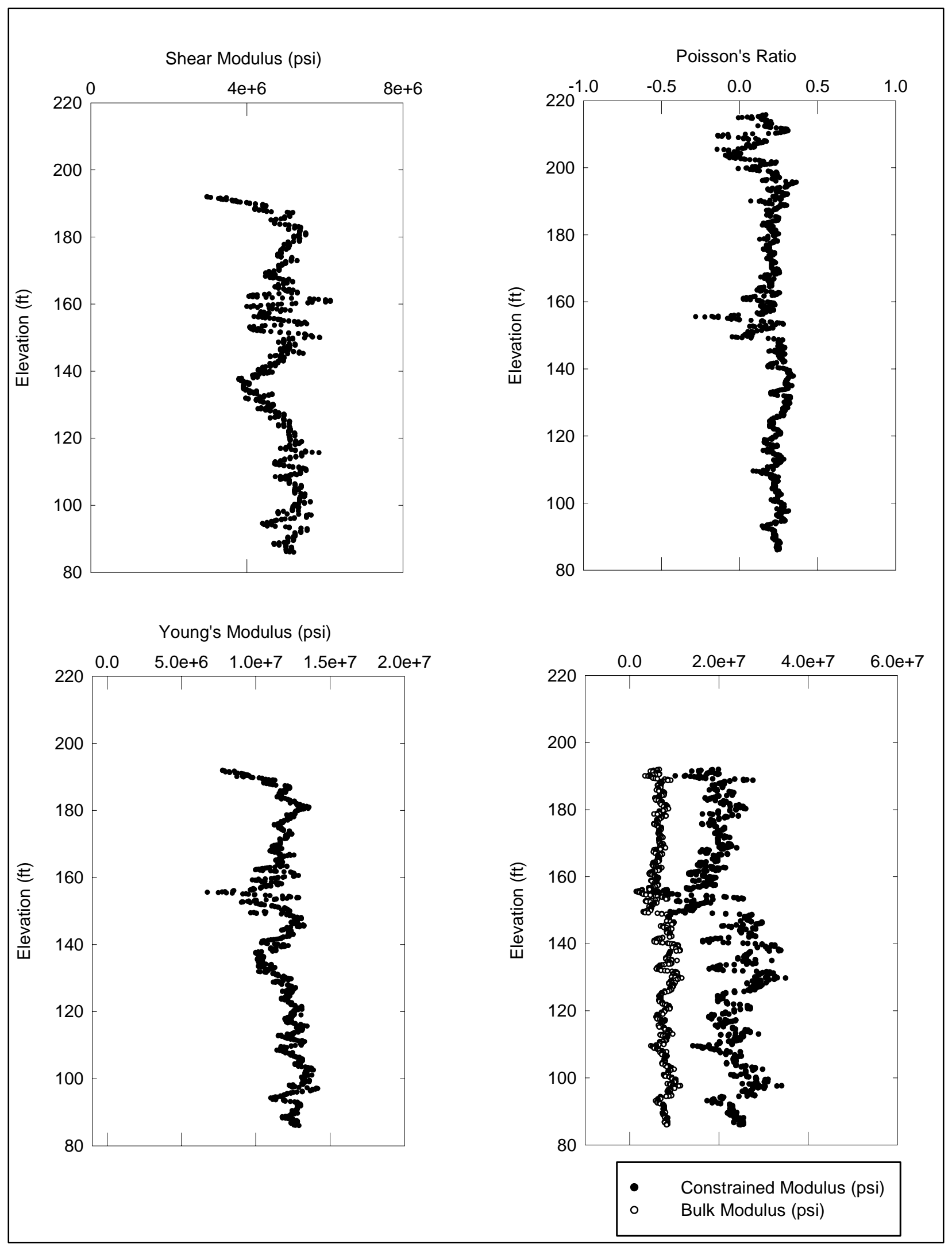

Figure D19. Monolith 21 - Relief Well No. 1 


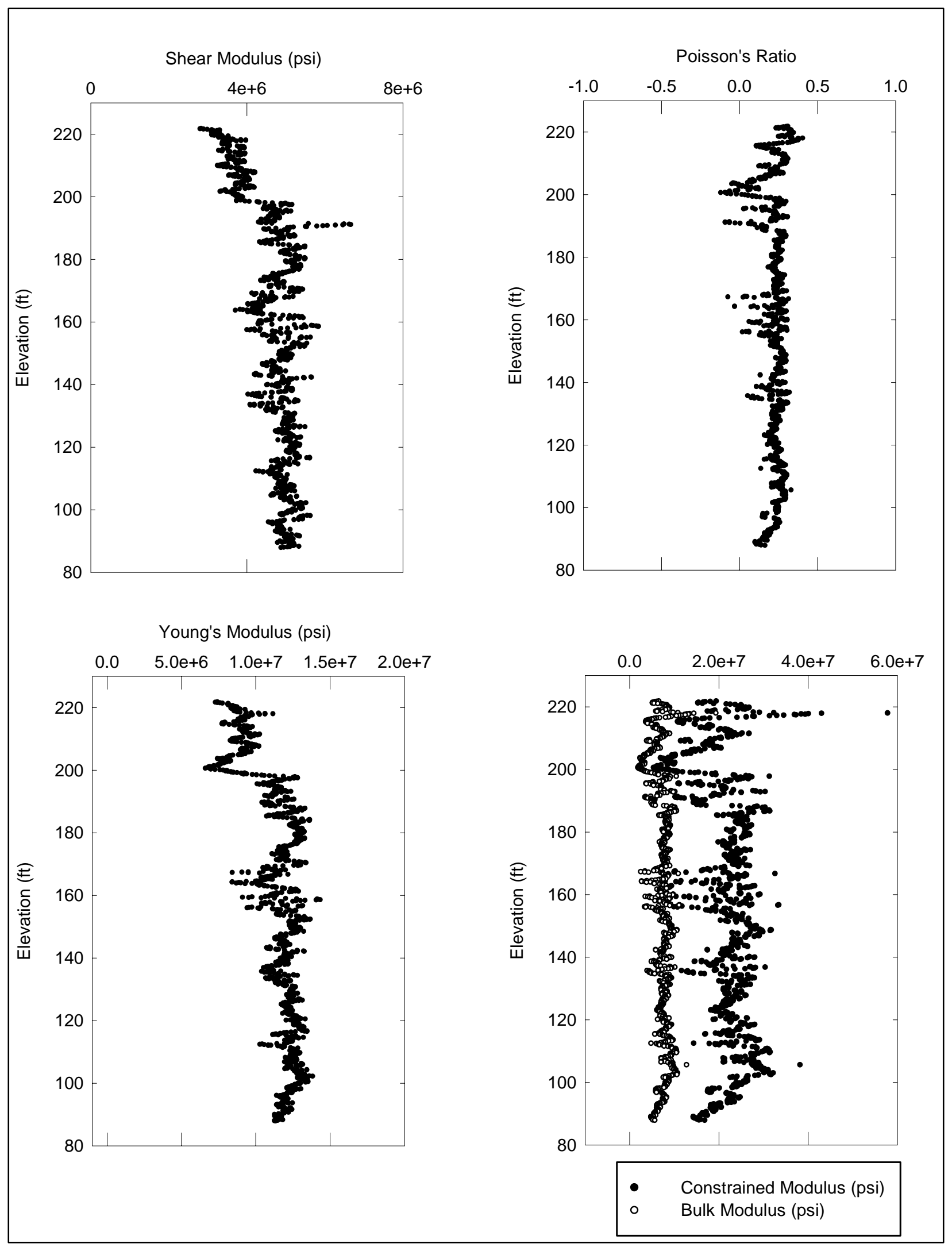

Figure D20. Monolith 21 - Relief Well No. 2 


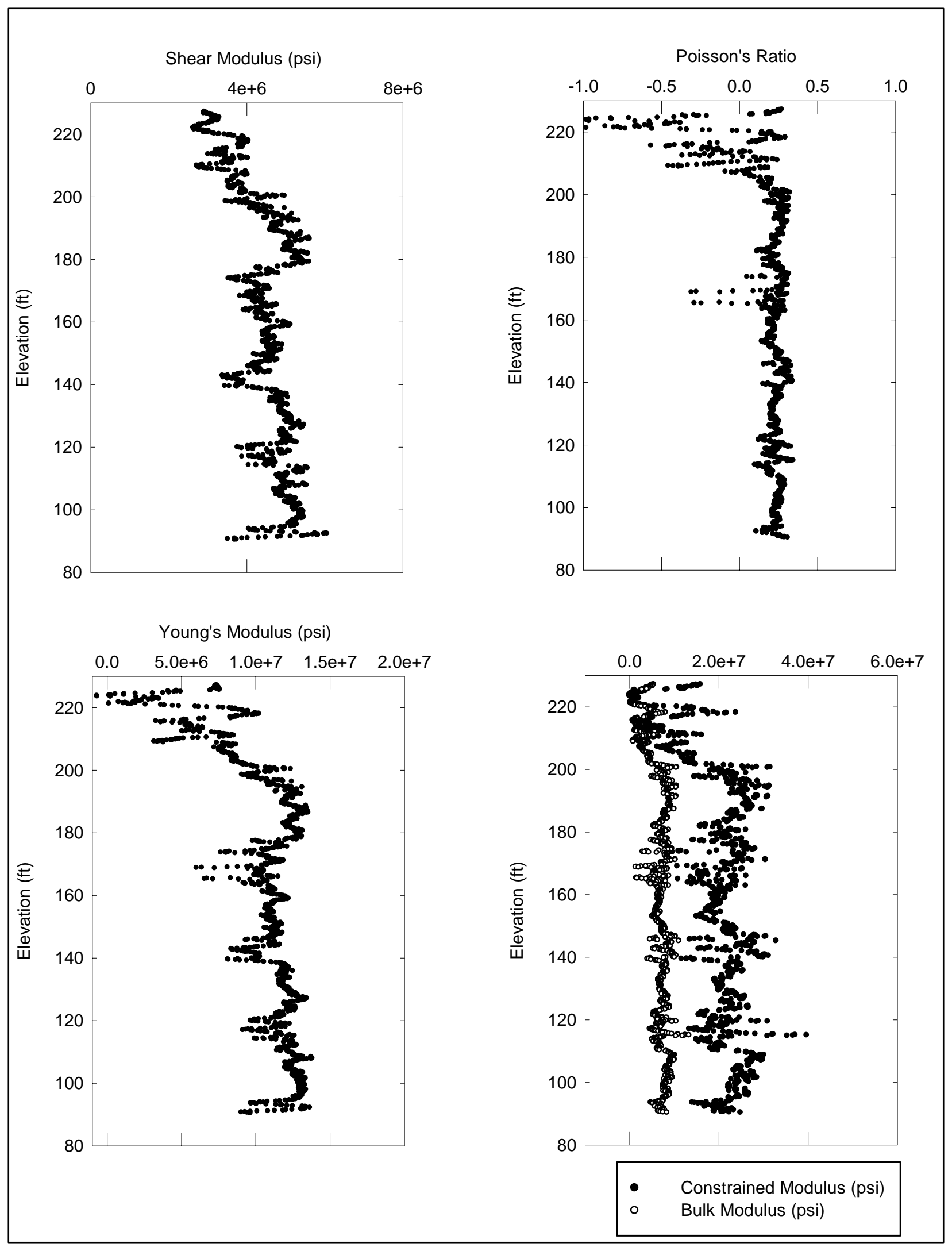

Figure D21. Monolith 21 - Relief Well No. 3 


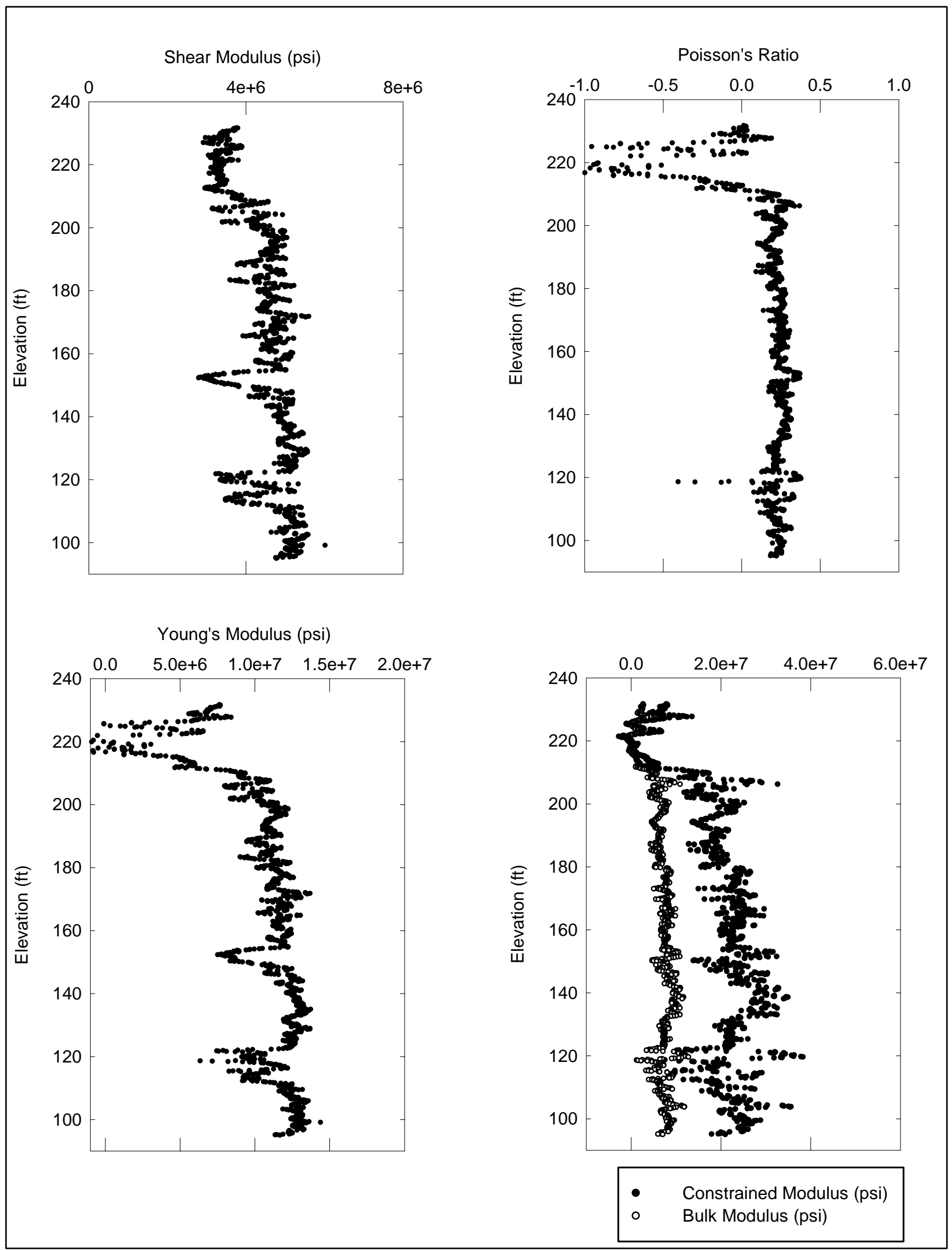

Figure D22. Monolith 21 - Relief Well No. 4 


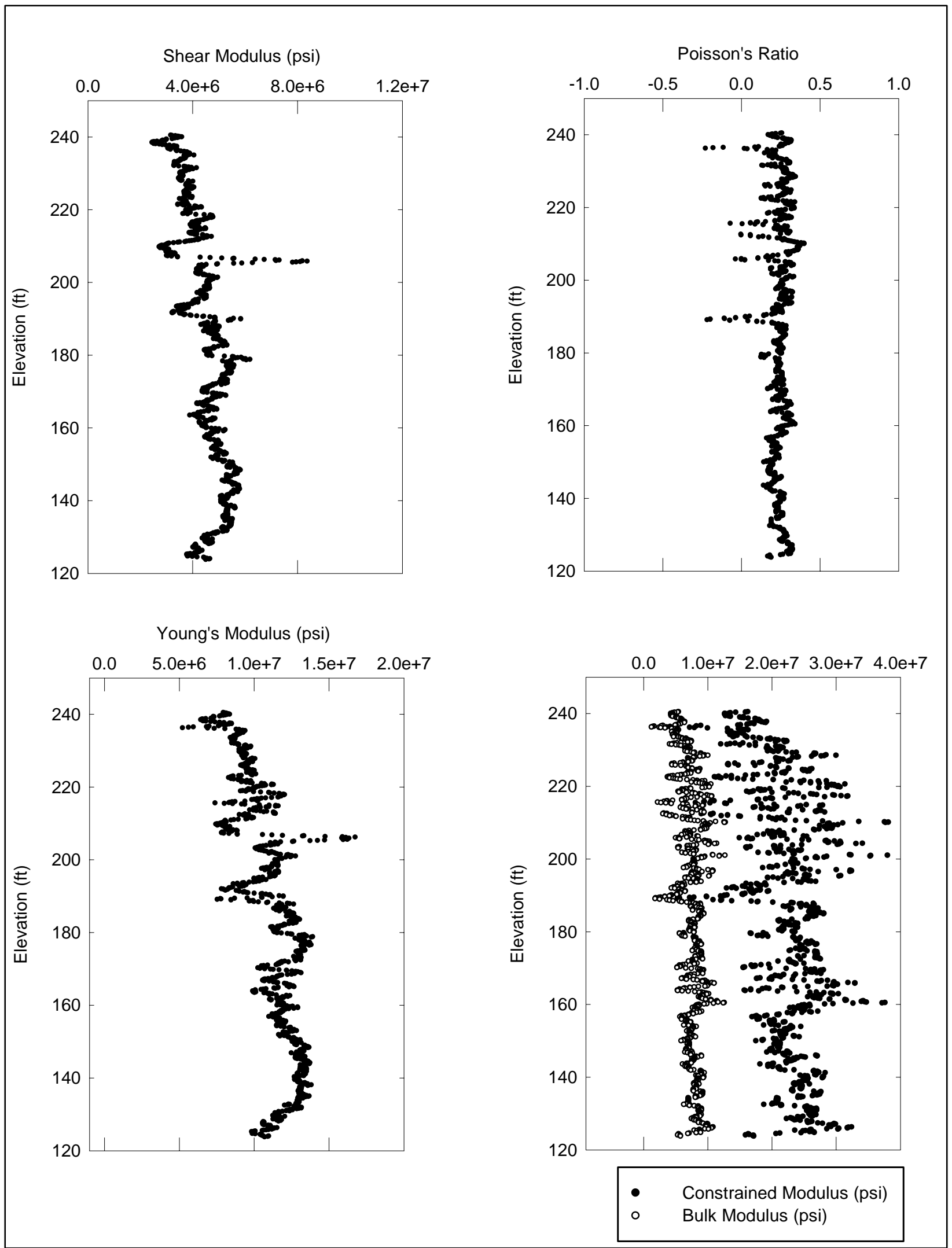

Figure D23. Monolith 22 - Relief Well No. 2 


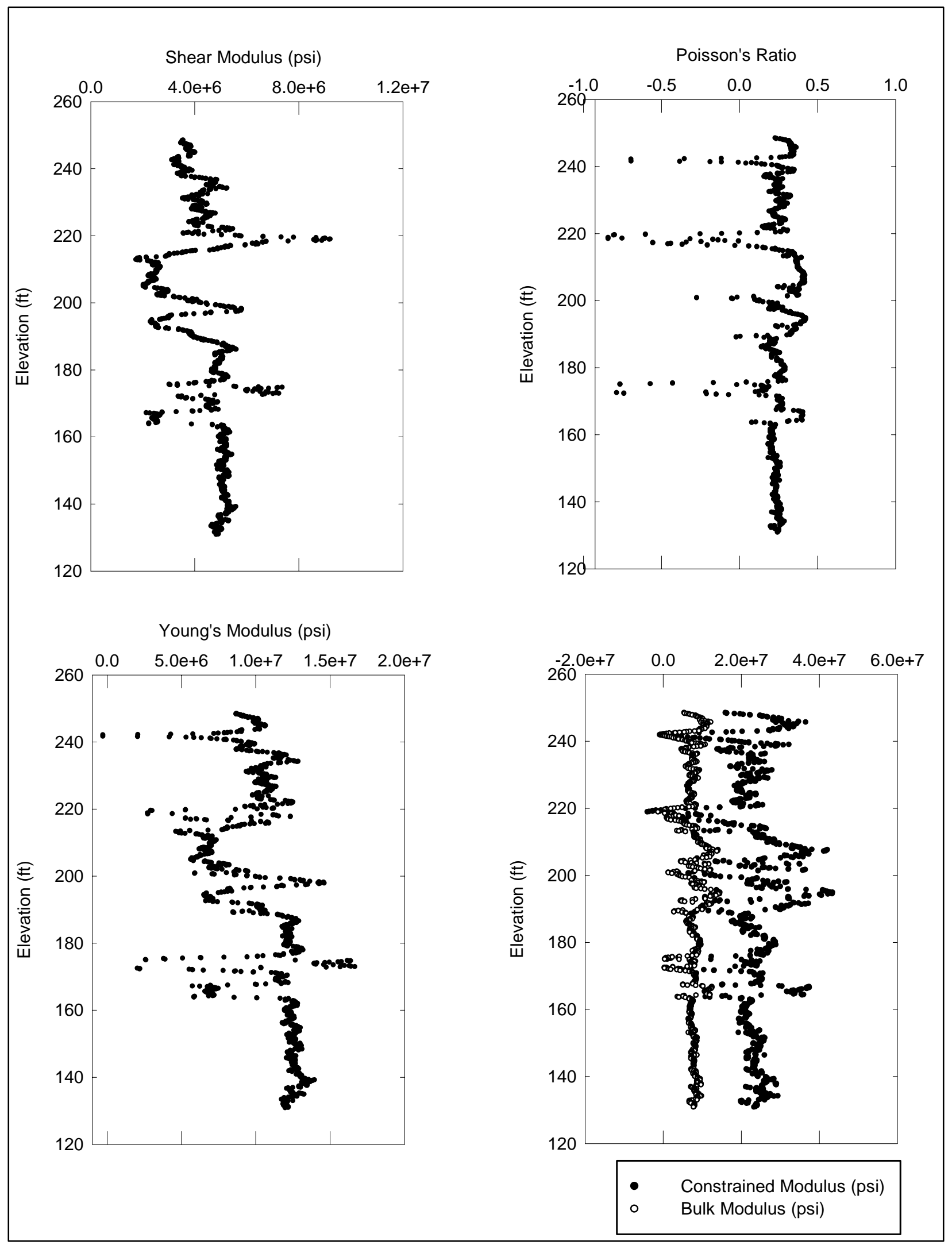

Figure D24. Monolith 22 - Relief Well No. 3 


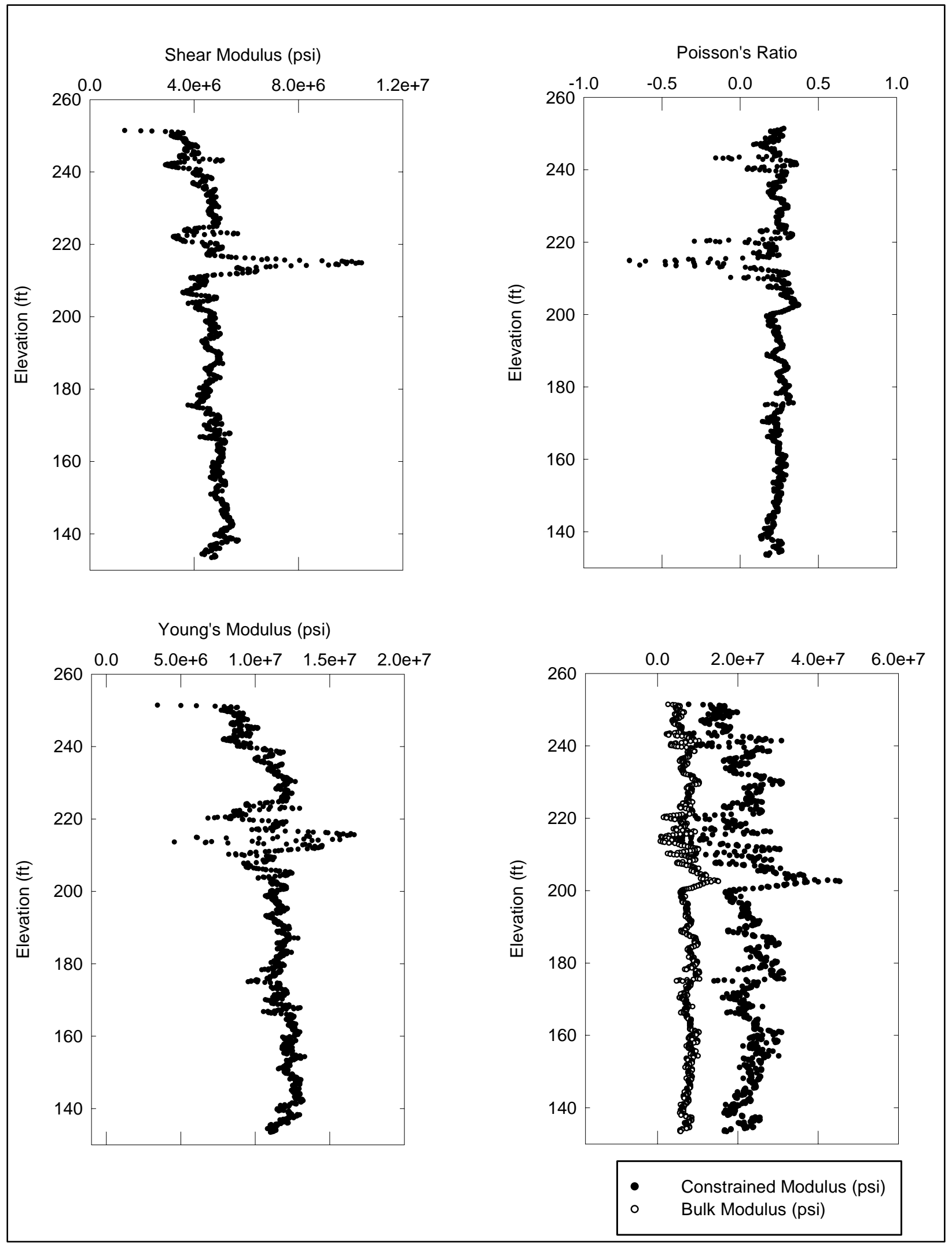

Figure D25. Monolith 22 - Relief Well No. 4 


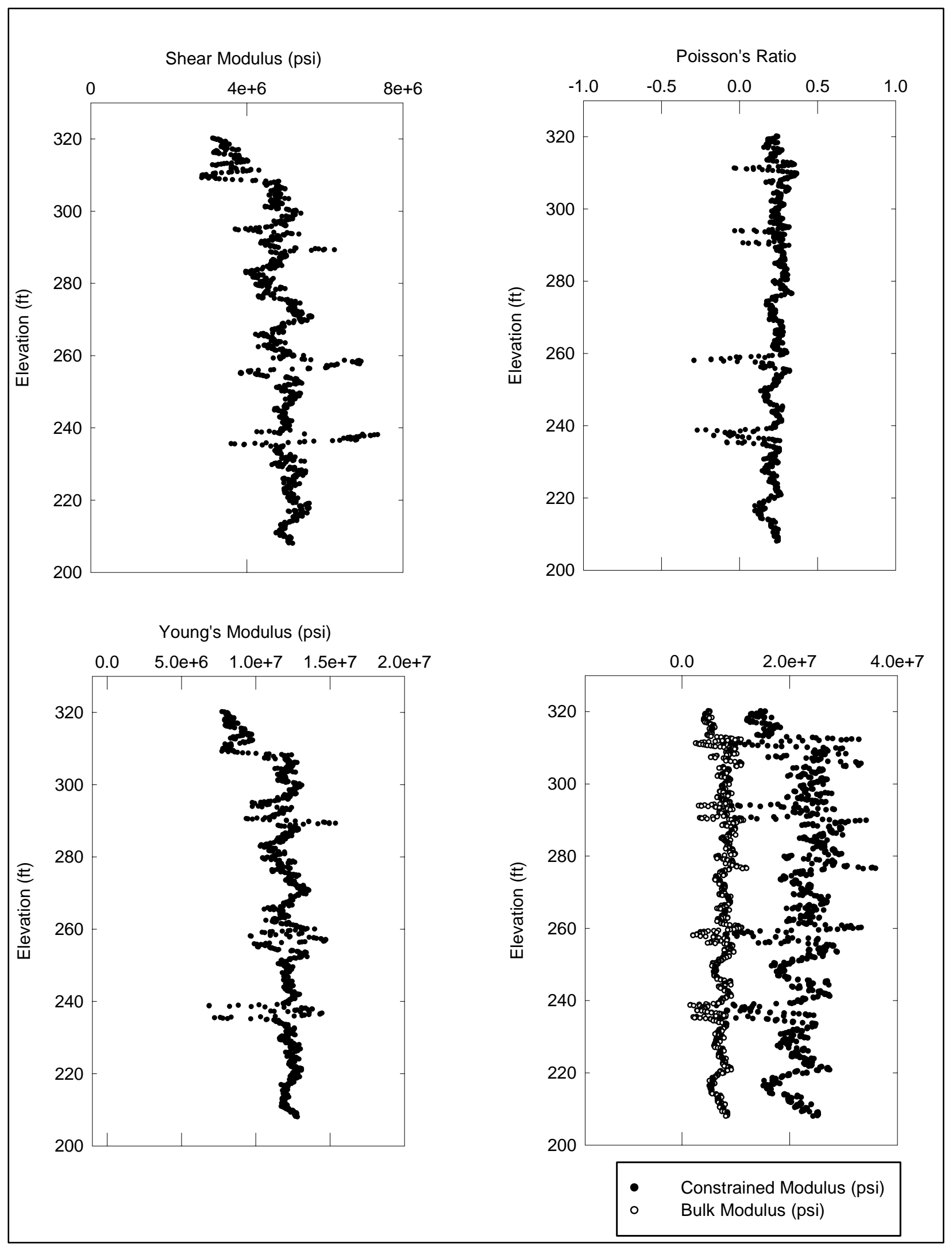

Figure D26. Monolith 27 - Relief Well No. 1 


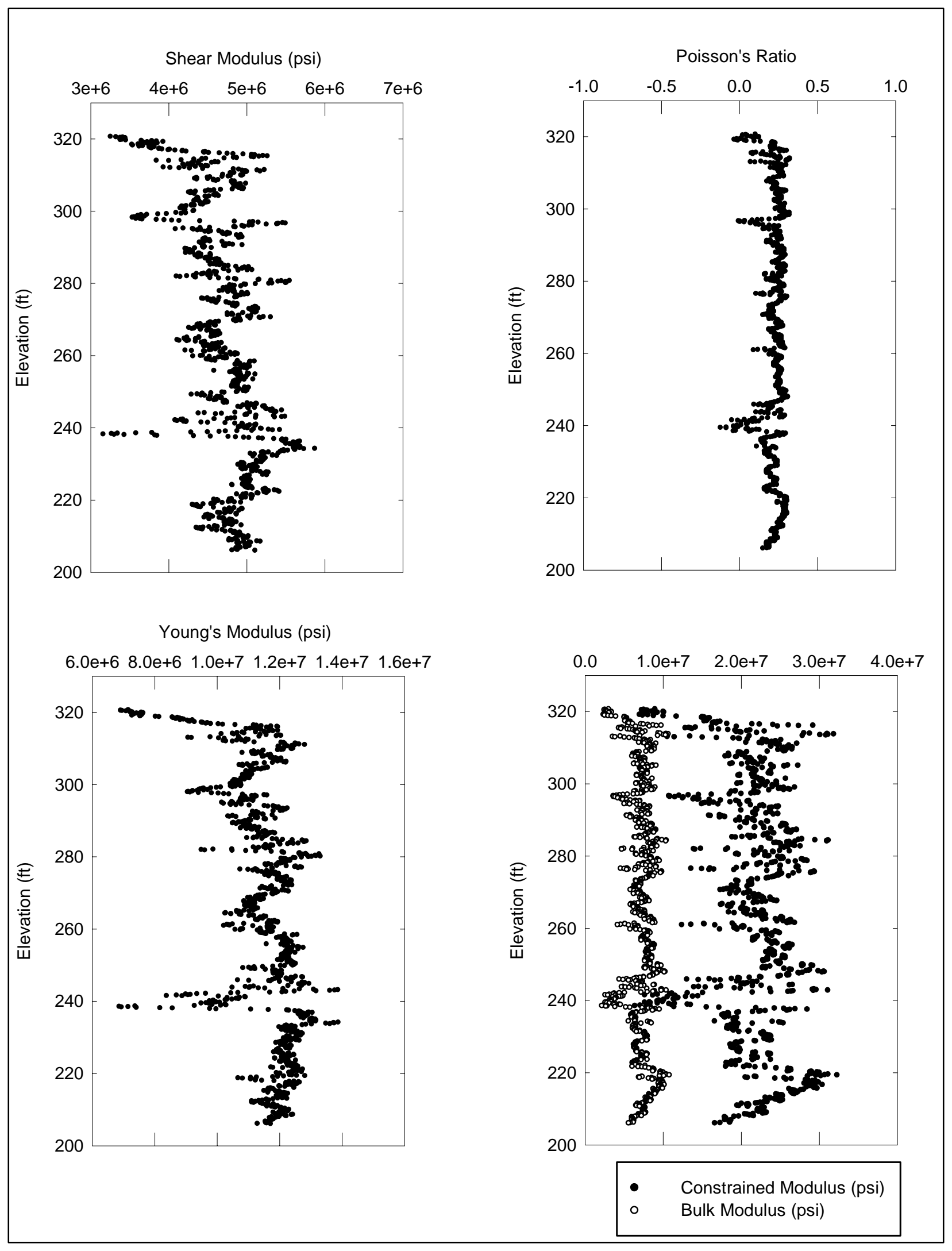

Figure D27. Monolith 27 - Relief Well No. 2 


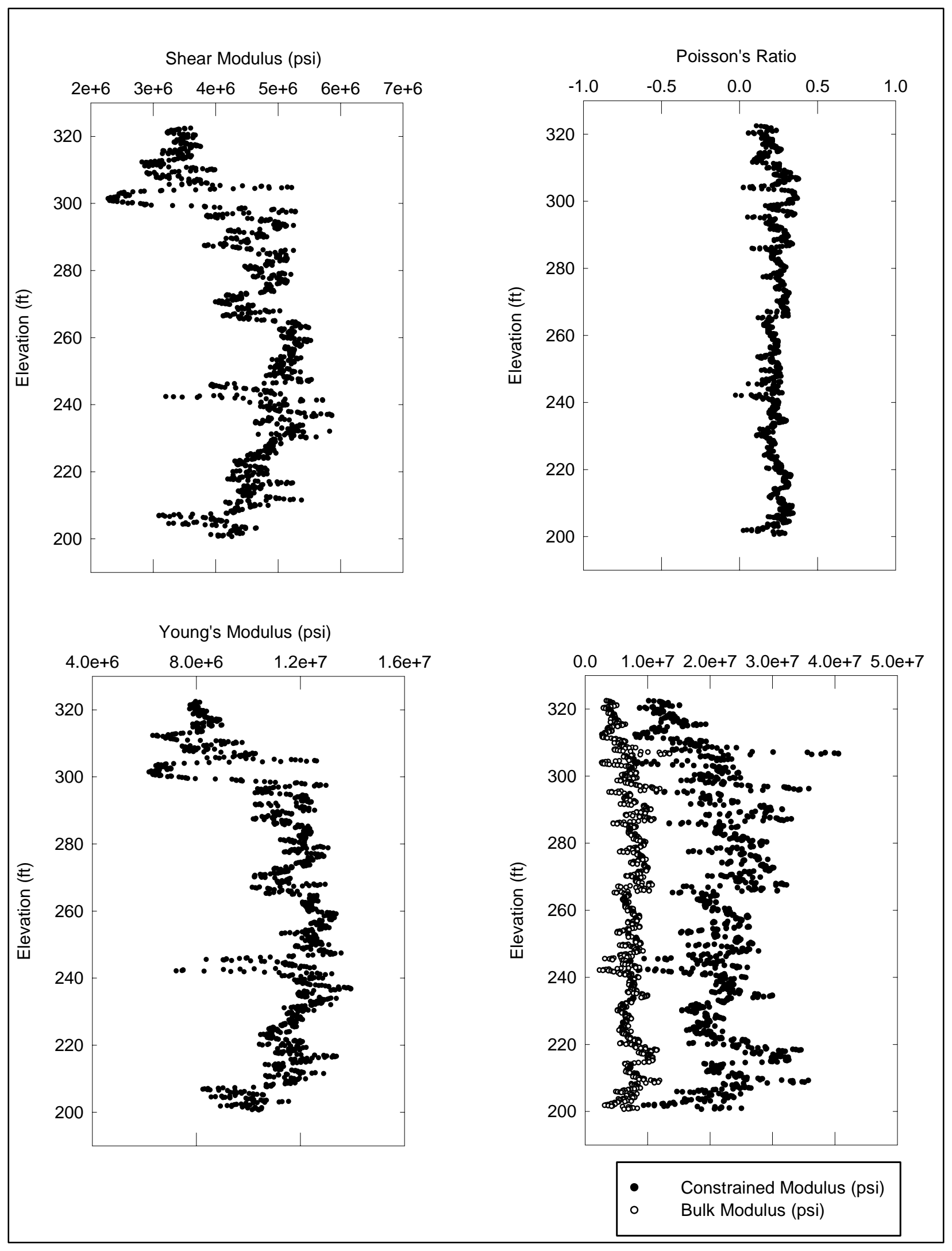

Figure D28. Monolith 27 - Relief Well No. 3 


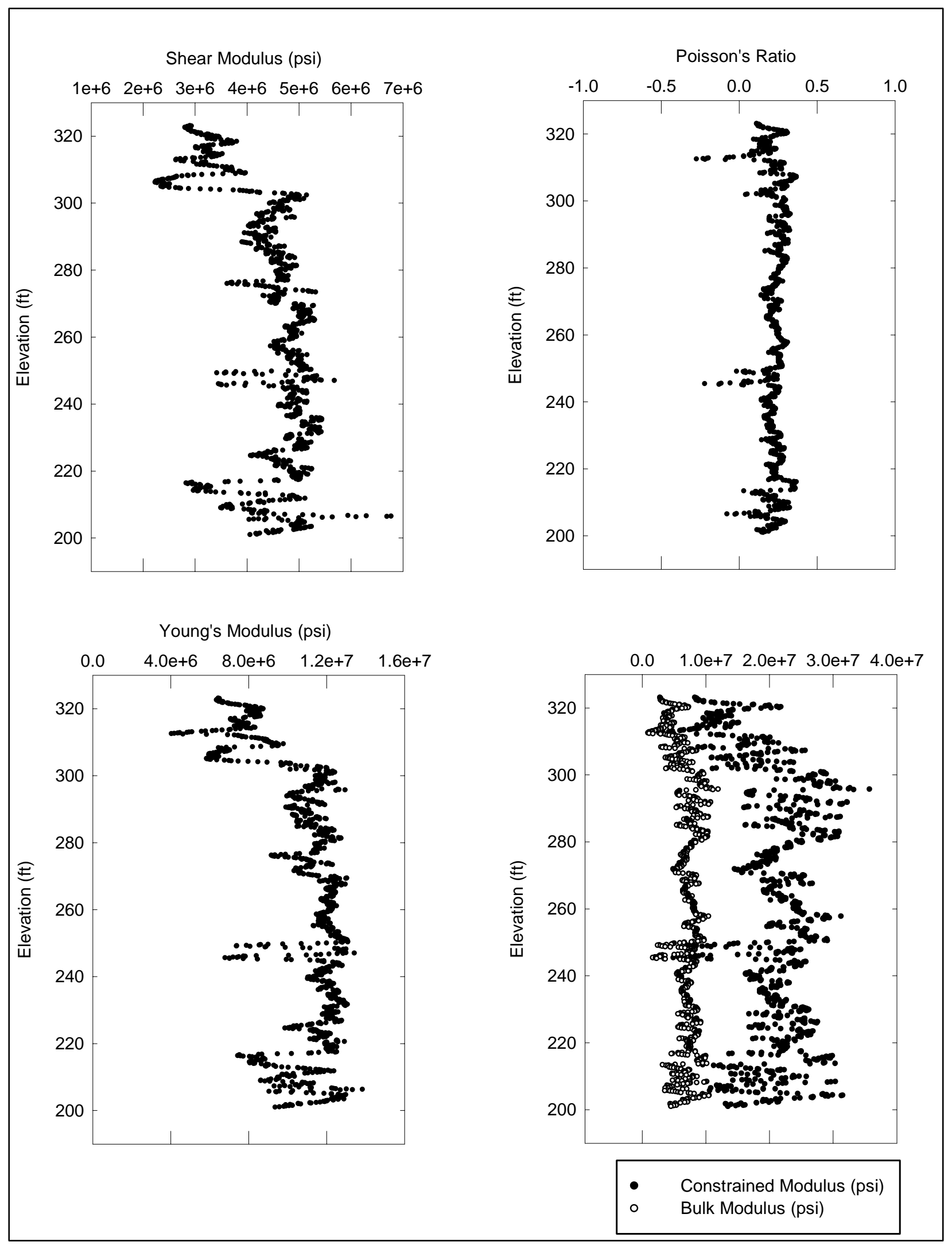

Figure D29. Monolith 27 - Relief Well No. 4 


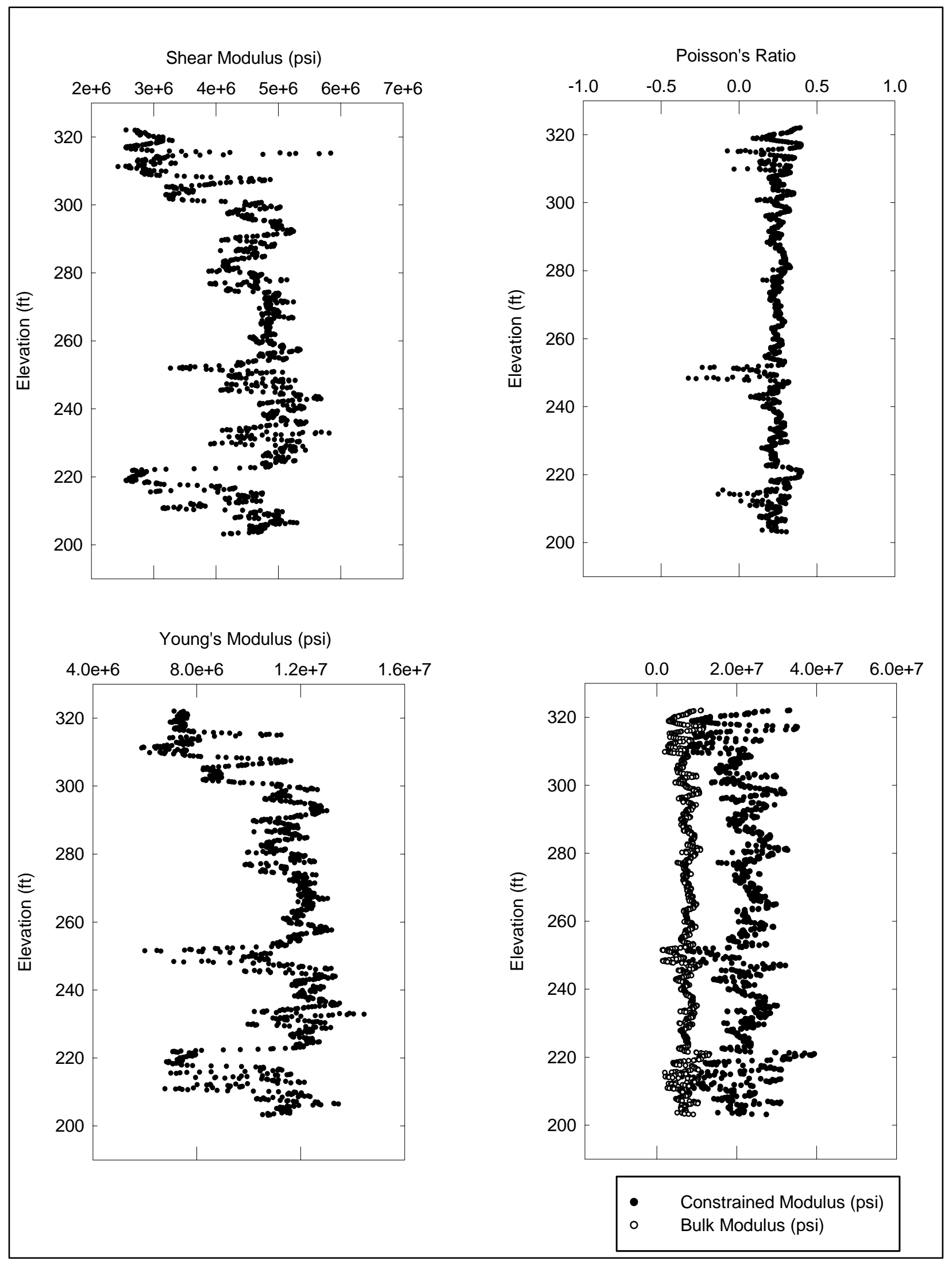

Figure D30. Monolith 27 - Relief Well No. 5 


\section{Appendix E Computed Young's Modulus Based on Average Crosshole Data}




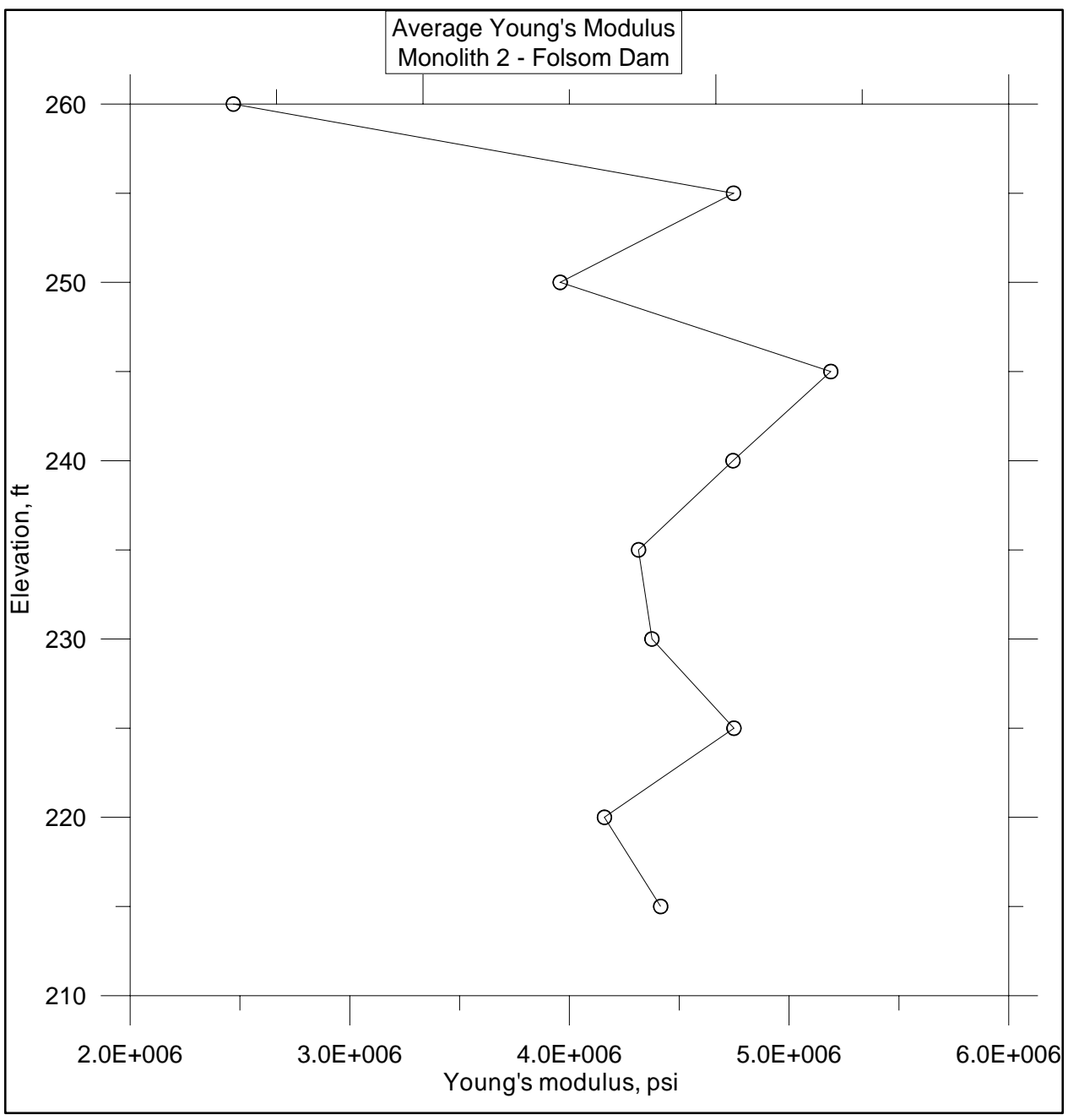

Figure E1. Average Young's modulus, Monolith 2 


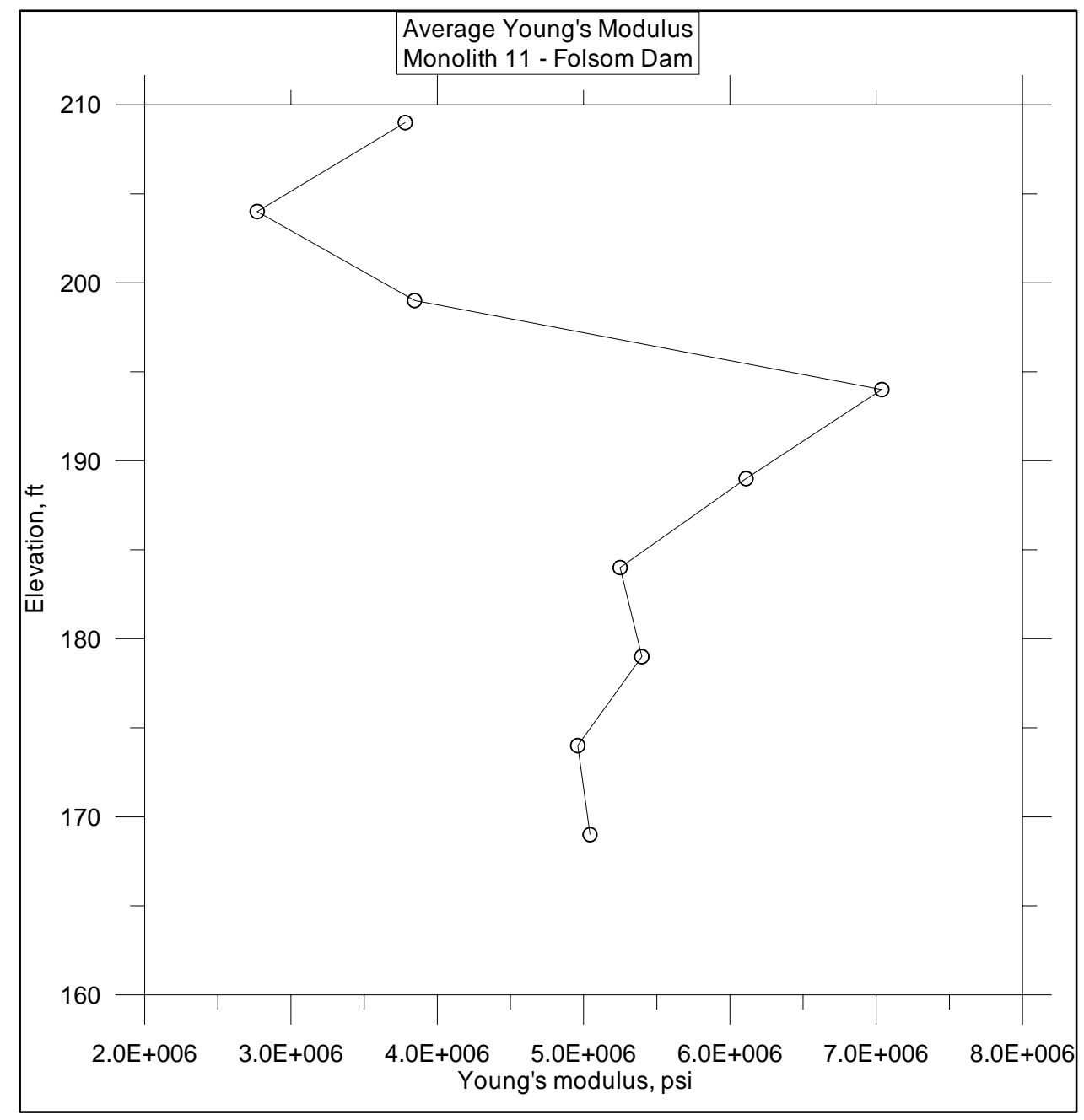

Figure E2. Average Young's modulus, Monolith 11 


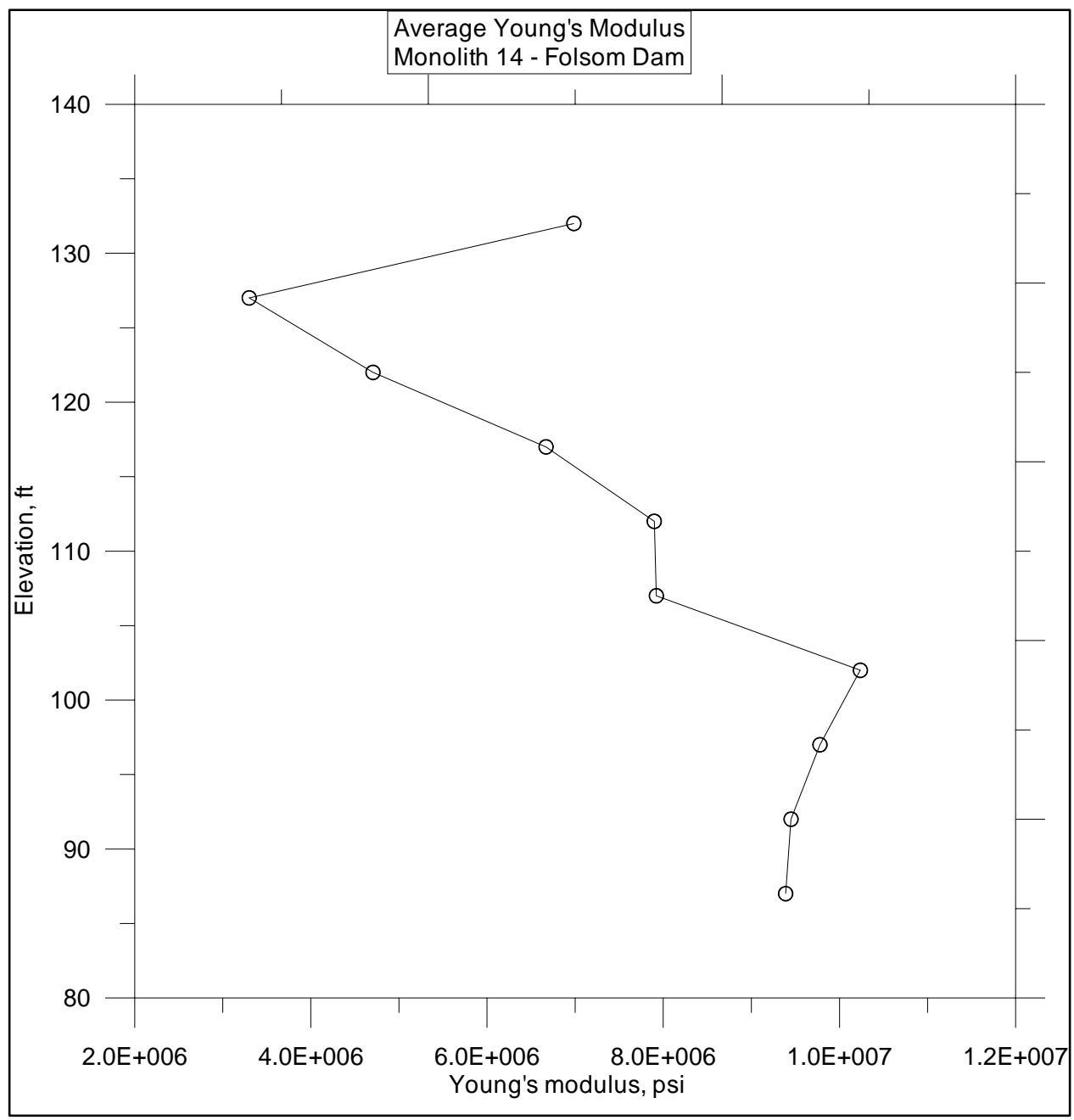

Figure E3. Average Young's modulus, Monolith 14 


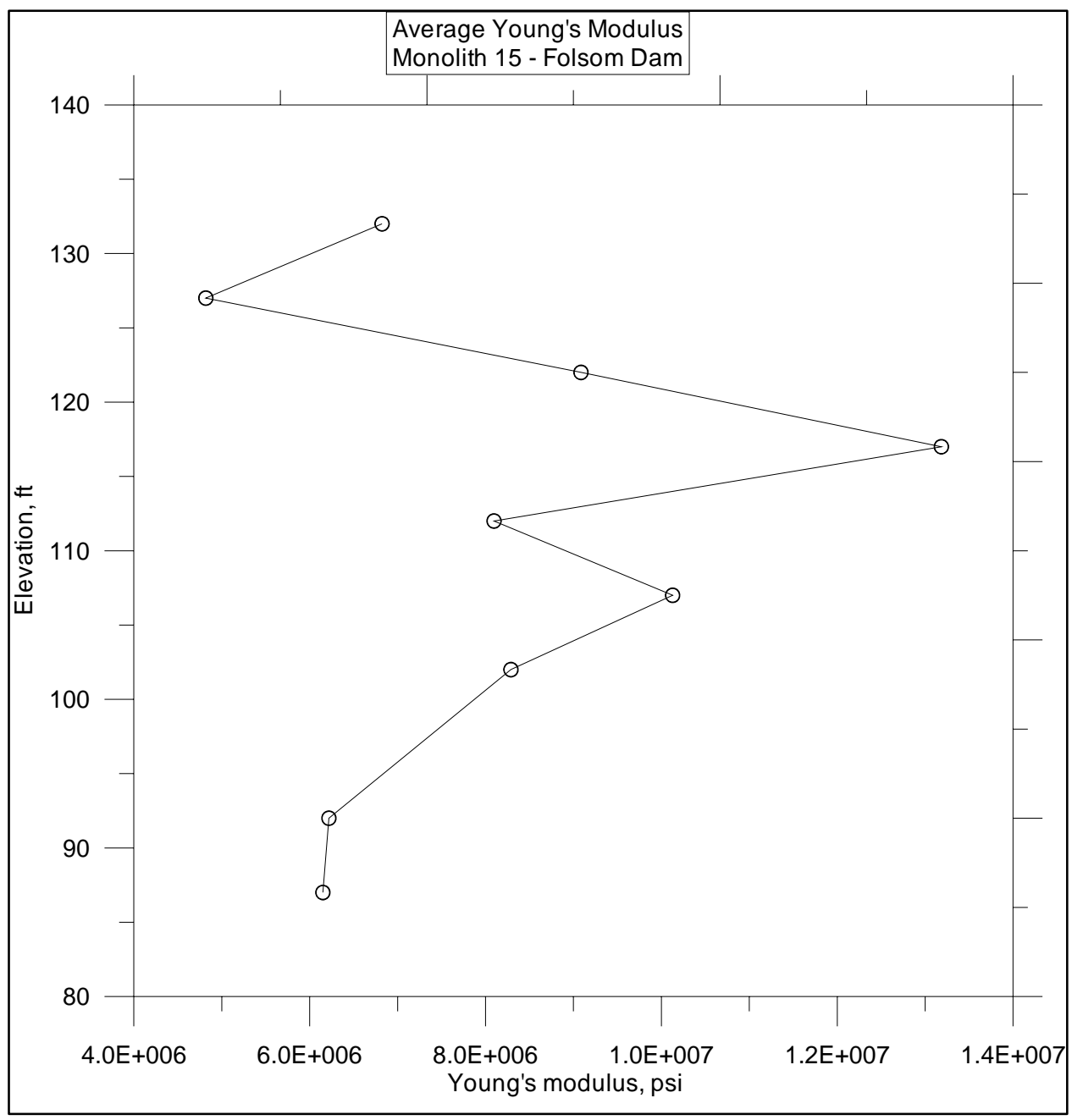

Figure E4. Average Young's modulus, Monolith 15 


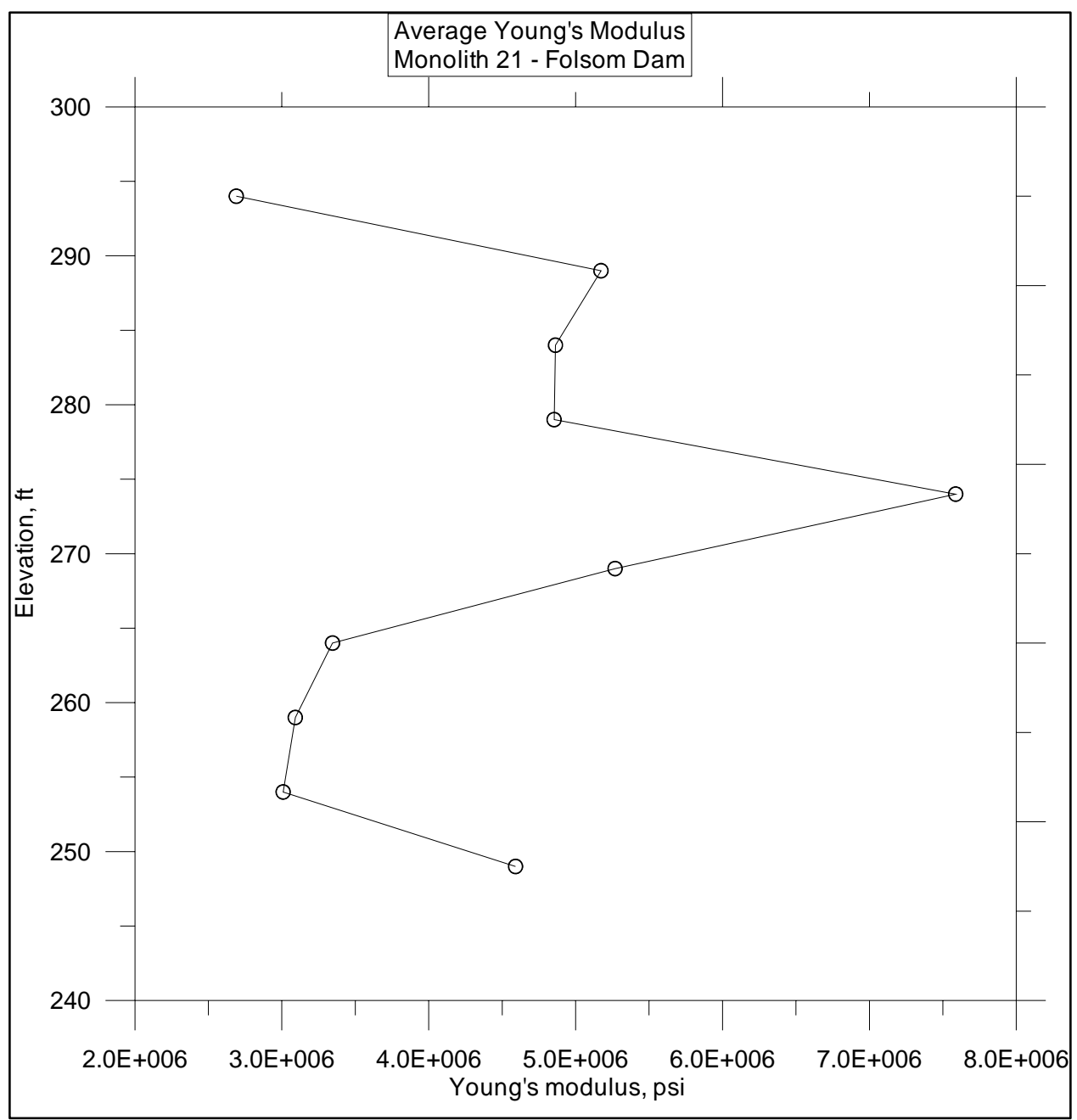

Figure E5. Average Young's modulus, Monolith 21 


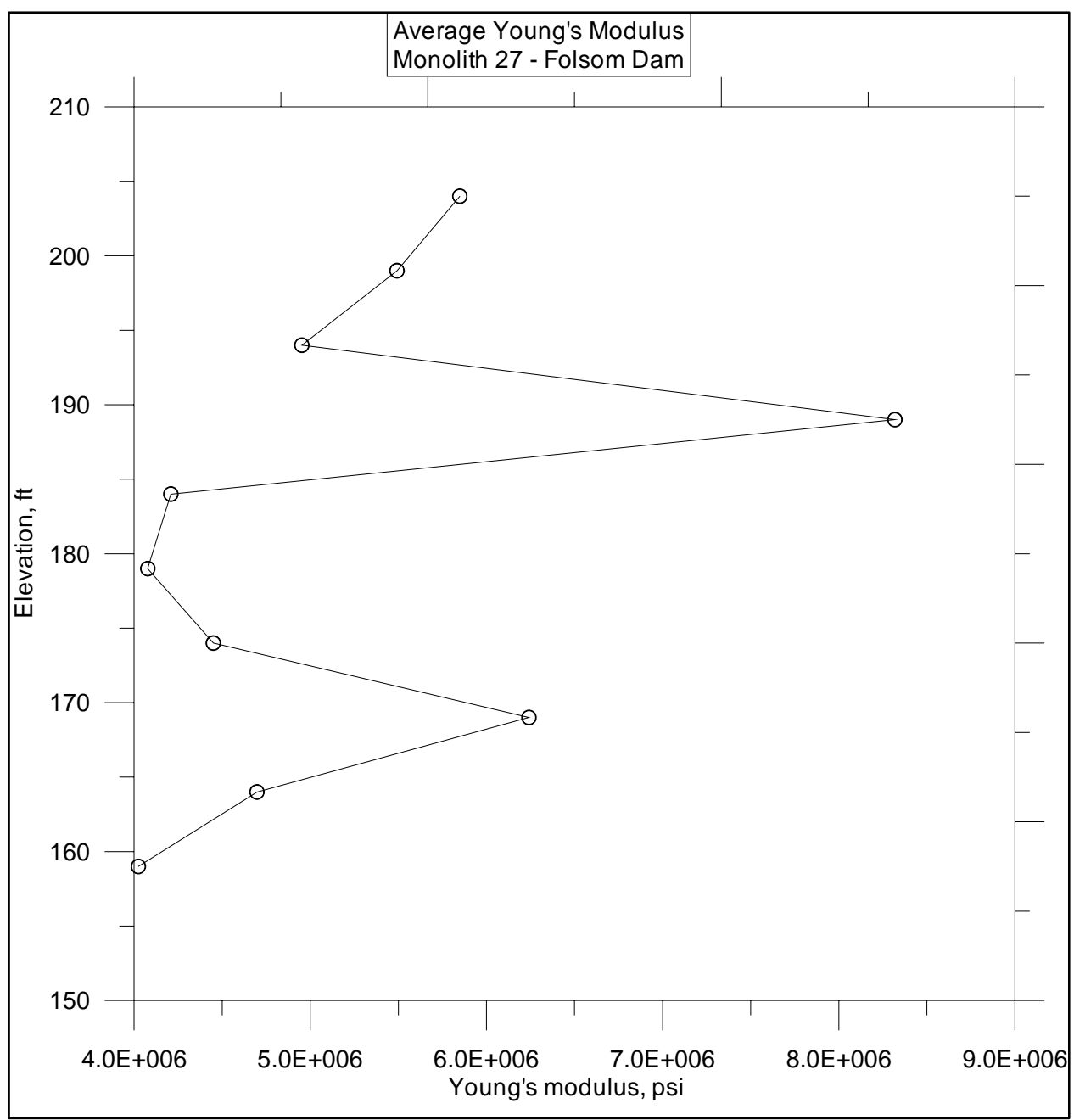

Figure E6. Average Young's modulus, Monolith 27 


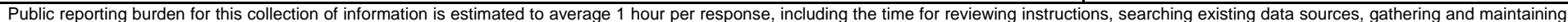

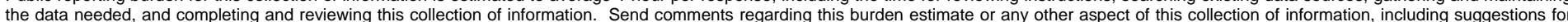

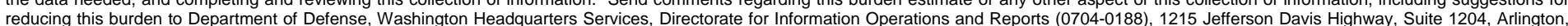

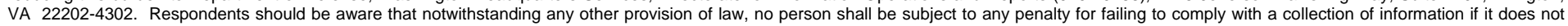
display a currently valid OMB control number. PLEASE DO NOT RETURN YOUR FORM TO THE ABOVE ADDRESS.

\begin{tabular}{l|c}
$\begin{array}{l}\text { 1. REPORT DATE }(D D-M M-Y Y Y Y) \\
\text { August } 2005\end{array}$ & $\begin{array}{c}\text { 2. REPORT TYPE } \\
\text { Final report }\end{array}$ \\
\hline
\end{tabular}

\section{TITLE AND SUBTITLE}

In Situ Geophysical Surveys for Estimation of Foundation Rock Properties, Concrete Gravity Section, Folsom Dam

3. DATES COVERED (From - To)

5a. CONTRACT NUMBER

5b. GRANT NUMBER

5c. PROGRAM ELEMENT NUMBER

\section{AUTHOR(S)}

\section{5d. PROJECT NUMBER}

José L. Llopis, Michael K. Sharp, and Enrique E. Matheu

\section{5e. TASK NUMBER}

\section{5f. WORK UNIT NUMBER}

\section{PERFORMING ORGANIZATION NAME(S) AND ADDRESS(ES)}

8. PERFORMING ORGANIZATION REPORT NUMBER

U.S. Army Engineer Research and Development Center Geotechnical and Structures Laboratory

ERDC/GSL TR-05-18

3909 Halls Ferry Road

Vicksburg, MS 39180-6199

\section{SPONSORING / MONITORING AGENCY NAME(S) AND ADDRESS(ES)}

U.S. Army Engineer District, Sacramento

1325 J Street

Sacramento, CA 95814

11. SPONSOR/MONITOR'S REPORT NUMBER(S)

\section{DISTRIBUTION / AVAILABILITY STATEMENT}

Approved for public release; distribution is unlimited.

\section{SUPPLEMENTARY NOTES}

\section{ABSTRACT}

This report presents a series of geophysical studies performed to determine the material characteristics of the foundation rock beneath the concrete gravity sections of Folsom Dam, California. The geophysical investigations were conducted to measure the values of compression- and shear-wave (P- and S-wave) propagation velocities as well as density of the foundation materials. The U.S. Army Engineer District, Sacramento, and the U.S. Army Engineer Research and Development Center agreed upon a finalized test program consisting of seismic crosshole testing and sonic and gamma-gamma logging. These measurements are used to compute rock property information for a dynamic analysis of the dam and its foundation. The field investigations and corresponding findings are described in this report.

\section{SUBJECT TERMS}

Concrete dams

16. SECURITY CLASSIFICATION OF:

a. REPORT

UNCLASSIFIED
Foundation rock properties

\begin{tabular}{l|c|}
$\begin{array}{l}\text { 17. LIMITATION } \\
\text { OF ABSTRACT }\end{array}$ & $\begin{array}{c}\text { 18. NUMBER } \\
\text { OF PAGES } \\
119\end{array}$ \\
\cline { 2 - 2 } &
\end{tabular}

Geophysical explorations 